\title{
أثر العواهل الاجتهاعية والاقتصادية على التخطيط الاستراتيجي للدخل المالي لمرحلة التقاعد وعلاقته بالرضا عن الحياة
}

\author{
إعداد \\ ه. ما يسة محمد أحمد الحبشمسل \\ كلية الاقتصاد المنزلي - جامعة المنوفية \\ -
}

مجلة بحوث التربية النوعية - جامعة المنصورة

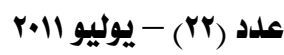




\section{أثر العواهل الاجتمهامية والاقتصادية على التخطيط الاستراتيجي للدذل المالي لمرحلة التقاعد وعلاقته بالرضا عن المياة}

إعداد

د ـ مايسةمحمد أحمد المبشيُ*

\section{هلخص البحث}

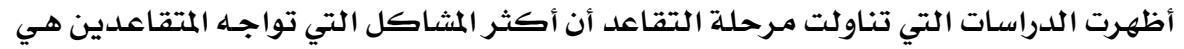

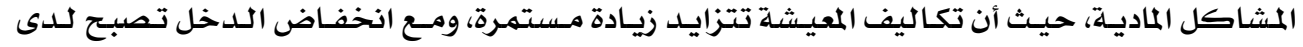

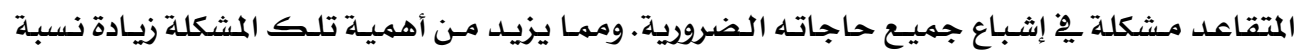

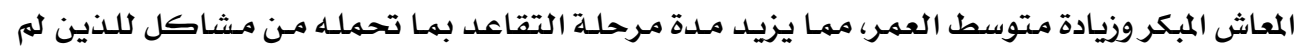

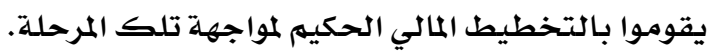

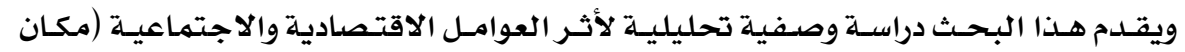

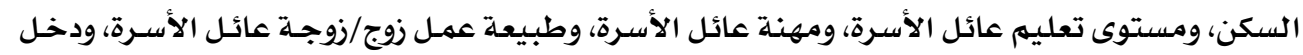

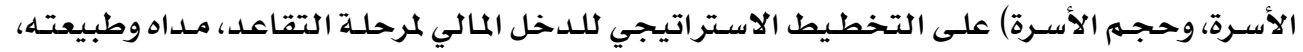

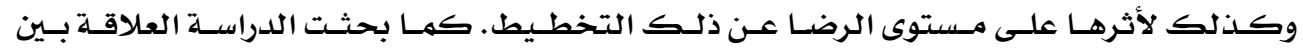

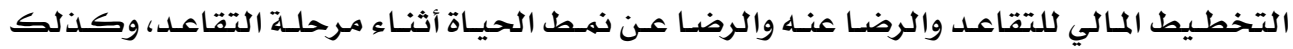

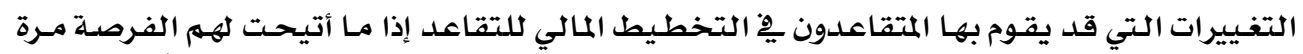

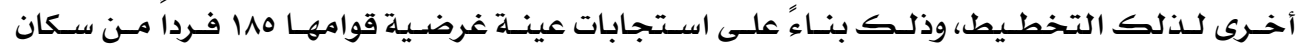

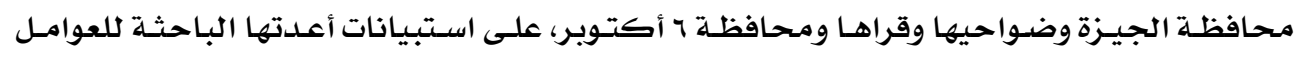

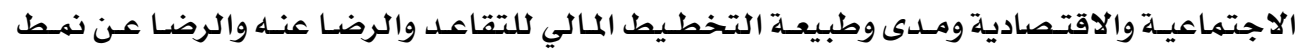
الحياة، بعد التحقق من صدقة والاتها وثباتها.

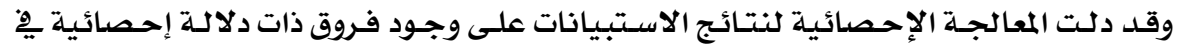

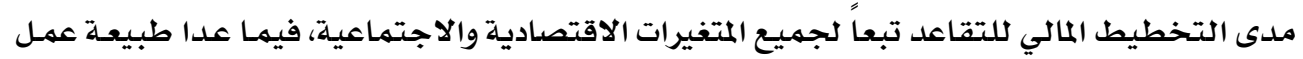

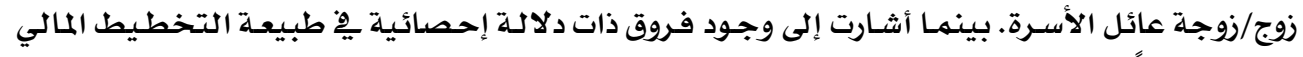

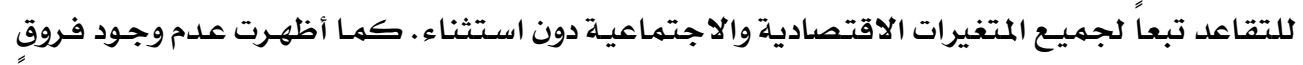

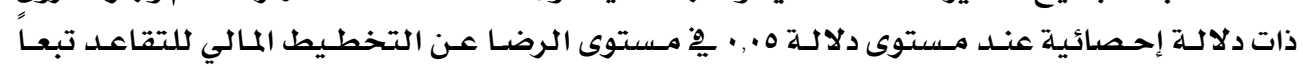

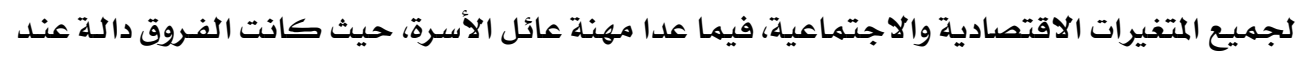

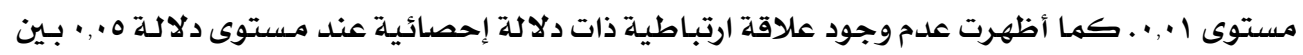

* كلية الاقتصاد المنزلي - جامعة المنوفية - شبين الكوم - المنوفية 
مدى التخطيط المالي للتقاعد والرضـا عن نهط الحيـاة أثناء مرحلـة التقاعد ووجـود علاقـة ارتباطيـة

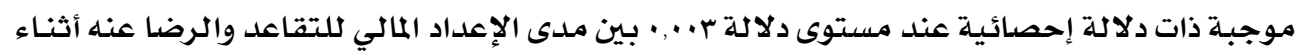

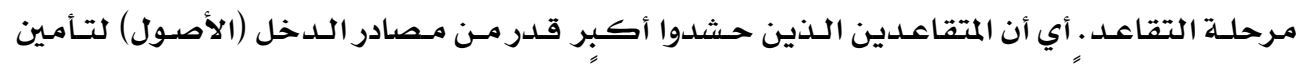

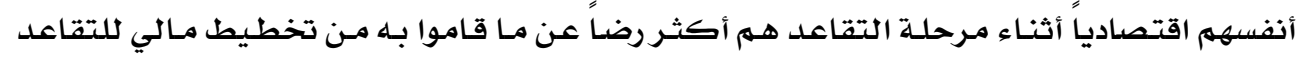

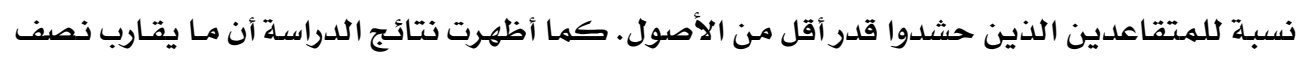

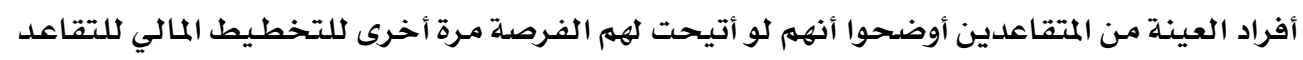

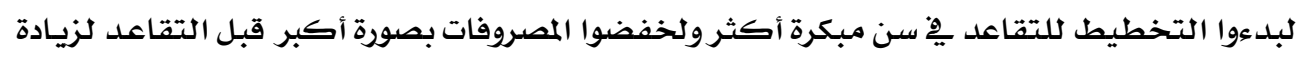

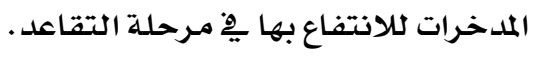

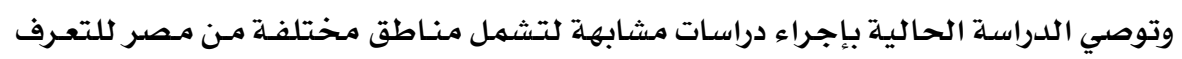

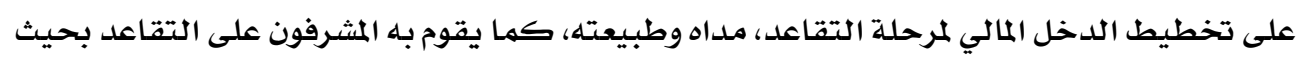

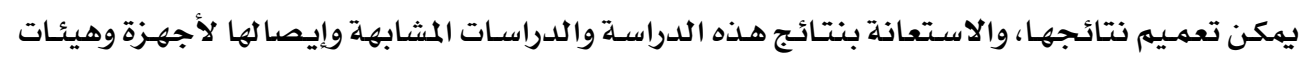

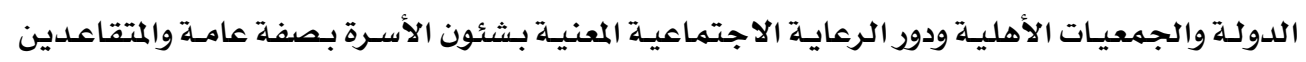

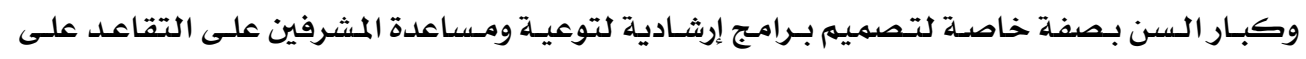

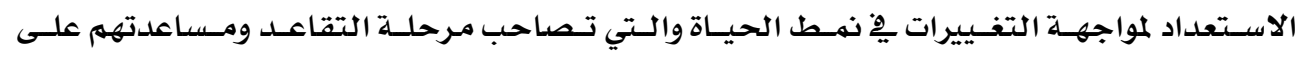

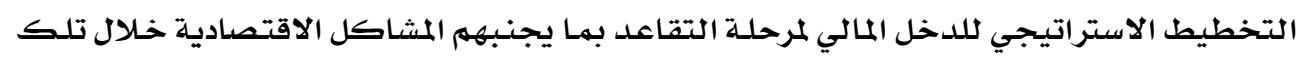

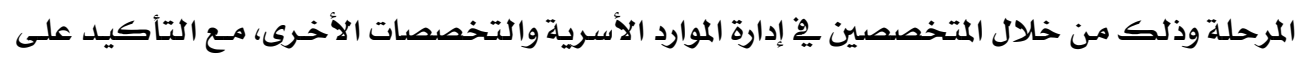

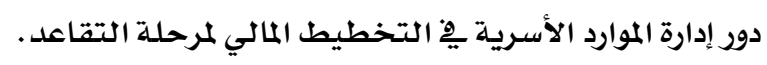




\section{Research summary}

\section{THE INFLUENCE OF SOCIO-ECONOMIC FACTORS ON THE STRATEGIC PLANNING FOR RETIREMENT OF FINANCIAL INCOME AND SATISFACTION WITH LIFE}

Dr. Maysa Mohammad Ahmad El-Habashy"

It has been indicated by several research studies that one of the most important problems confronting retirees are the financial problems, due to the constant inflation and the corresponding decrease in value of unchanged income of the retirees. The problem is further compounded with the increasing rate of early retirement and the increase of average ages, resulting in a longer period of retirement and exposure to its problems.

This research presents a descriptive, analytical study of the influence of socio-economic factors (place of residence, education level, occupation, nature of spouse work, income, family size, and satisfaction with marriage) on the extent and nature of strategic financial planning for retirement and satisfaction with it, and the relation between financial planning for retirement and satisfaction with it and satisfaction with life during retirement, for a targeted sample of 185 individuals of Giza Governorate and its suburbs and villages and 6th of October Governorate, as indicated in their response to a socio-economic and strategic financial planning for retirement questionnaire developed by the author.

The results indicated that there are statistically significant differences in the extent of strategic financial planning for retirement according to all socioeconomic factors, excepting nature of spouse work, and that there are statistically significant differences in the nature of strategic financial planning for retirement according to all socio-economic factors without exceptions. The results also indicated that there are no statistically significant differences at the 0.05 level in satisfaction with strategic financial planning for retirement according to all socioeconomic factors, excepting occupation, where differences were significant at the 0.01 level. The study also revealed that there is no significant relation at the 0.05 level between extent of strategic financial planning for retirement and satisfaction with life during retirement, while there is a significant positive relation at the 0.003

\footnotetext{
* Faculty of Home Economic - Minofiyah University
} 
level between extent of strategic financial planning for retirement and satisfaction with it during retirement. The study also revealed that almost half of the investigated individuals indicated that if they were given another chance to financially plan for retirement, they would start planning at earlier age and that they would decrease their spending before retirement to increase savings to be used during retirement.

The findings of the present investigation urges for applying similar research to other regions of Egypt so that the results can be generalized and employed by concerned government bodies, social institutions, and civil society in designing programs for preparing retirees to adapt to changes in life style during retirement and to effectively financially plan for this important stage of their lives. To this end, specialists in family resources have a central role in advising on financial planning for retirement. 


\section{أثر العواهل الاجتمهاوية والاقتصادية على التخطيط الاستراتيجي للدذل يُل المالي لمرحلة التقاعد وعلاقته بالرضا عن المياة}

إعداد

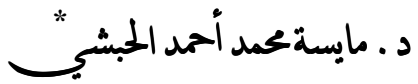

الاقدهة ومشكلة البمث :

يعتبر التقاعد أحد أهم الأحداث ِِّ مجـرى حيـاة الأسـرة، بـه تتغير أو تتوقف أنهـاط حياتيـة

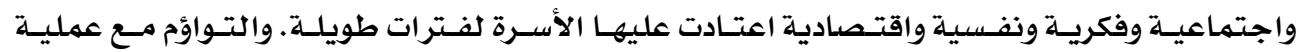

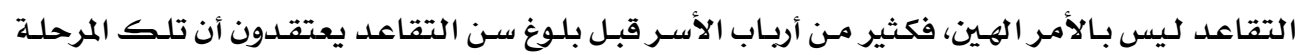

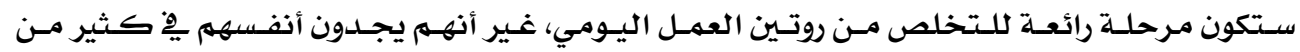

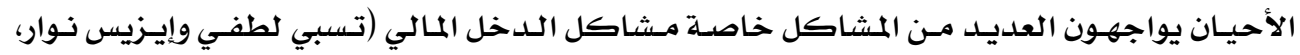

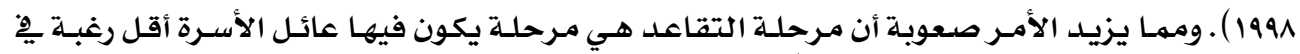

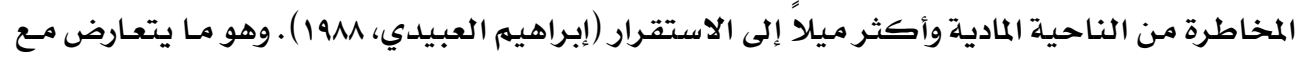

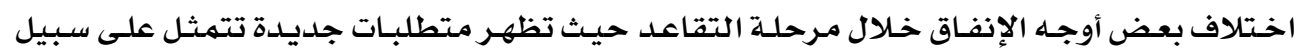

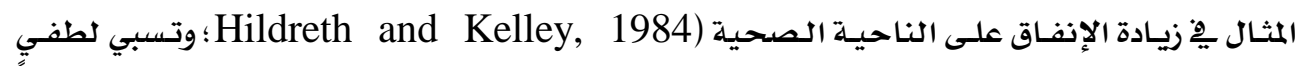

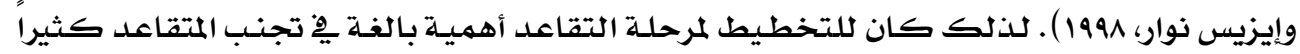

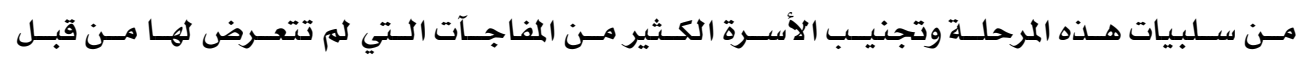
(McKenna and Nichols, 1986)

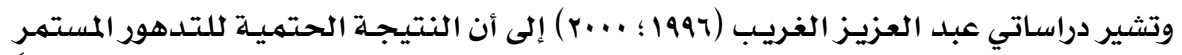

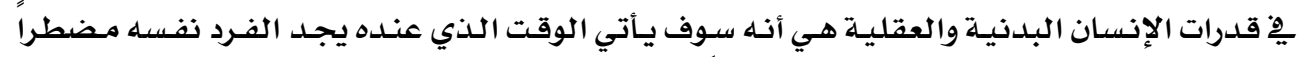

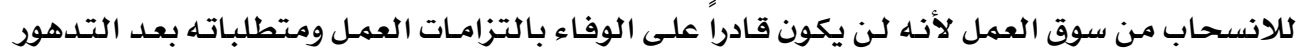

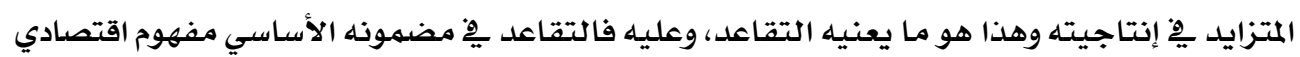

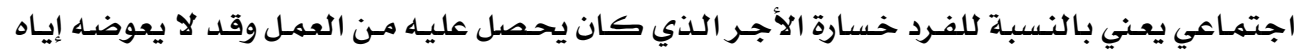

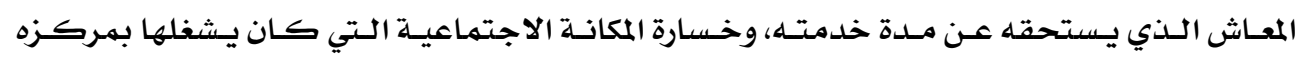

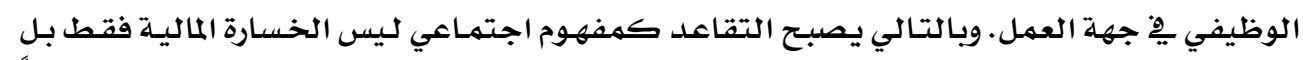

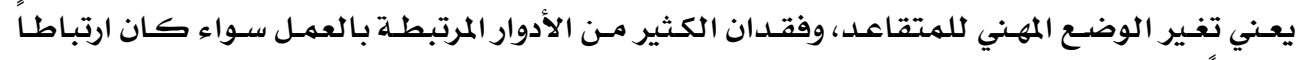
مباشراً أو غير مباشر، ووجود وقت فراغ مـع عدم الارتباط بعمل معين.

* كلية الاقتصاد المنزلي - جامعة المنوفية - شبين الكوم - المنوفية 


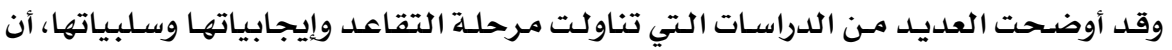

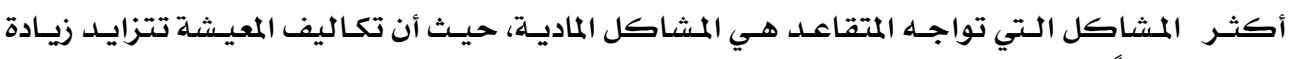

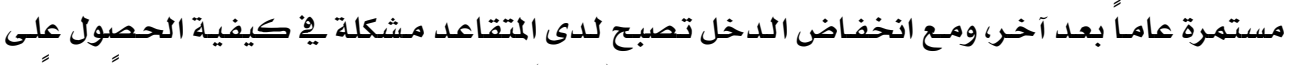

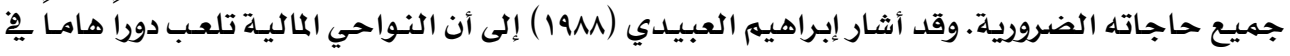

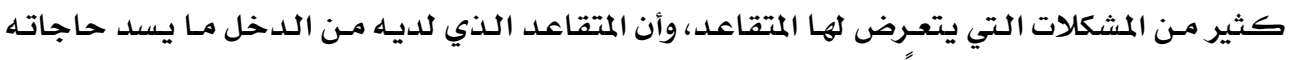

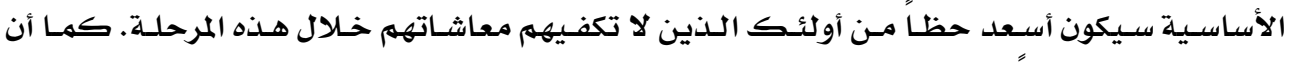

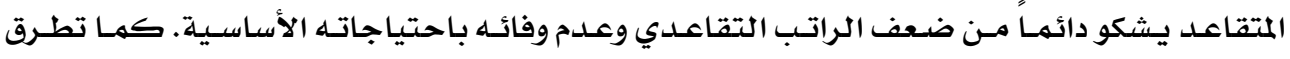

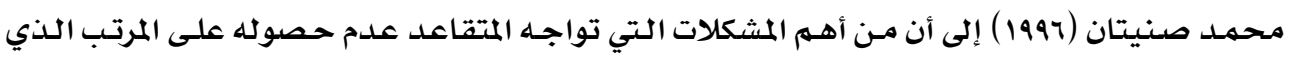

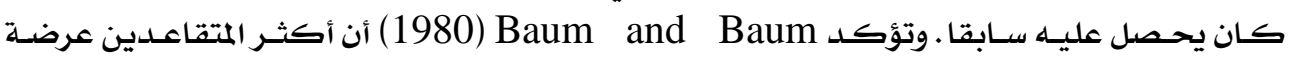

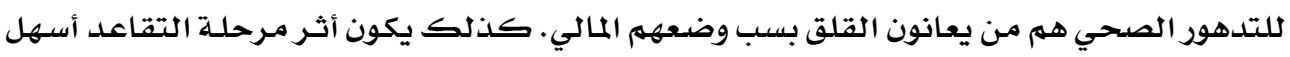

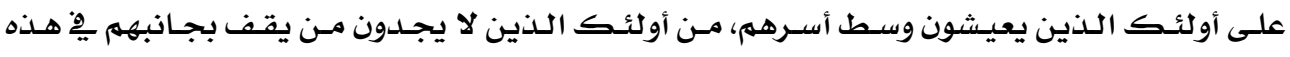

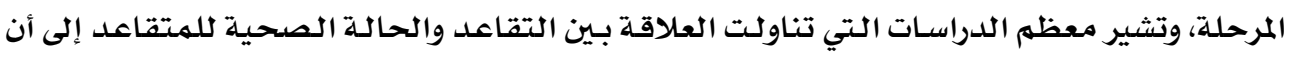

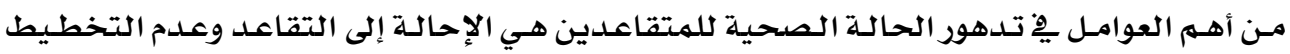
لمرحلة التقاعد.

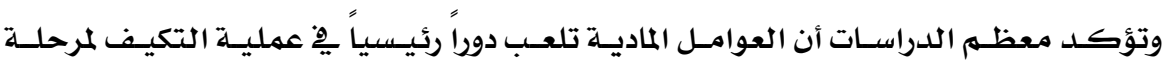

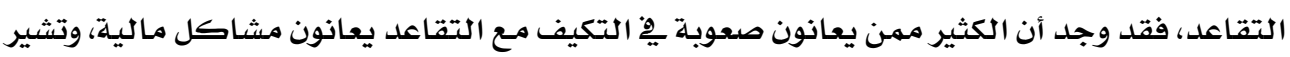

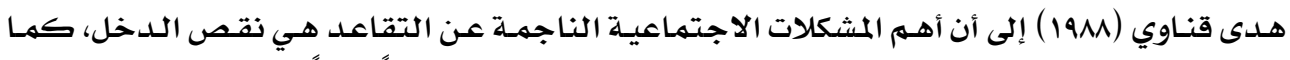

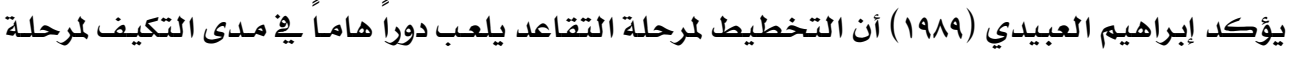

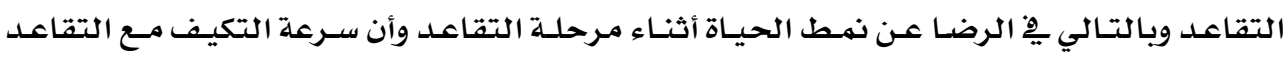

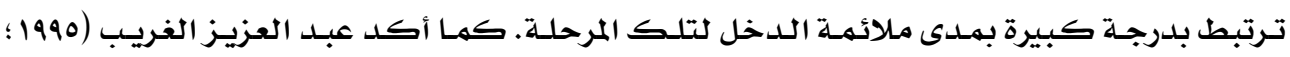

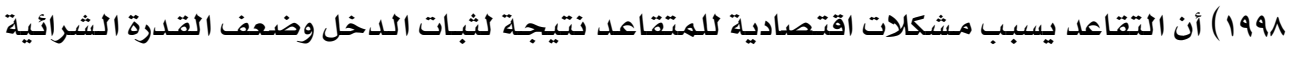

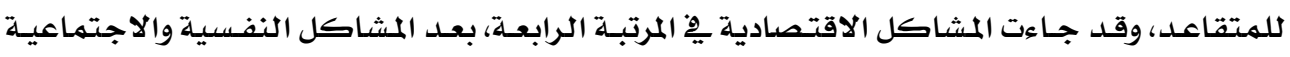

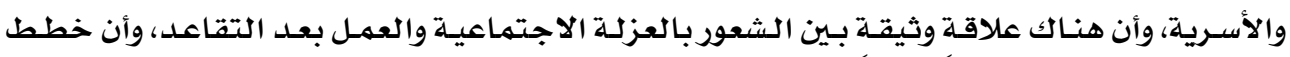

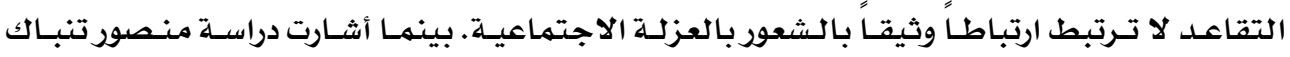

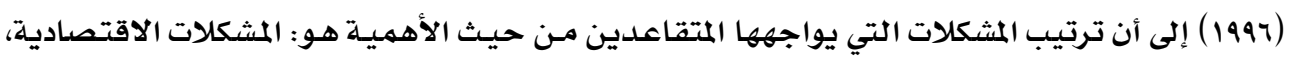

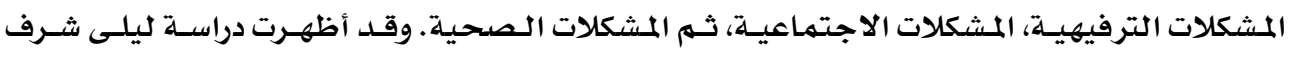

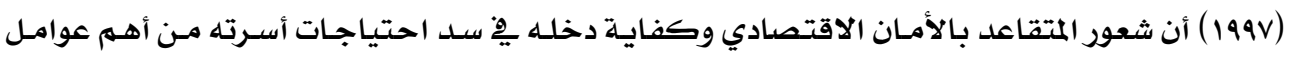

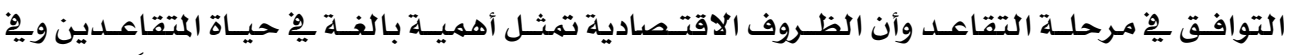

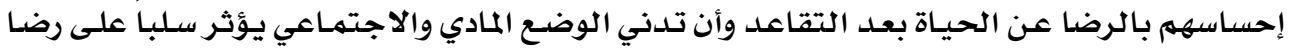

المتقاعد عن حياته.

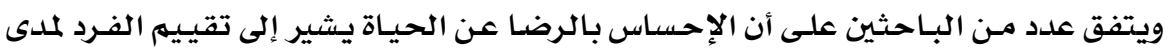

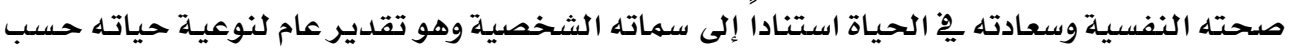

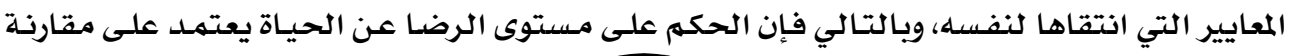


الفرد لظروفه بالمستوى المثالي الذي يفترضه لحياته وهذا المستوى المثالي ليس إجباريـا بـل هو علامـة

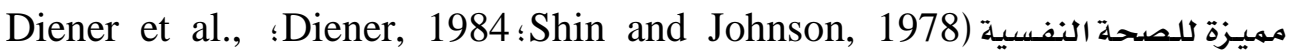

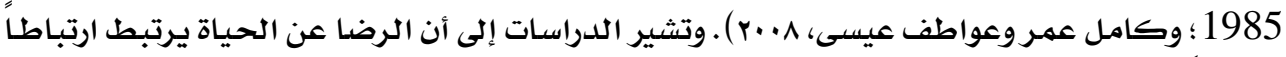
إيجابياً بتقدير الفرد لذاته (Lewinsohn et al., 1993 (Emmons and Diener, 1985).

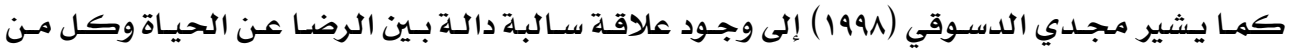

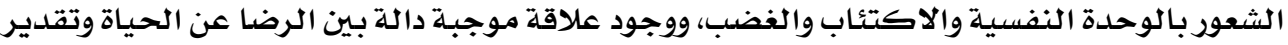

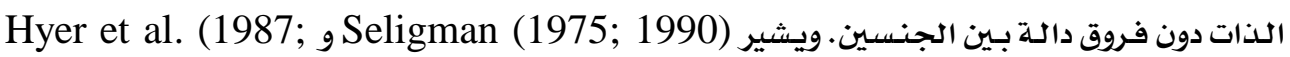
Saunders and Roy (2000) إلى أن المستوى المنتخفض مـن الرضـا عن الحيـاة هـو بدايـة

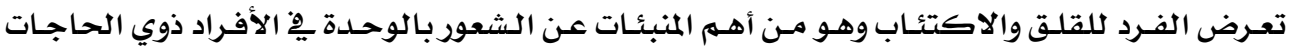
الاجتهاعية غير المثبعـة.

وِيْ هذا الصدد يشير علي الديب (1914) إلى أن المتقاعدين الذين يعملون بعد التقاعد أكثر الكير

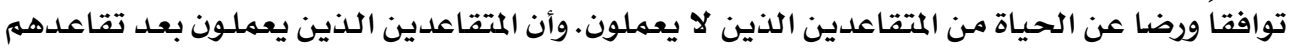

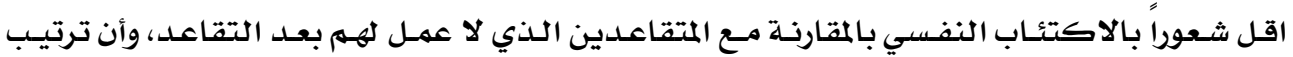

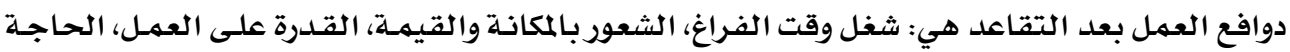

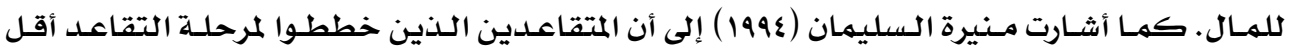

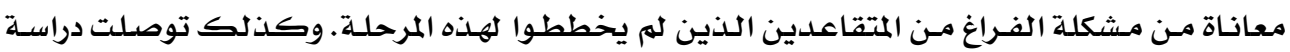

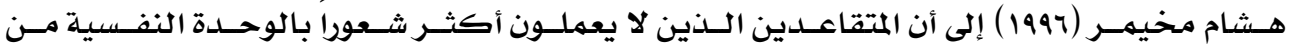
المتقاعدين الذين يعملون أثناء مرحلة التقاعد.

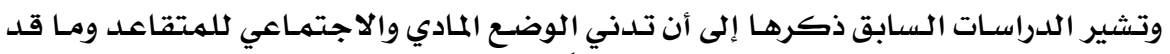

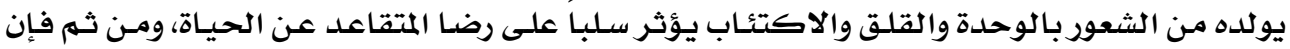

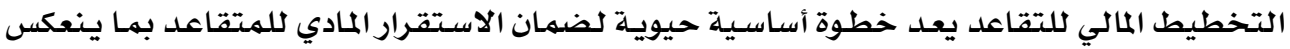

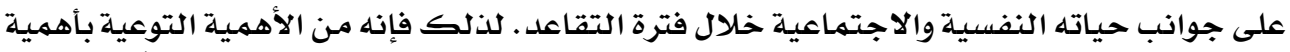

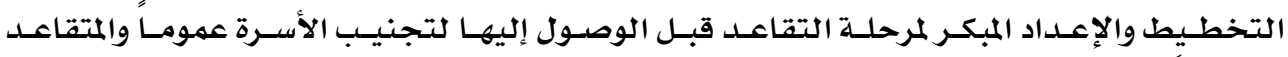

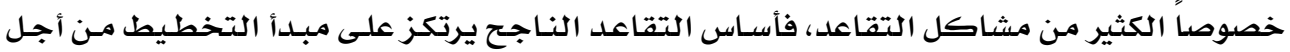

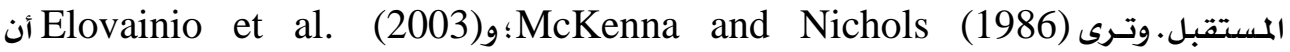

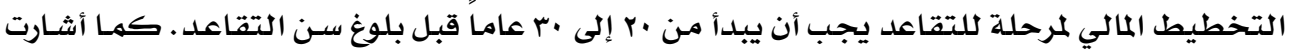

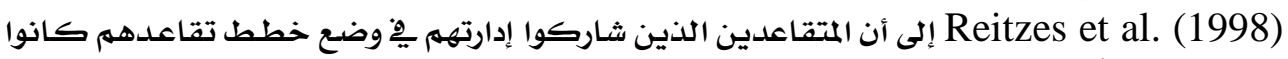

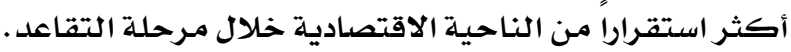

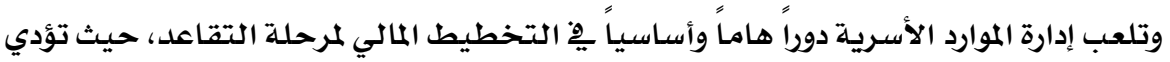

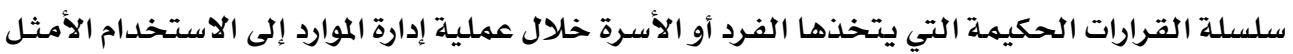

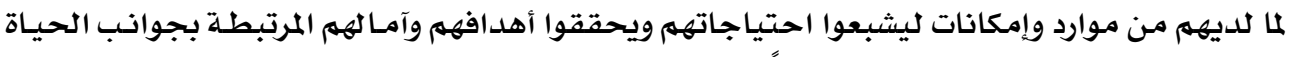

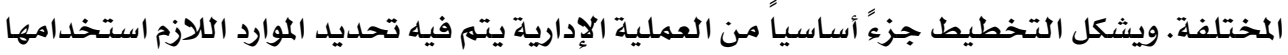




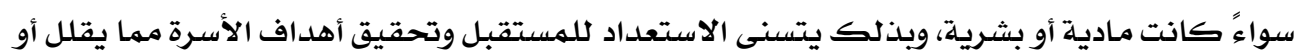

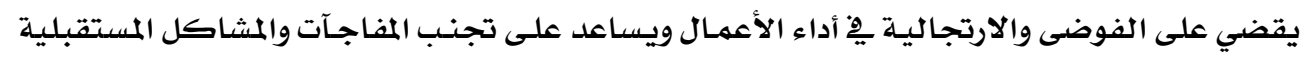

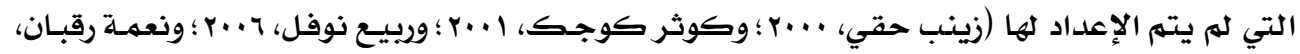

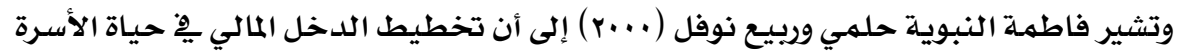

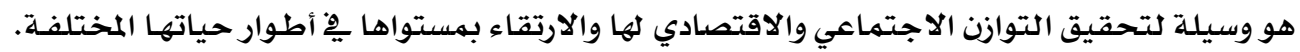

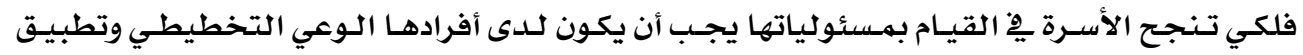

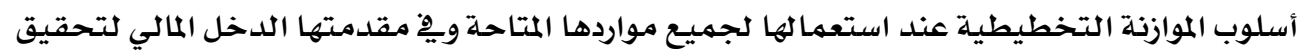

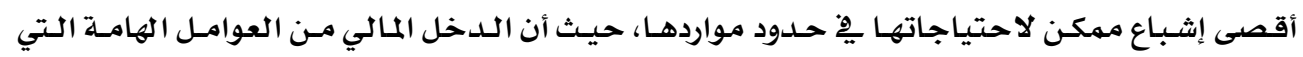

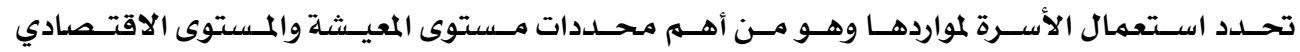

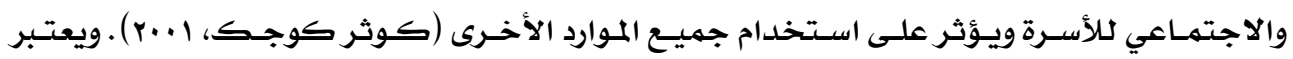

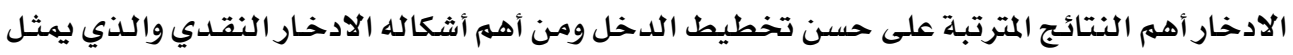

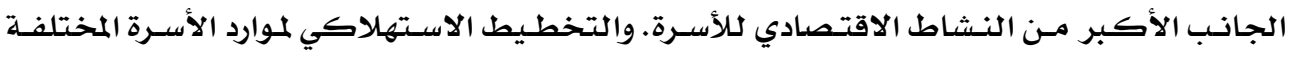

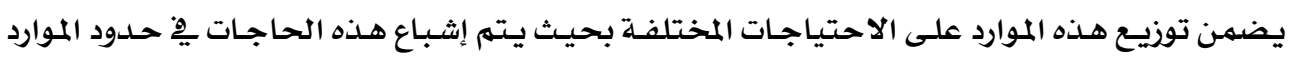
المتاحة وتوجيه الفائض نحو الادخار (تسبي لطفي وإيزيس نوار، 1991) .

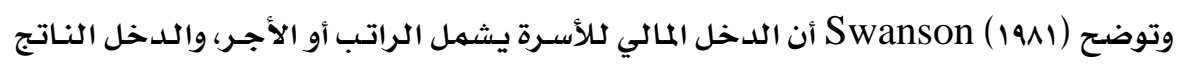

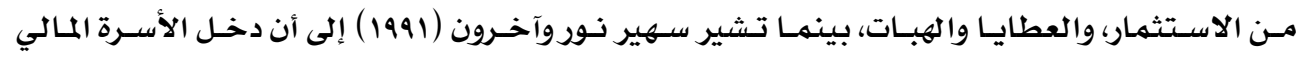

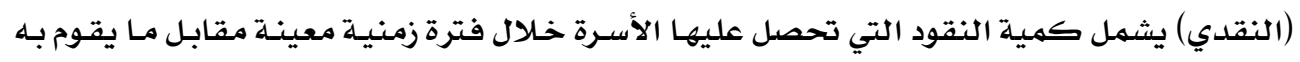

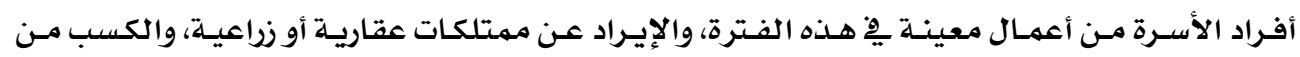

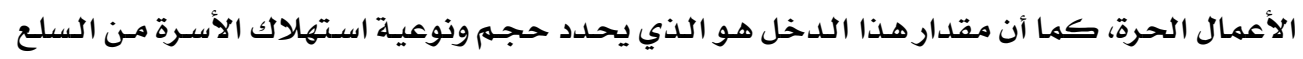

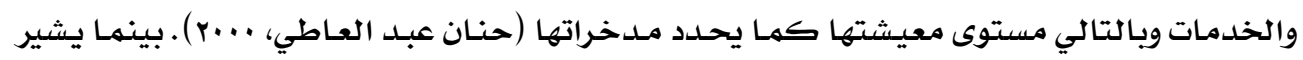

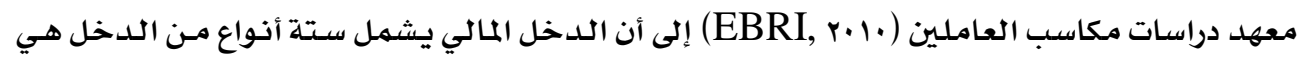

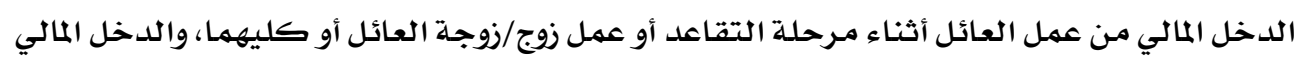

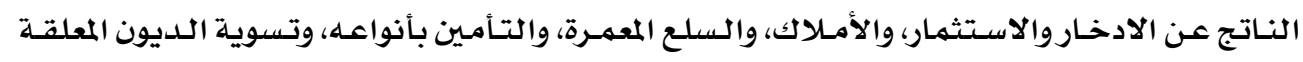
قبل التقاعد.

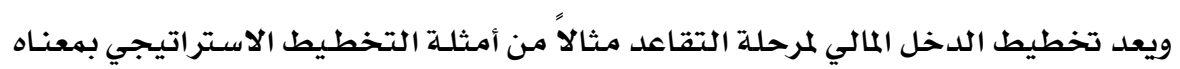

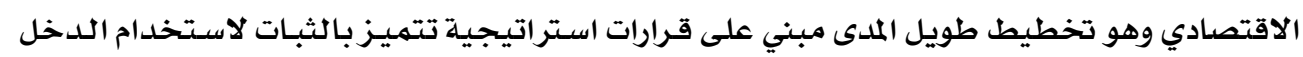

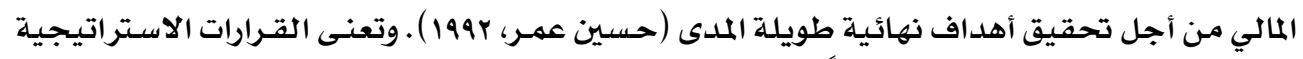

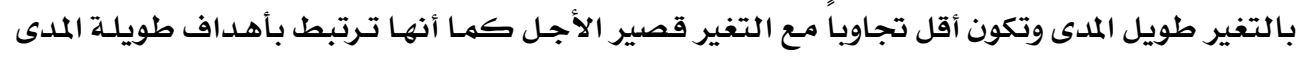

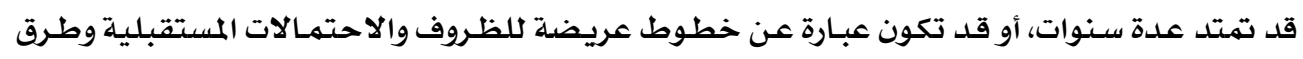

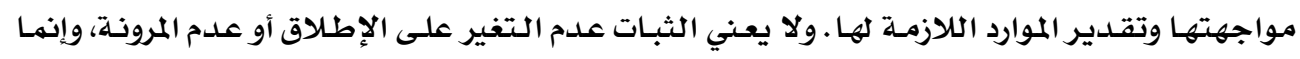

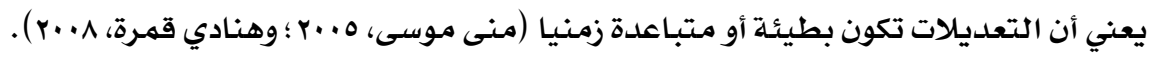




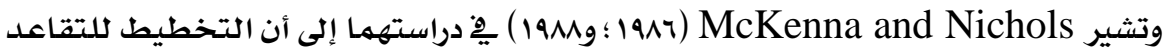

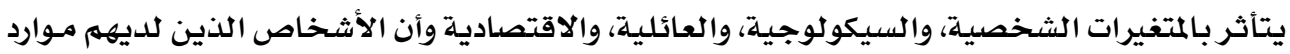

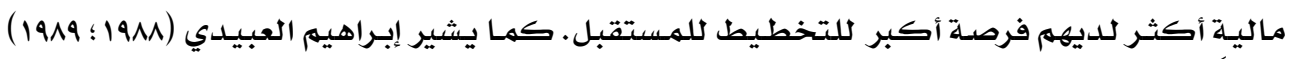

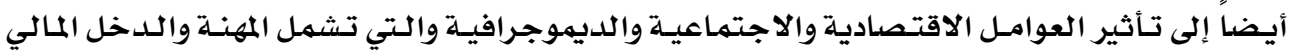

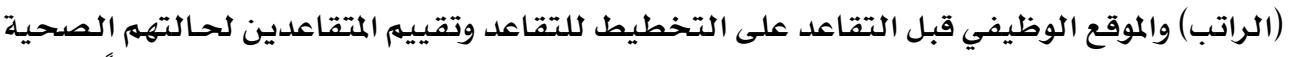

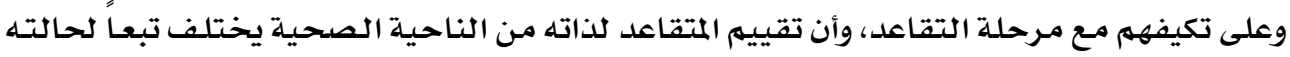

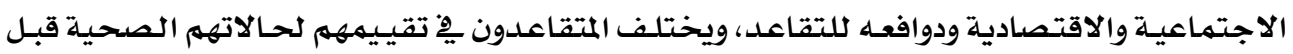

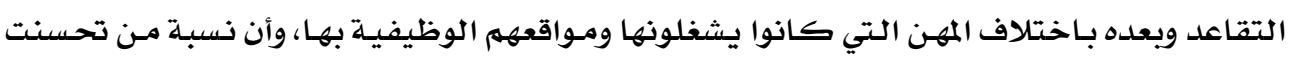

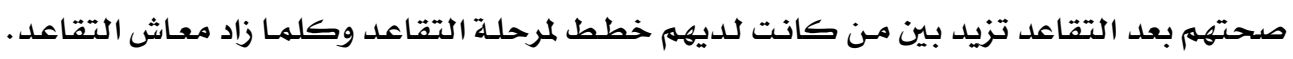

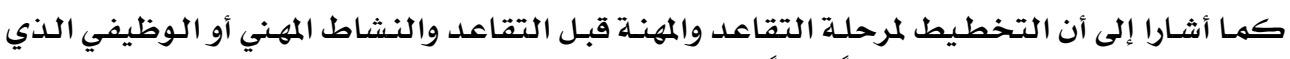

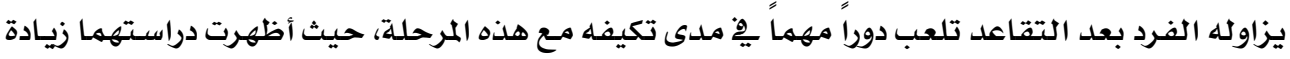

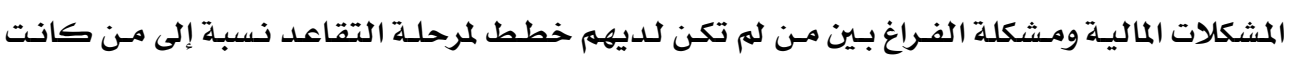
لديهم خطط لهذه المرحلة.

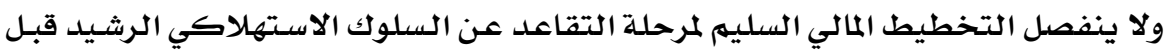

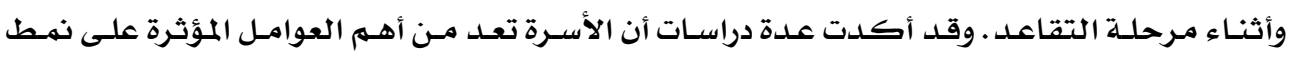

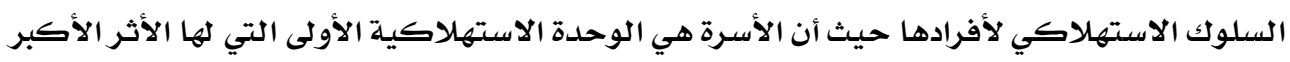

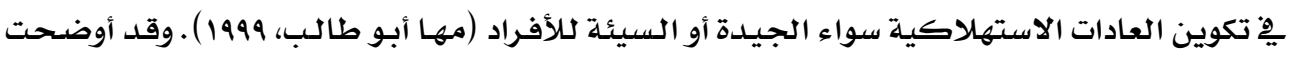

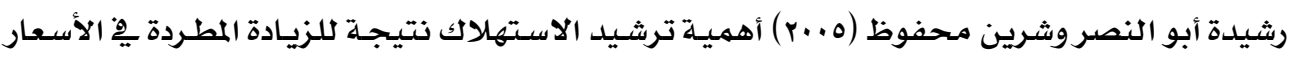

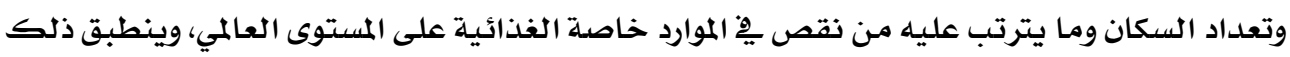

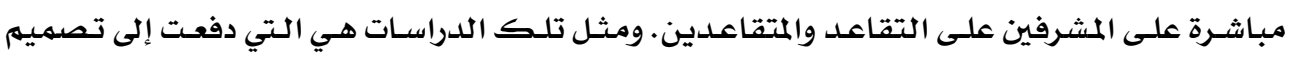

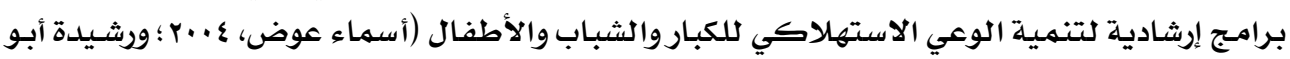

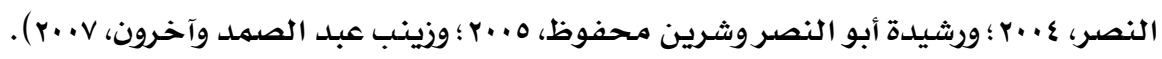

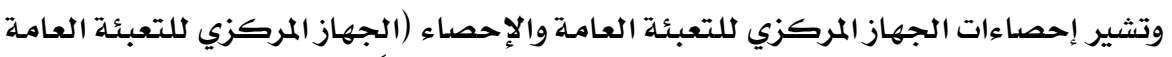

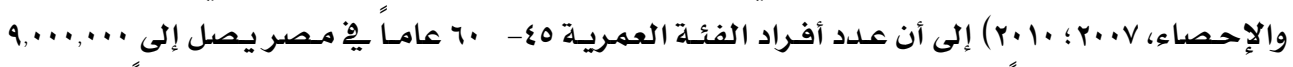

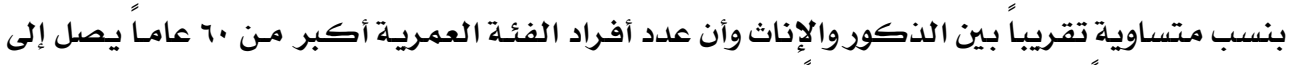

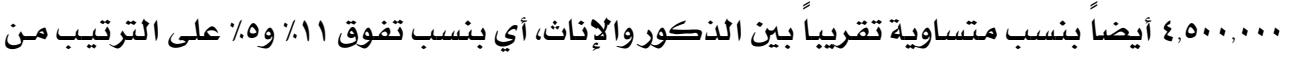

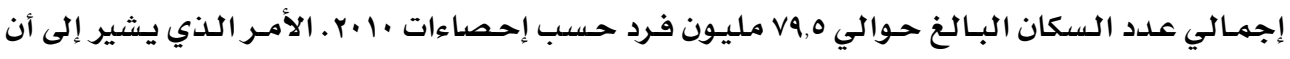

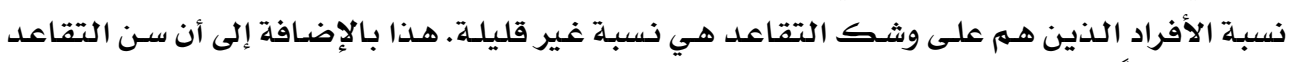

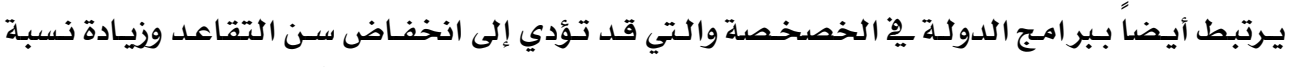

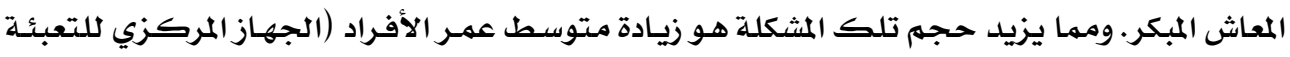

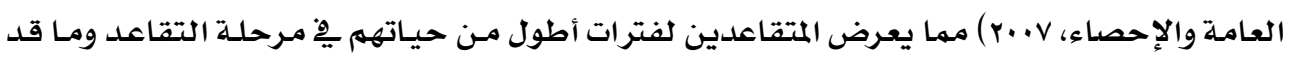

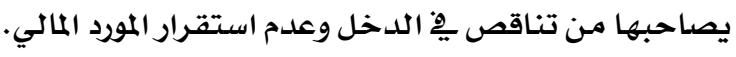


وبالرغم من حجم تلك المشكلة فإنه لا توجد معلومـات دقيقة عن مـدى وطبيعـة التخطيط

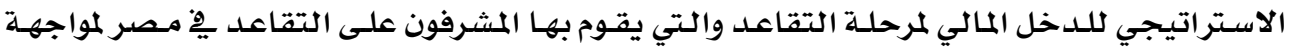

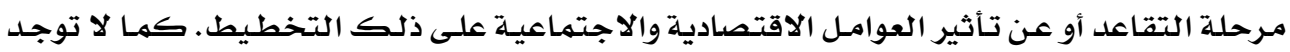

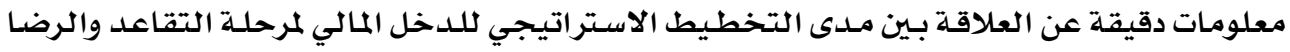

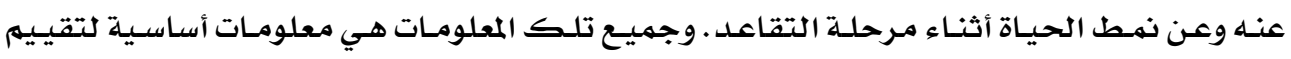

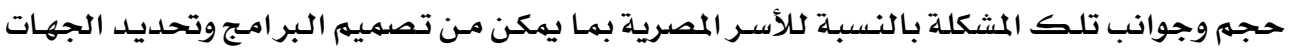
والسبل لاحتوائها.

ولكل الأسباب السابقة انبثقت مشكلة البحث الحالي والتي تتلخص يِّ التساؤلات التالية:

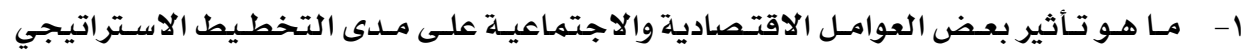

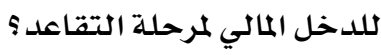

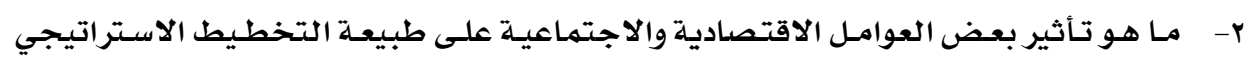

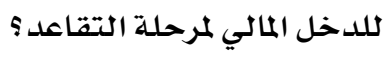

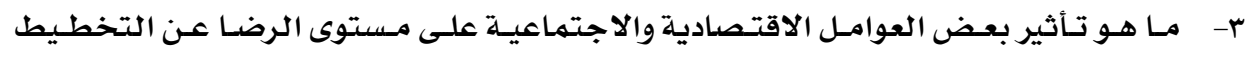

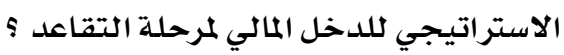

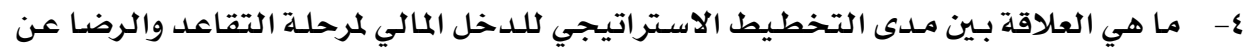

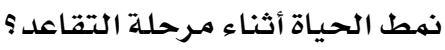

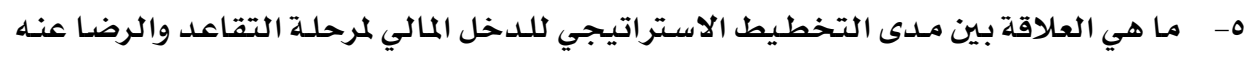

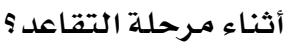

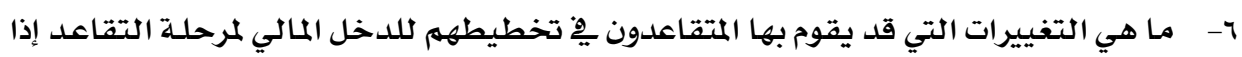
ما أتيحت لهم الفرصة مـرة أخرى لذلك الك التخطيط.

$$
\text { وتتمثل أهداف الدراسلة فِ : }
$$

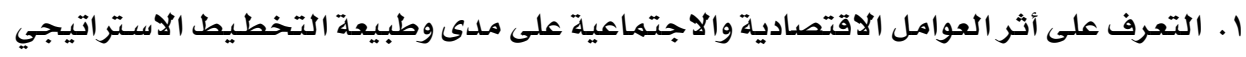

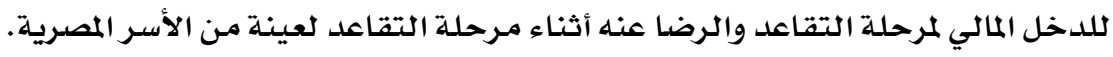

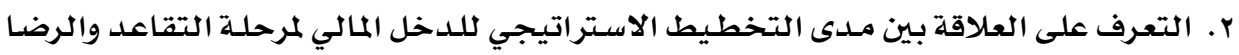

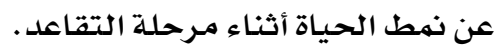

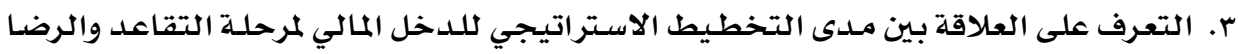

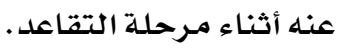

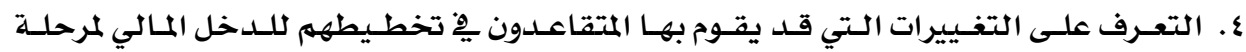

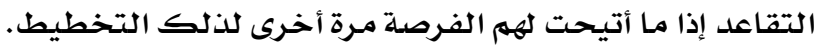




\section{أهميسة البمث : \\ ترجـع أهمية هذه الدراسـة إلى :}

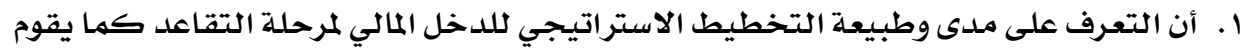

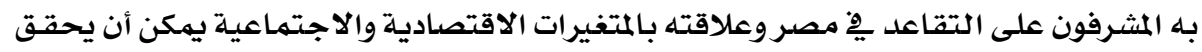

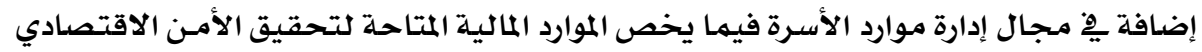

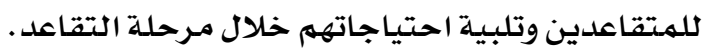

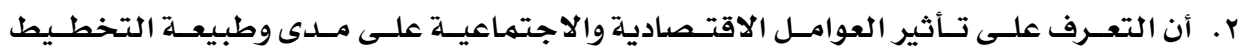

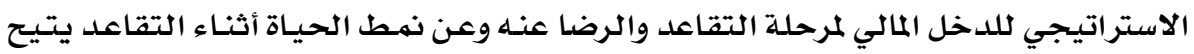

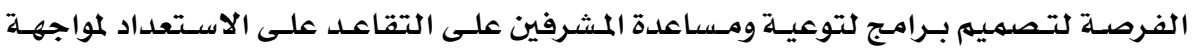

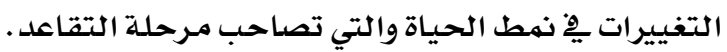

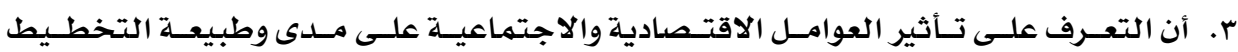

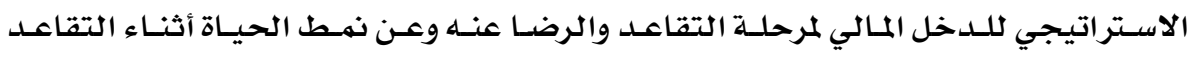

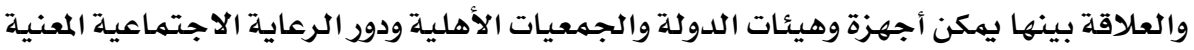

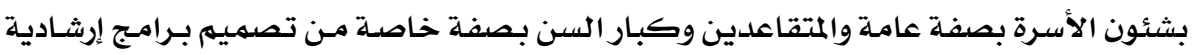

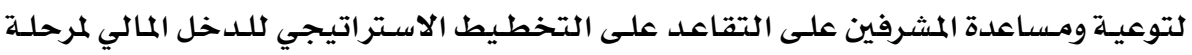

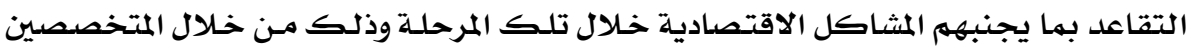

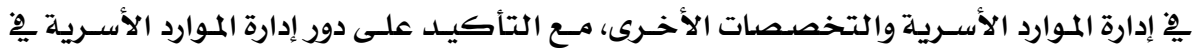
التخطيط المالي لمرحلة التقاعد.

$$
\text { تلخصت فروض الدراسـة يِّ الفروض التالية : }
$$

ا ـ توجد فروق ذات دلالة إحصائية يِّ مدى التخطيط الاستراتيجي للدخل المالي لمرحلة التقاعد تبعاً للعوامل الاقتصادية والاجتماعية.

$$
\text { وينبثق منسه الفروض الفرعية التالية: }
$$

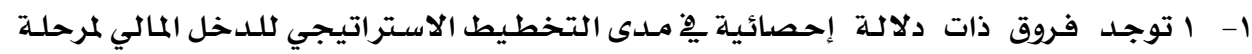
التقاعد نتيجة لمتغير مكان السكن.

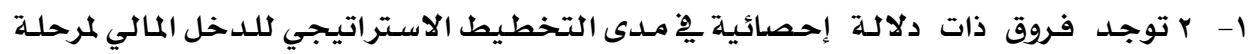
التقاعد نتيجة لمتغير مستوى تعليه عائل الأسرة.

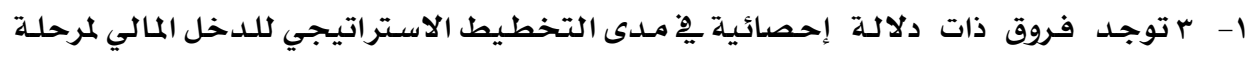
التقاعد نتيجة لمتغير المهنة.

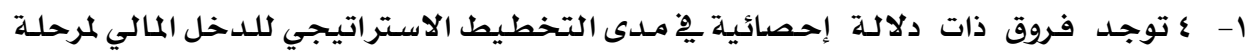
التقاعد نتيجـة لمتغير دوام مهنـة زوج/زوجة داتلة عائل الأسرة. 


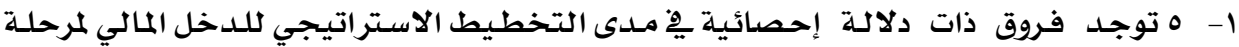

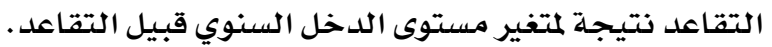

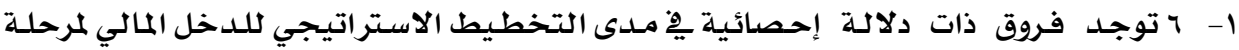
التقاعد نتيجة لمتغير حجهم الأسرة.

r . توجد فروق ذات دلالة إحصائية ِِِ طبيعـة التخطيط الاستراتيجي للدخل المالي لمرحلـة التقاعد

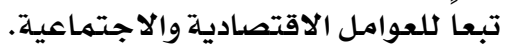
وينبثق منـه الفروض الفرعية التالية:

ץ- ا توجـد فروق ذات دلالـة إحصائية ِِِ طبيعـة التخطيط الاسـتراتيجي للـدخل المالي لمرحلـة التقاعد نتيجة لمتغير مكان السكن.

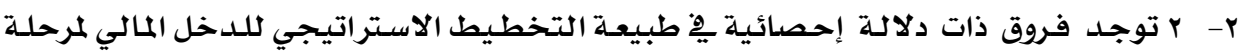
التقاعد نتيجة لمتغير مستوى تعليهم عائل الأسرة.

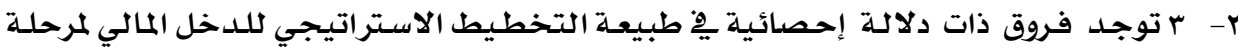
التقاعد نتيجة لمتغير المهنة.

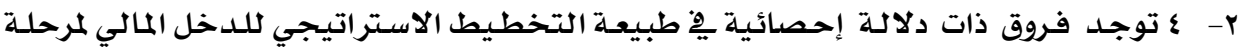

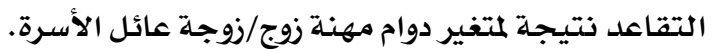

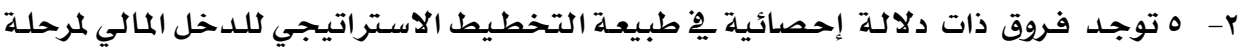

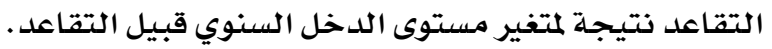

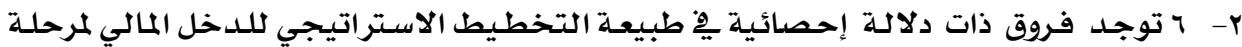
التقاعد نتيجة لمتغير حجهم الأسرة.

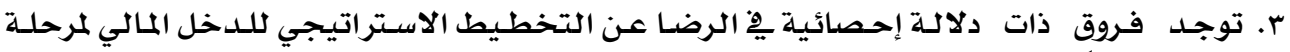

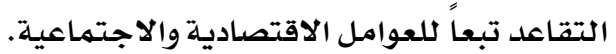
وينبثق منـه الفروض الفرعية التالية:

r- اتوجد فروق ذات دلالة إحصائية يِ الرضا عن التخطيط الاستراتيجي للدخل المالي لمرحلـة التقاعد نتيجة لمتفير مكان السكن.

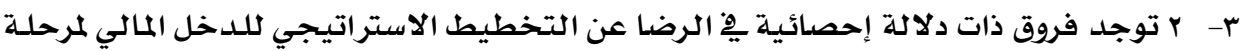
التقاعد نتيجة لمتغير مستوى تعليه عائل الأسرة.

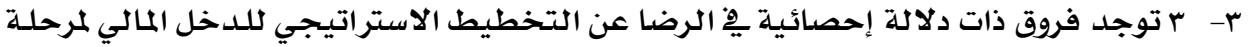
التقاعد نتيجة لمتغير المهنة.

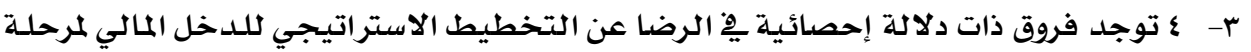

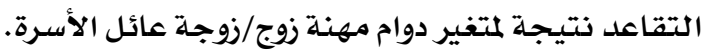

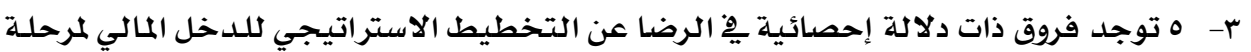
التقاعد نتيجة لمتغير مستوى الدخل السنوي قبيل التقاعد. 
مجلة بحوث التربية النوعية - عدد rr - r.ll بوليو

ب- ب توجد فروق ذات دلالة إحصائية ِِّ الرضا عن التخطيط الاستراتيجي للدخل المالي لمرحلـة

التقاعد نتيجة لمتغير حجم الأسرة.

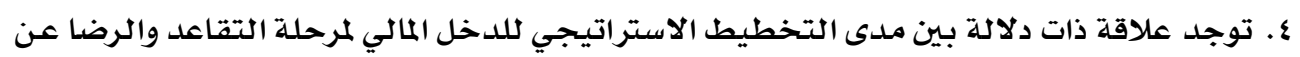
نهط الحياة أثناء مـرحلة التقاعد.

ه. توجد علاقة ذات دلالة بـين مدى التخطيط الاستراتيجي للدخل المالي لمرحلة التقاعد والرضنا عنهـ أثناء مرحلة التقاعد.

\section{متغيرات البحث :}

المتفيرات المستقلة:

ا ـ متغير مكان السكن وله ب مستويات (قرية، ضاحية، مدينة).

r . متغير مستوى تعليهم عائل الأسـرة وله ؛ مستويات (إعدادي، ثانوي، فني، جامعي) .

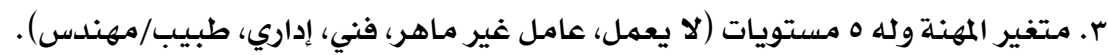

ع. متغير طبيعة مهنة زوج/زوجة عائل الأسـرة وله ب مستويات (لا يعمل، نصف دوام، دوام كامل) .

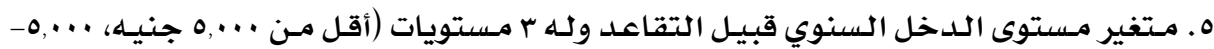

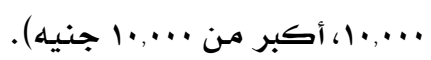

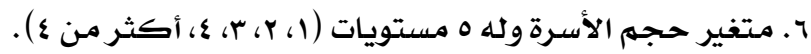

المتفيرات التابعة:

تتمثل المتغيرات التابعة فٍِ :

ا- مدى التخطيط الاستراتيجي للدخل المالي لمرحلة التقاعد،

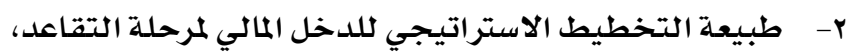

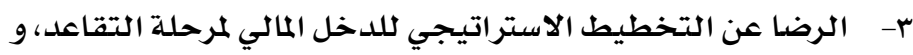
ع- الرضا عن نهط الحياة أثناء مـرحلة التقاعد.

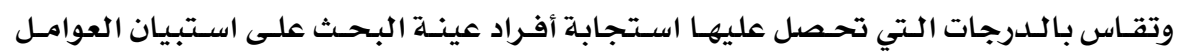

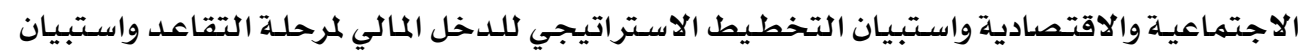
الرضا عن نهط الحياة، وجميعها من إعداد البـاحثة.

\section{التعريفات الإجرائية لمصطات الصهات البحث :}

• التقاعد : هو انقطاع الشخص عن أداء وظيفة ما ظل يؤديها حتى سن التقاعد، ولكن ذلك لا

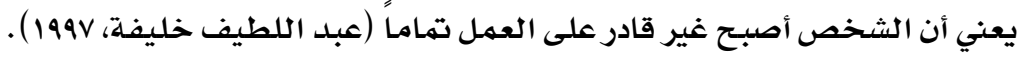

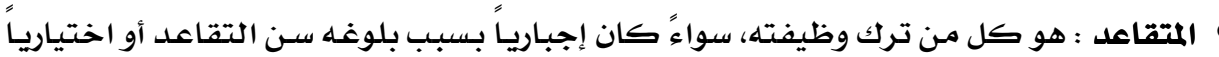
بسببـ ظروفه الصحية (عبد اللطيف خليفة، و 199V) . • عائل الأسرة : وهو الذي يحقق الجانب الأكبر من دخل الأسرة الكلي. 


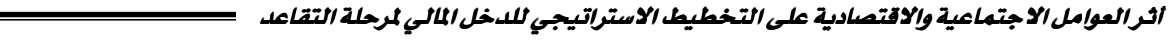

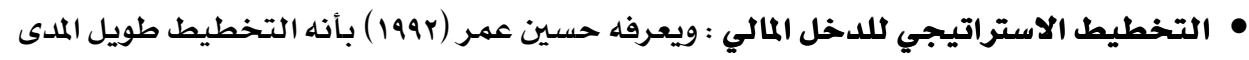

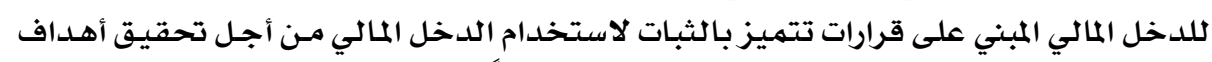

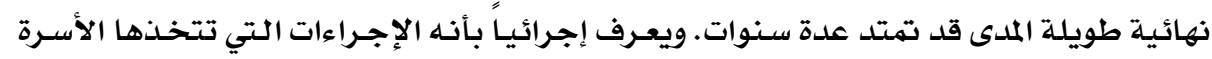

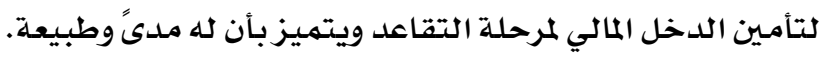

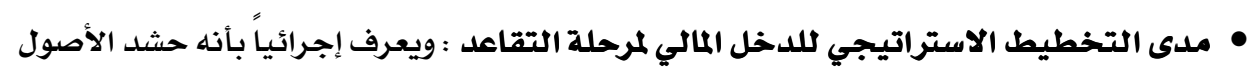

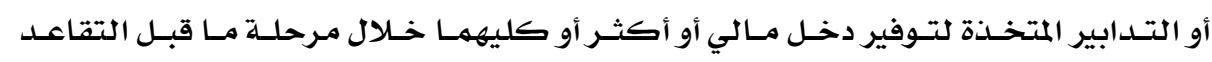
لاستغلالها خلال مـرحلة التقاعد.

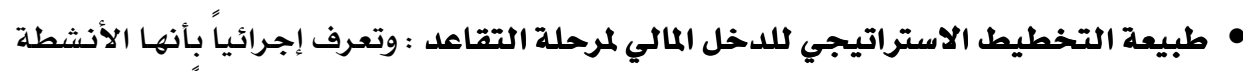

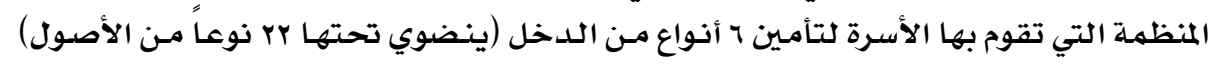

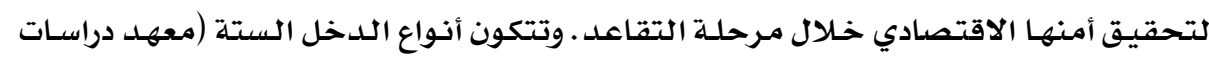

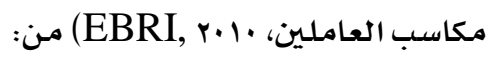

ا ـ الدخل المالي من عمل العائل أثناء مرحلة التقاعد أو عمل زوج/زوجـة العائل أو كليهما،

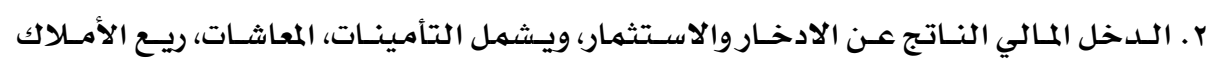

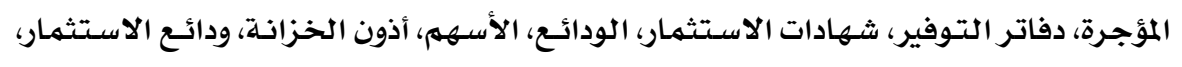

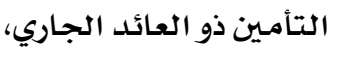
r. الأملاك، وتشمل ملكية مـكان الإقامـة، الأملاك الأخرى خلاف المنزل،

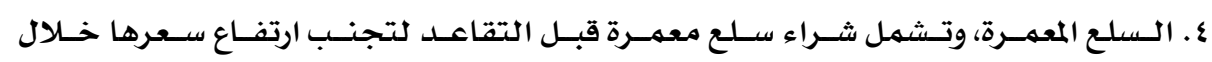

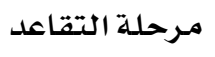

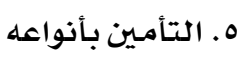
1. تسوية الديون المعلقة قبل التقاعد.

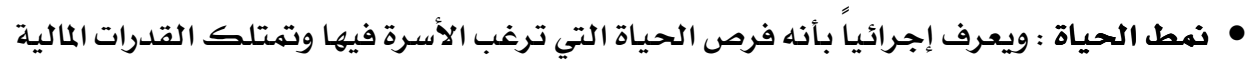
كتحقيقها.

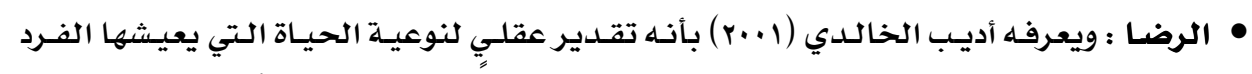

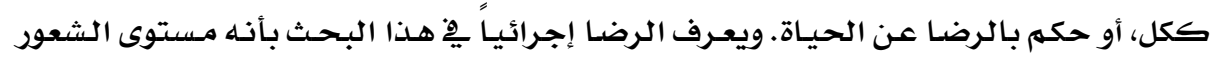

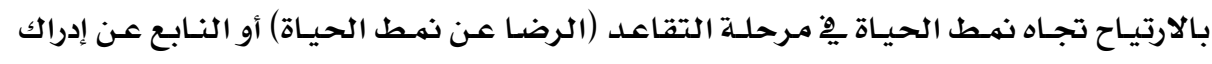

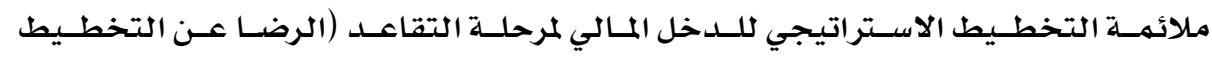

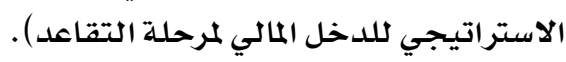

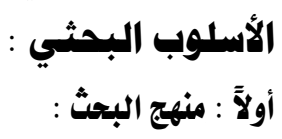

اتبع البحث المنهج الوصفي التحليلي الذي يقوم على تجميع الحقائق والمعلومات ومقارنتها

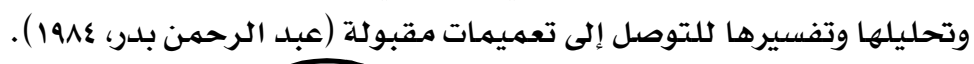


اقتــرت الدراسـة على سـكان محافظــة الجيـزة وضـواحيها وقراهـا ومحافظــة 7 أكتـوبر،

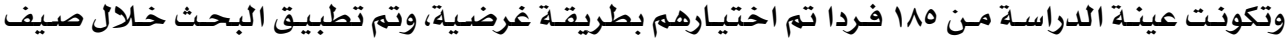

تكونت عينة الدراسـة من 1100 فرداً تم اختيارهم بطريقة غرضيـة مـن سـكان محافظلة الجيزة

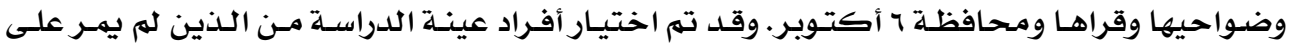

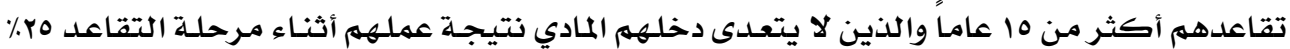
من دخلهم قبل التقاعد.

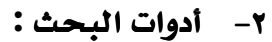

اشتملت الأدوات المستخدمـة على ثلاثة استبيانات مـن إعداد الباحثة وهي استبيان العوامـل

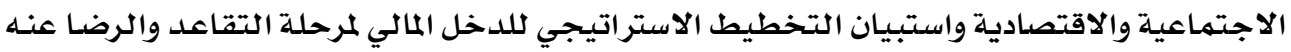

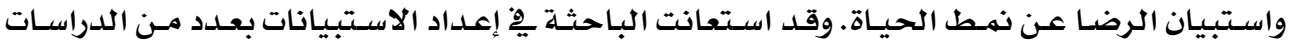

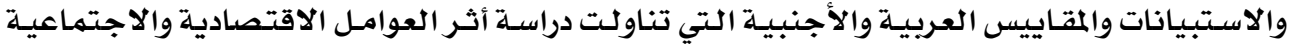

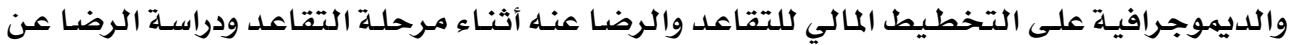

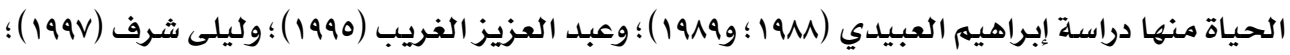

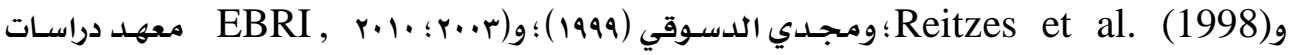

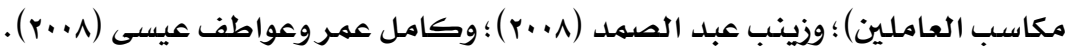

\section{أـ استبيان العوامل الاجتماعية والاقتصادية}

شمل استبيان العوامل الاجتماعية والاقتصادية فقرات خاصدة بالسن، ومكان السكن، والحالة

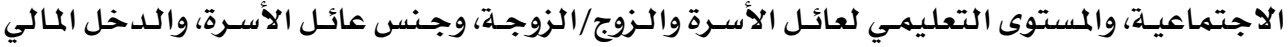

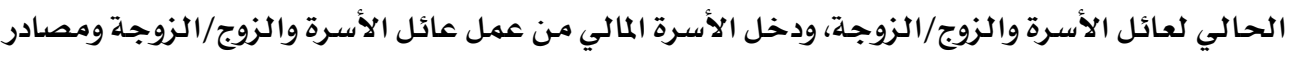

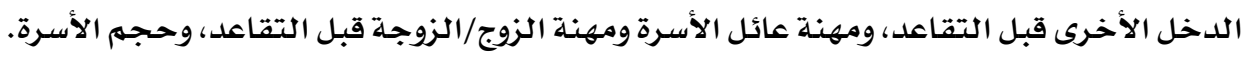
بـ استبيان التخطيط الاستراتيجي للدخل المالي لمرحلة التقاعد

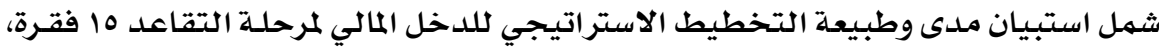

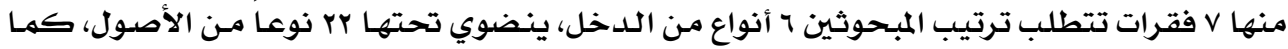

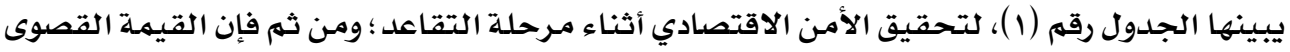

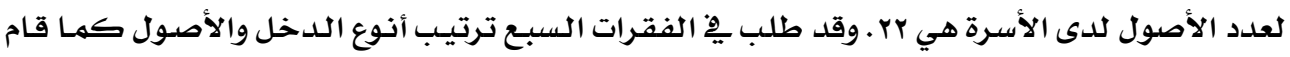

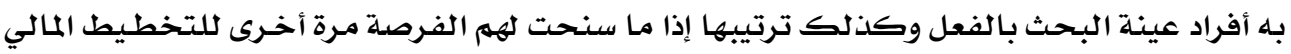

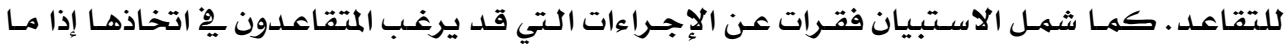

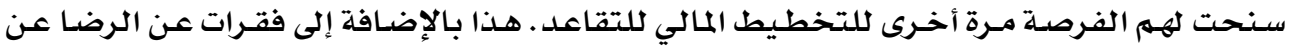


التخطيط الاستراتيجي للدخل المالي لمرحلة التقاعد، واستخدم مقياس رياعي لتقدير مستوى ذلك

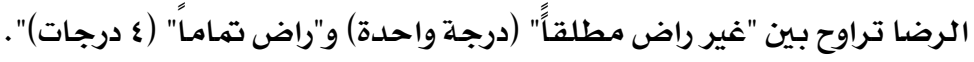
جدول (1) : تصنيف الأصول ِِّ أنواع الدخل الستة باستبيان التخطيط المالي لمرحلة التقاعد

\begin{tabular}{|c|c|c|c|}
\hline الأصول & & الأصول & \\
\hline تأمين الحياة (عائل الأسرة الرئيسي) & ir & ت ت تأمينات & 1 \\
\hline تأمين الحياة (زوج/زوجة عائل الأسرة الرئيسي) & ir & 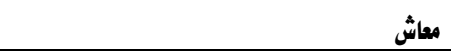 & $r$ \\
\hline التأمين الصحي & $1 \varepsilon$ & عمل عائل الأسرة الرئيسي أثناء التقاعد & $r$ \\
\hline تأمين على المنزل & 10 & عمل زوج/زوجة عائل الأسرة الرئيسي & $\varepsilon$ \\
\hline تأمين على السيارة & 17 & ريع أملاك مؤجرة & 0 \\
\hline أسهم & iv & ملكية مكان الإقامة & 1 \\
\hline 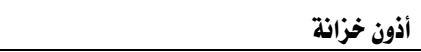 & in & دفتر توفير ذو الجوائز & $r$ \\
\hline ودائع استثمار & 19 & دفتر توفير & $\wedge$ \\
\hline التأمين ذو العائد الجاري & r. & 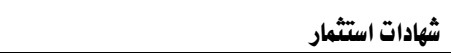 & 9 \\
\hline أملاك أخرى خلاف المنزل & ri & 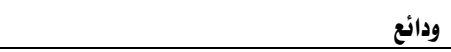 & 1. \\
\hline تسوية ديون قبل التقاعد & rr & شراء سلع معمرة قبل التقاعد لتجنب ارتفاع سعرها & 11 \\
\hline
\end{tabular}

صدق الاستبيان :

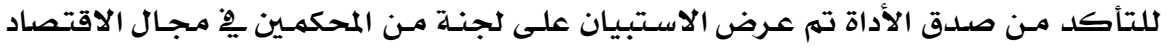

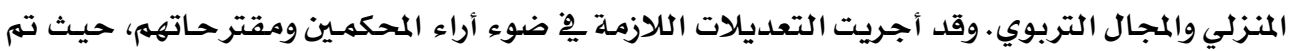

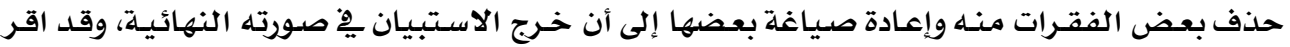

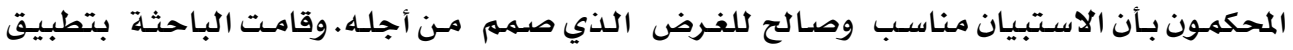

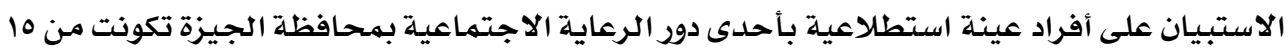

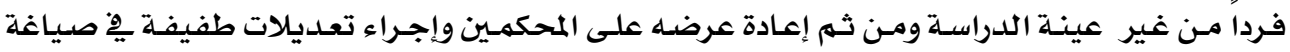

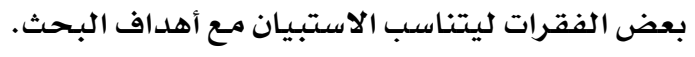

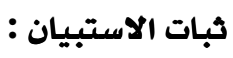

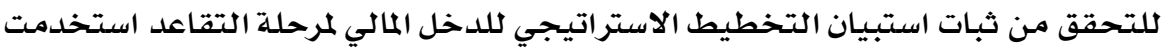

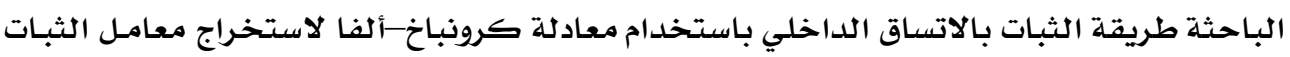

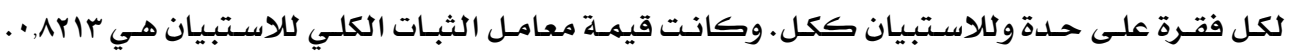

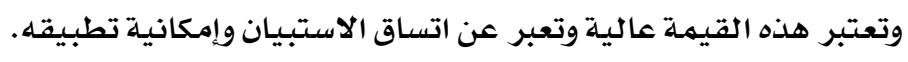

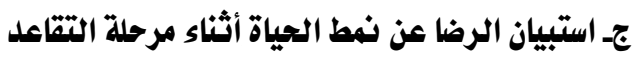

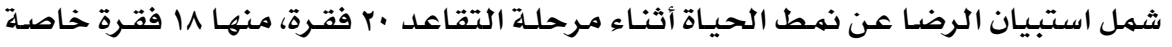

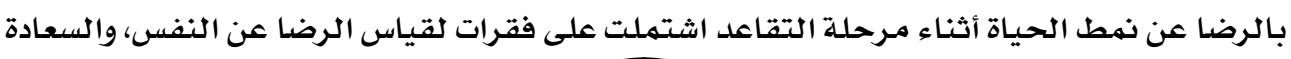


والتقبل، والشعور بالأمن، والثعور بالتوفيق يِّ الحياة، والرضـا عن العلاقات مـع الآخرين، ومـدى تقبـل

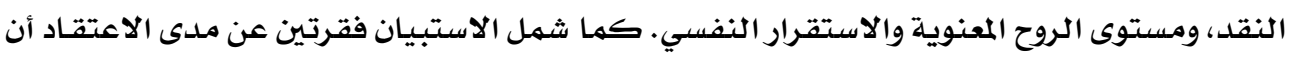

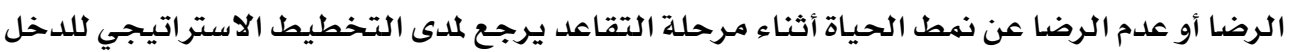

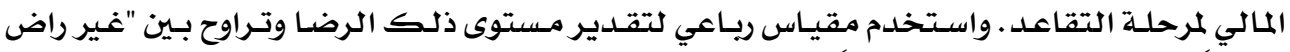

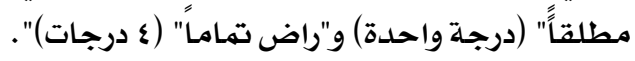

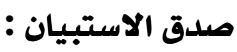

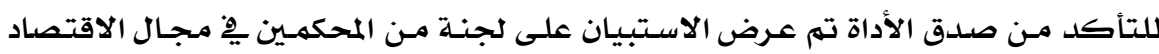

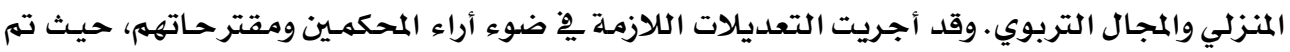

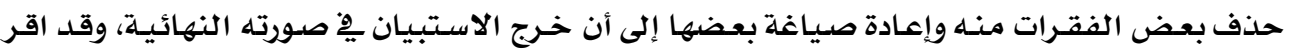

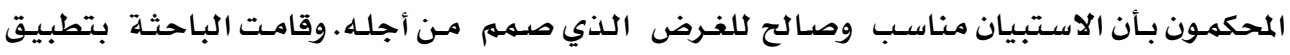

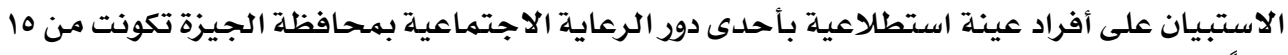

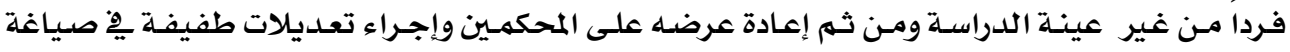

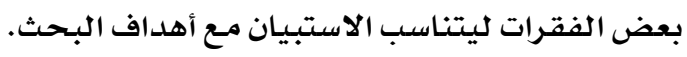
ثبات الاستبيان : بان

للتحقق من ثبات استبيان الرضا عن نمط الحياة أثناء مرحلة التقاعد استخلدمت الباحثة

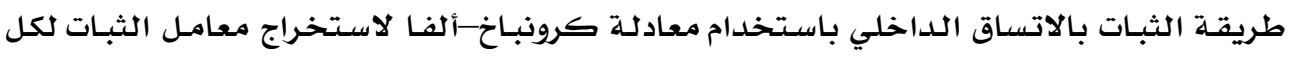

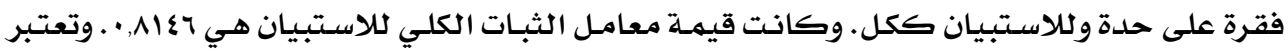

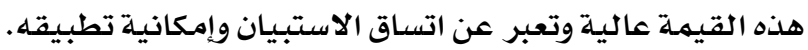

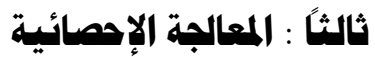

قامت الباحثة بتوزيع الاستبيانات على عينة الدراسة ومن ثم قامت بتفريغ وتحليل نتائجها

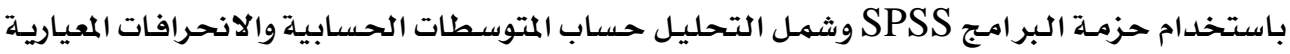

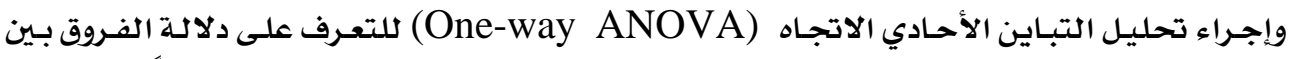

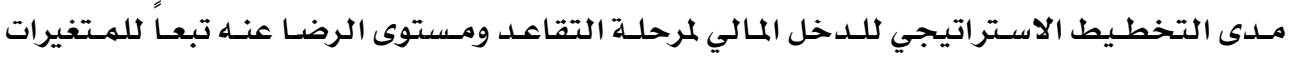

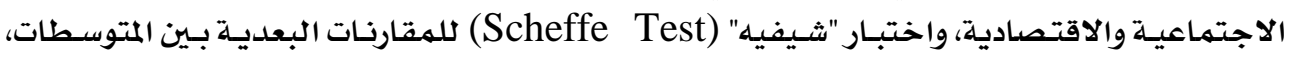

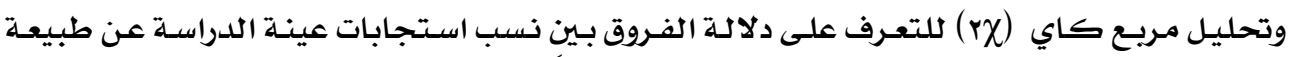

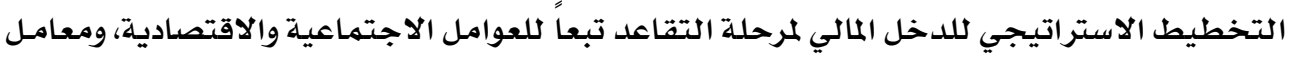

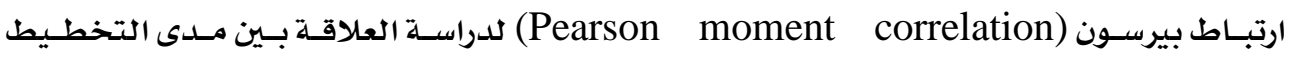

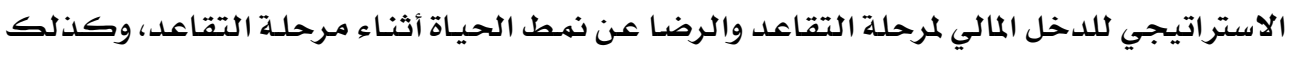

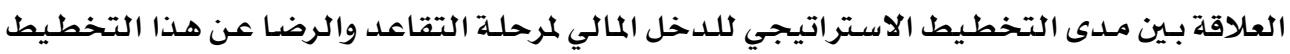
أثناء مرحلة التقاعد. 


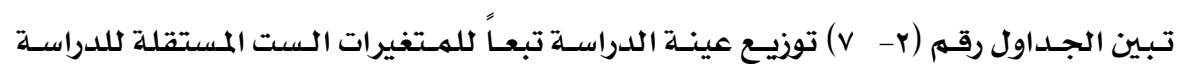

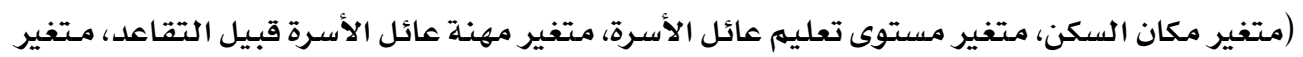

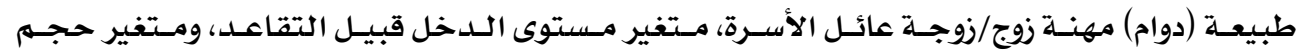

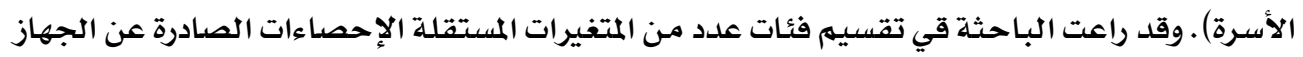

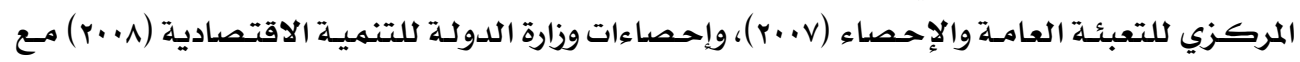

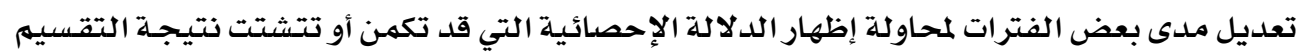

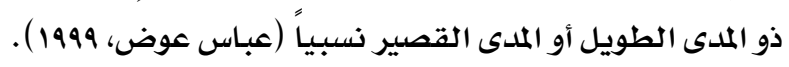
جدول (r) توزيع أفراد عينة الدراسة تبعاً لمكان السكن عودين

\begin{tabular}{|c|c|c|}
\hline النسبـة المئويـة ٪ & العدد & مكان السكن \\
\hline 53.5 & 99 & مدينة \\
\hline 27.0 & 50 & ضاحية \\
\hline 19.5 & 36 & قرية \\
\hline $1 \ldots$, & 185 & المجموع \\
\hline
\end{tabular}

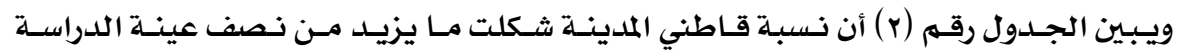

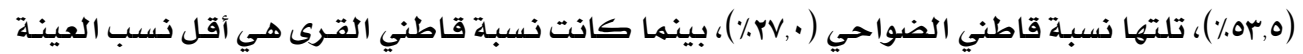
.$(\% 19,0)$

\begin{tabular}{|c|c|c|}
\hline النسبـة المئويـة ٪ & العدد & مستوى التعليم \\
\hline 31.4 & 58 & إعدادي \\
\hline 25.9 & 48 & ثانوي \\
\hline 13.5 & 25 & تعليهم فني \\
\hline 22.2 & 41 & تعليم جامعى \\
\hline 7.0 & 13 & له يجب \\
\hline 100.0 & 185 & المجموع \\
\hline
\end{tabular}

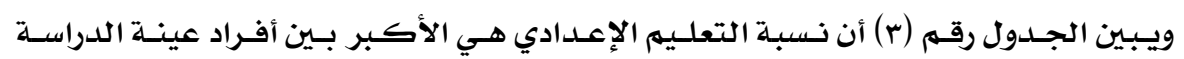

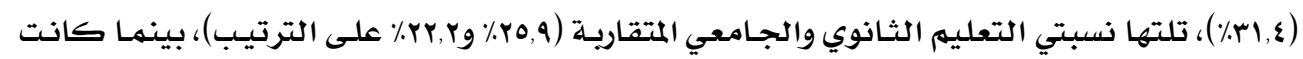

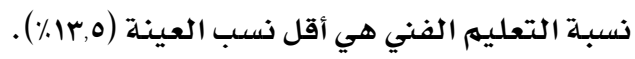


جدول (؟) توزيع أفراد عينة الدراسة تبعاً لمهنة عائل الأسرة

\begin{tabular}{|c|c|c|}
\hline النسبــة المئويـة ٪ & العدد & المهنة \\
\hline 1.6 & 3 & لا يعمل \\
\hline 23.8 & 44 & عامل غير مـاهر \\
\hline 34.1 & 63 & فنى \\
\hline 17.8 & 33 & إداري \\
\hline 21.1 & 39 & طبيب/مهندس \\
\hline 1.6 & 3 & لهم يجب \\
\hline 100.0 & 185 & المجموع \\
\hline
\end{tabular}

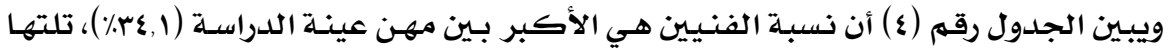

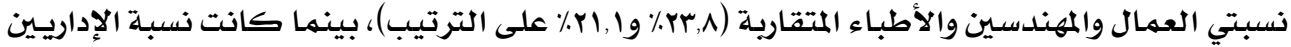

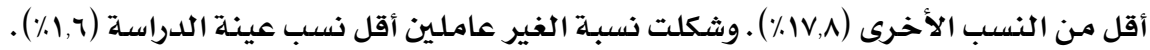

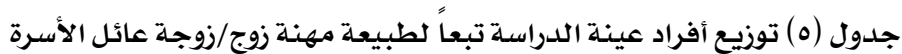

\begin{tabular}{|c|c|c|}
\hline النسبـة المئويـة ٪ & العدد & دوام المهنـة \\
\hline 35.7 & 66 & لا يعمل \\
\hline 13.0 & 24 & نصف دوام \\
\hline 36.2 & 67 & دوام كامل \\
\hline 15.1 & 28 & لهم يجب \\
\hline 100.0 & 185 & المجموع \\
\hline
\end{tabular}

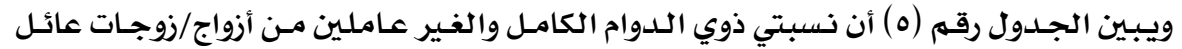

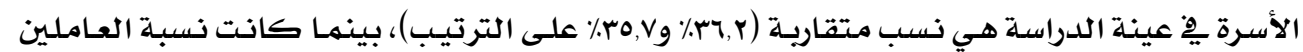

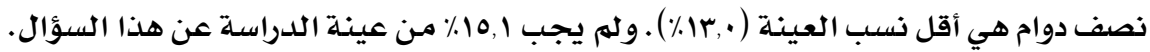
جدول (ج) توزيع أفراد عينة الدراسـة تبعاً لمتوسط الدخل خلال · ل1 سنوات سابقة على التقاعد

\begin{tabular}{|c|c|c|}
\hline النسبـة المئوية ٪ & العلدد & الدخل بـالجنيـي \\
\hline 41.6 & 77 & أقل من ...,0 \\
\hline 25.9 & 48 & $1, \ldots-0, \ldots$ \\
\hline 32.4 & 60 & أكثر مـن ..., 1 \\
\hline 100.0 & 185 & المجموع \\
\hline
\end{tabular}




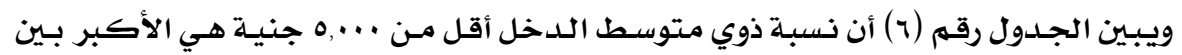

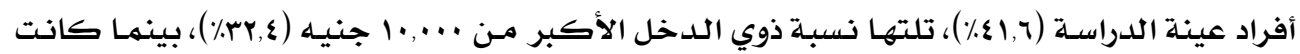

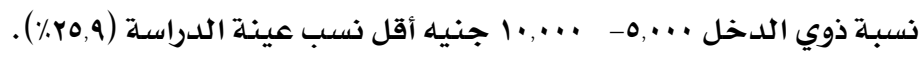
جدول (v) توزيع أفراد عينة الدراسة تبعاً لحجم الأسرة

\begin{tabular}{|c|c|c|}
\hline النسبـة المئويـة ٪ & العدد العد & عدد الأفراد \\
\hline 4.3 & 8 & 1 \\
\hline 17.3 & 32 & r \\
\hline 31.9 & 59 & $r$ \\
\hline 26.5 & 49 & $\varepsilon$ \\
\hline 19.5 & 36 & أكثر من ع \\
\hline 0.5 & 1 & له يجب \\
\hline 100.0 & 185 & المجموع \\
\hline
\end{tabular}

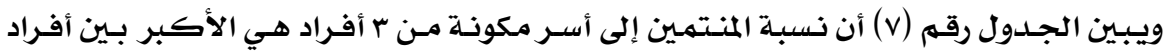

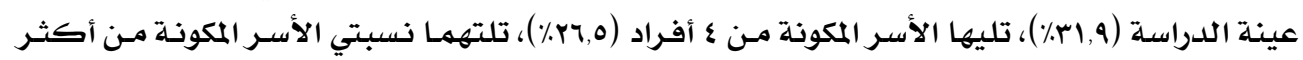

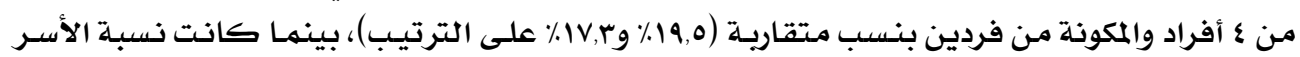
المكونة من فرد واحد هي أقل نسبة (r, ؟ء) ).

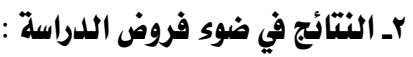
الفرض الأول :

وللإجابـة عن التسـاؤل البحثي الأول "مـا هو تأثير بعض العوامـل الاقتصادية والاجتماعيـة

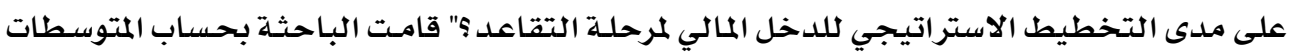

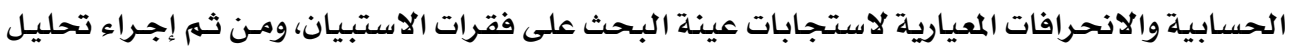

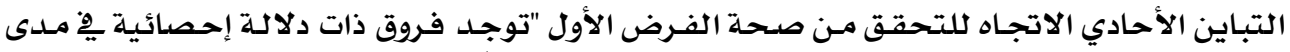

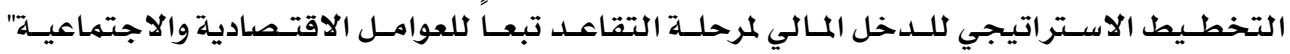

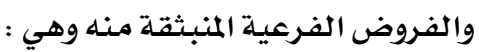

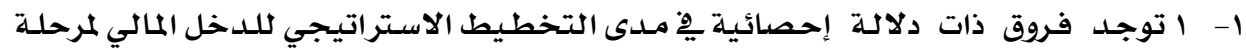
التقاعد نتيجة لمتغير مكان السكن.

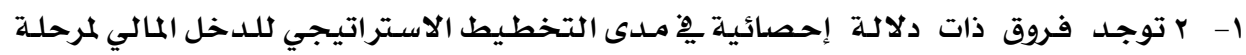

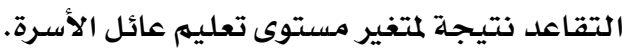

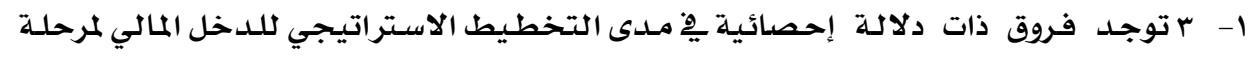
التقاعد نتيجة لمتغير المهنة. 


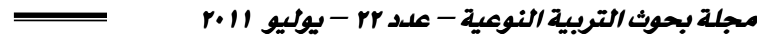

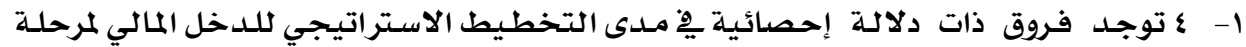

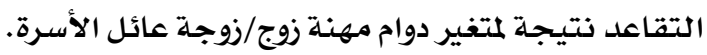

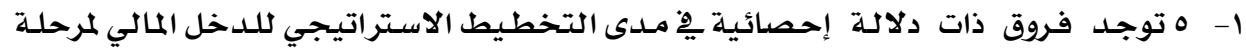
التقاعد نتيجة لمتغير مستوى الدخل السنوي قبيل دوريل التقاعلد. ا- 1 توجـد فروق ذات دلالـة إحصائية يِّ مـدى التخطيط الاستراتيجي للدخل المالي لمرحلـة

$$
\text { التقاعد نتيجة لمتغير حجم الأسرة. }
$$

ويظهـر الجـدول رقم (^) نتائج تحليـل التبـاين لأثر مـتغيرات البحـث المستقلة الست (مكـان

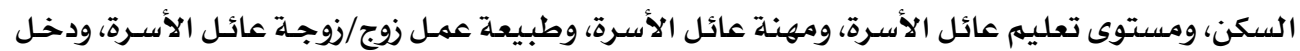

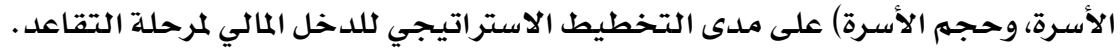
جدول (^) : نتائج تحليل التباين الأحادي الاتجاه لدلالة الفروق بين مدى تخطيط الدخل المالي لمرحلة التقاعد تبعاً للمتغيرات المستقلة.

\begin{tabular}{|c|c|c|c|c|c|c|c|c|}
\hline مستوى الدلالة & ف & $\begin{array}{c}\text { الانحراف } \\
\text { متوسط } \\
\text { (داخلي) } \\
\end{array}$ & $\begin{array}{c}\text { متوسط } \\
\text { الانحراف } \\
\text { (بيني) } \\
\end{array}$ & 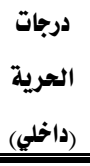 & الحرجية & $\begin{array}{c}\text { مجموع مربعات } \\
\text { الانحراف } \\
\text { (داخلي) } \\
\end{array}$ & 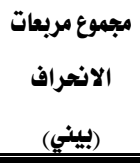 & المتفير \\
\hline 0.01 & 31.48 & 15.39 & 484.50 & lar & $r$ & 2801.11 & 969.00 & مكان السكن \\
\hline 0.01 & 21.27 & 15.27 & 324.74 & 174 & $r$ & 2564.95 & 974.22 & مستوى التعليم \\
\hline 0.01 & 12.39 & 22.05 & 273.20 & ivA & $r$ & 3924.94 & 819.61 & مهنة العائل \\
\hline 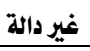 & 0.44 & 19.88 & 8.75 & $10 \varepsilon$ & $r$ & 3060.91 & 17.49 & عمل زوج/زوجة العائل \\
\hline 0.01 & 29.06 & 15.75 & 457.57 & lar & $r$ & 2865.74 & 915.15 & دخل الأسرة \\
\hline 0.01 & 8.10 & 17.66 & 143.01 & iva & $\xi$ & 3160.39 & 572.05 & حجم الأسرة \\
\hline
\end{tabular}

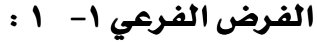

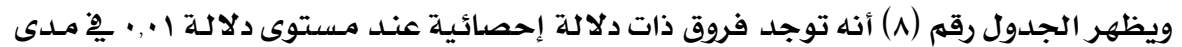

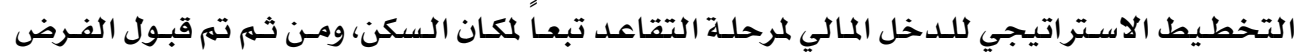

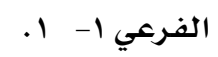

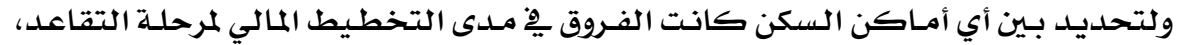

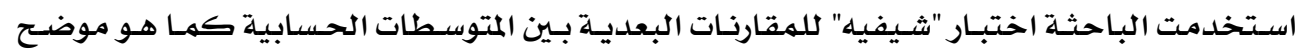

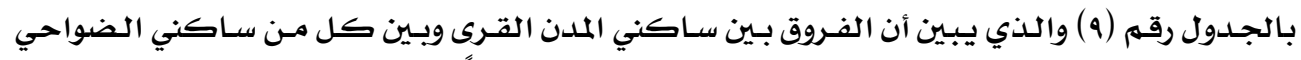

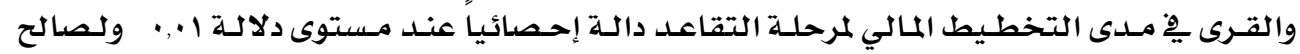

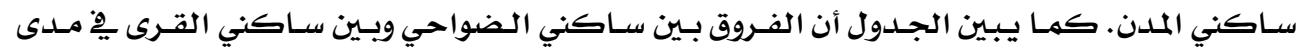

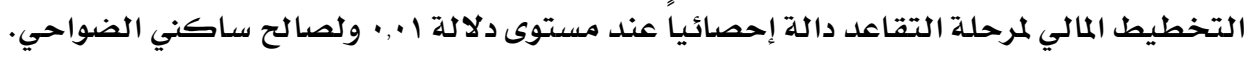




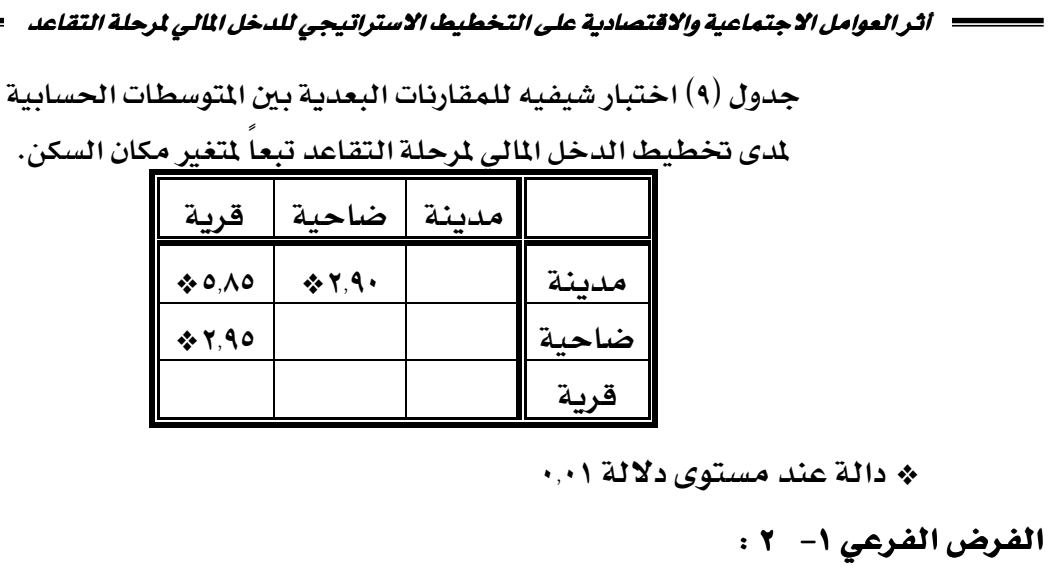

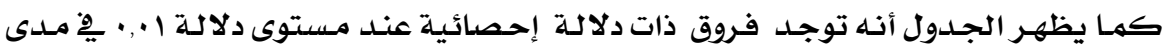

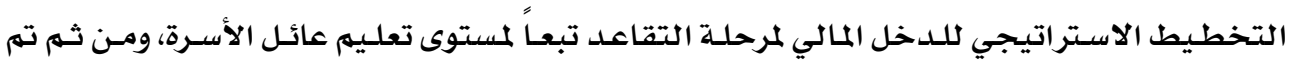

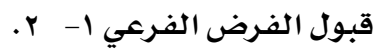

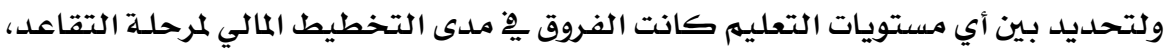

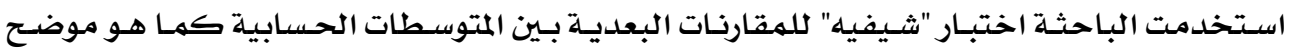

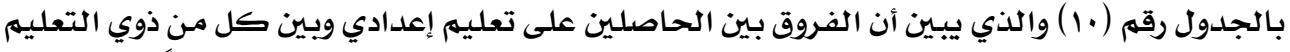

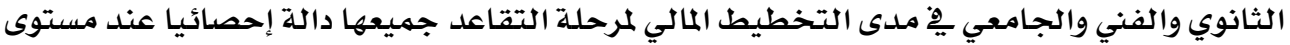

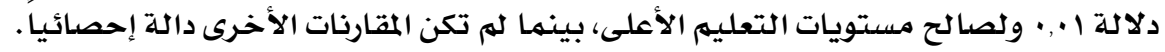

جدول ( . ) اختبار شيفيه للمقارنات البعدية بين المتوسطات الحسابية

لمدى تخطيط الدخل المالي لـرحلة التقاعد تبعا لمتغير مستوى تعليهم عائل الأسـرة.

\begin{tabular}{|c|c|c|c|c|}
\hline تعليه جامعي & تعليهم فني & ثانوي & إعدادي & \\
\hline$\otimes, 0 \mathrm{~V}-$ & $* 0,7 \Lambda-$ & $* r, Y r-$ & & إعدادى \\
\hline r, - & $Y, \varepsilon\rceil-$ & & & ثانوى \\
\hline \multirow[t]{2}{*}{$\cdot, 11$} & & & & تعليهم فنى \\
\hline & & & & تعليه جامعي \\
\hline
\end{tabular}

* دالة عند مستوى دلالة ا.,.

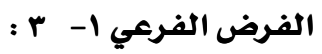

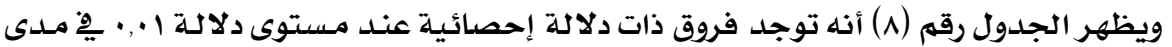

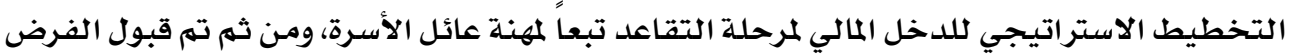

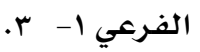

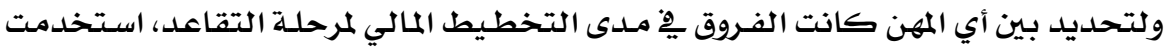

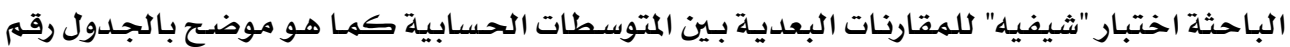

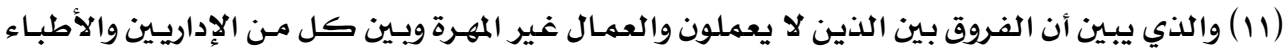




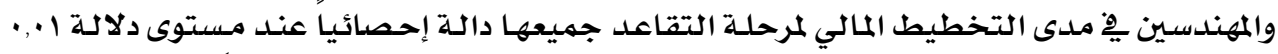

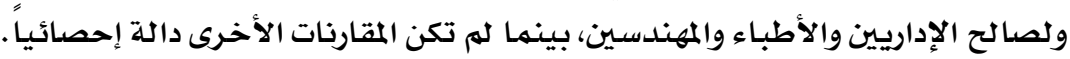

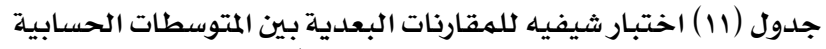

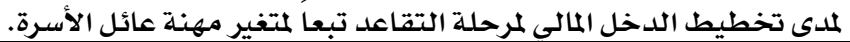

\begin{tabular}{|c|c|c|c|c|}
\hline طبيب/مهندس & 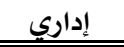 & فني & لا يعمل أو عامـل غير ماهر & \\
\hline$\$ 0, \mu 1-$ & $\$ 0,1 V-$ & Y,Yr - & & لا يعمل أو عامل غير مـاهر \\
\hline$r \cdot \wedge-$ & Y,QE - & & & فني \\
\hline \multirow[t]{2}{*}{$\cdot, 1 \varepsilon \quad-$} & & & & إداري \\
\hline & & & & طبيب/مهندس \\
\hline
\end{tabular}

• • دالة عند مستوى دلالة ا.,.

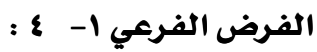

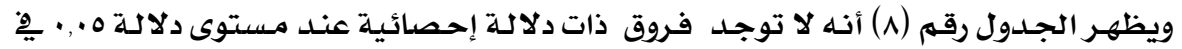

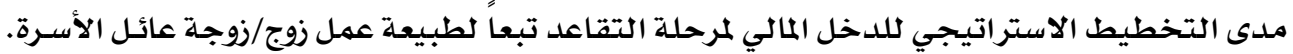

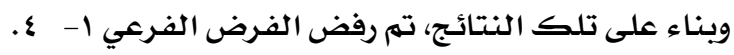

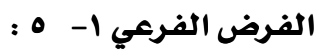

كما يظهر الجدول رقم (^) أنه توجد فروق ذات دلالدة إحصائية عند مستوى دلالـة ا +. -

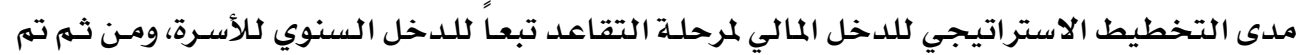

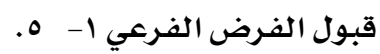

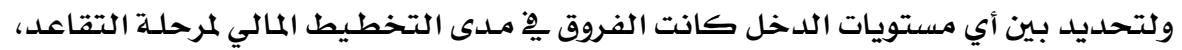

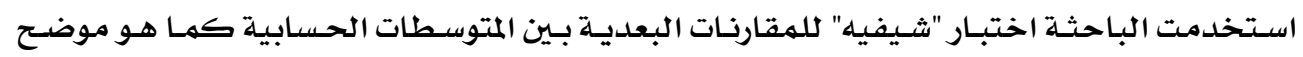

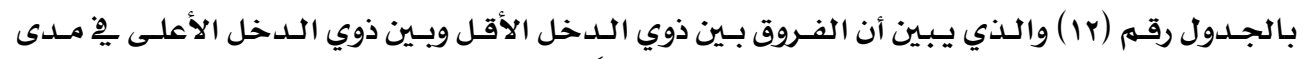

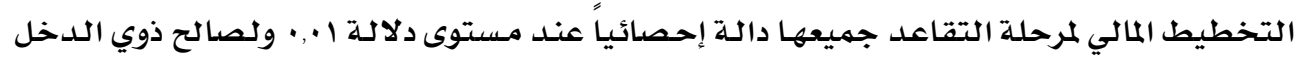

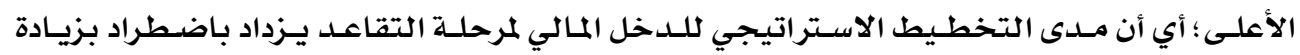
الدخل.

جدول (r ا ) اختبار شيفيه للمقارنات البعدية بين المتوسطات الحسابية

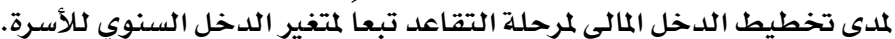

\begin{tabular}{|c|c|c|c|}
\hline أكثر من ..., 1 & $1, \ldots-1,-0, \ldots$ & أقل من ...,0 & \\
\hline$\$ 0,19-$ & $* Y, V I-$ & & أقل مـن ..., \\
\hline$\& Y, \Sigma \Lambda \quad-$ & & & $1, \ldots,-0, \ldots$ \\
\hline & & & أكثر من ..., . \\
\hline
\end{tabular}

ه دالة عند مستوى دلالة ا +, . 


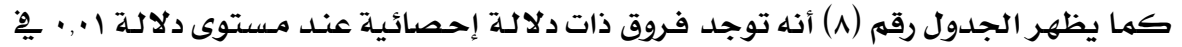

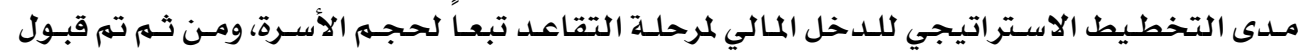
الفرض الفرعي 1-

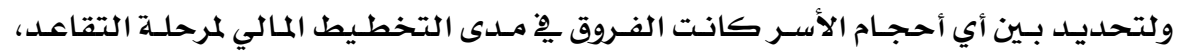

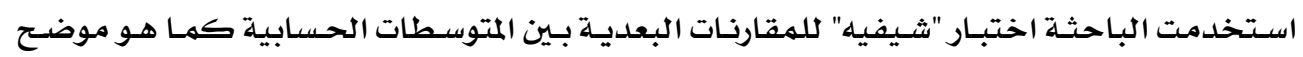

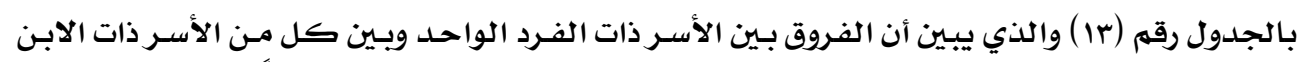

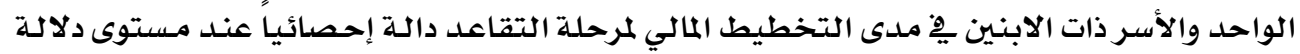

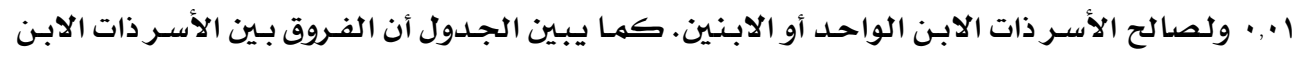

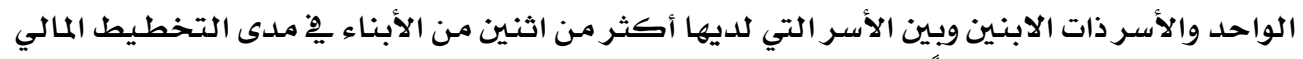

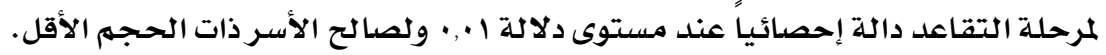
جدول (r) اختبار شيفيه للمقارنات البعدية بين المتوسطات الحسابية

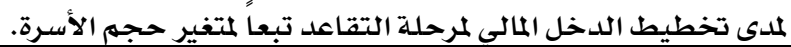

\begin{tabular}{|c|c|c|c|c|c|}
\hline أكثر مـن ع & $\varepsilon$ & $r$ & $r$ & 1 & \\
\hline$r, \cdot \Lambda \quad-$ & $\$ 7$, or - & $\$ 7,09-$ & $0, \mathrm{r} \Lambda-$ & & 1 \\
\hline$r, r$. & $1,1 \varepsilon-$ & $|, Y|-$ & & & r \\
\hline$* r, 01$ & $\cdot, \cdot v$ & & & & $r$ \\
\hline \multirow[t]{2}{*}{$\& r, \varepsilon \varepsilon$} & & & & & $\varepsilon$ \\
\hline & & & & & أكثر من ع \\
\hline
\end{tabular}

• دالة عند مستوى دلالة ا +,

الفرض الثاني :

وللإجابة عن التسـاؤل البحثي الثاني "مـا هو تـأثير بعض العوامـل الاقتصـادية والاجتماعيـة

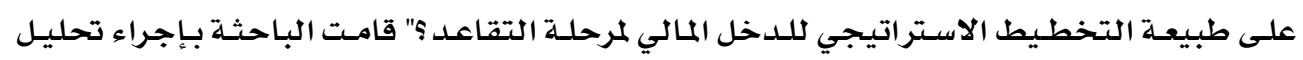

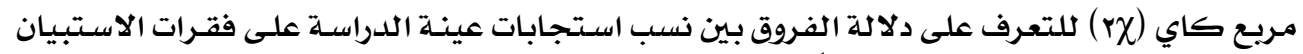

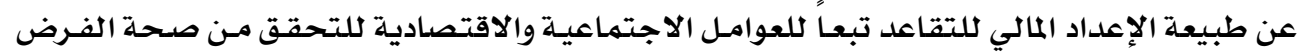

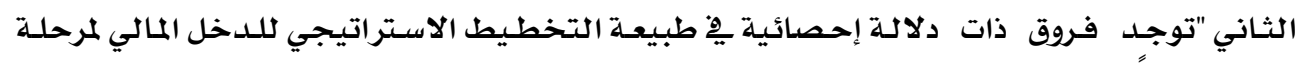

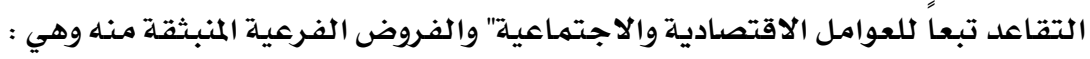

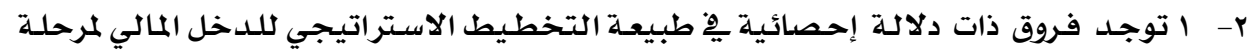
التقاعد نتيجة لمتغير مكان السكن.

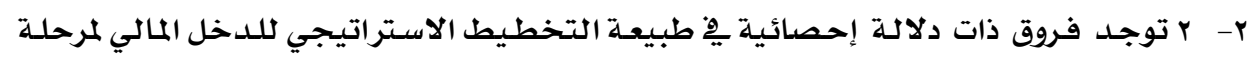
التقاعد نتيجة لمتغير مستوى تعليه عائل الأسرة. 


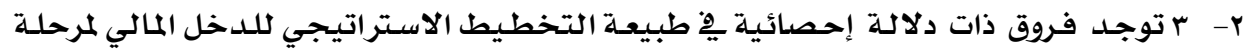
التقاعد نتيجة لمتغير المهنة.

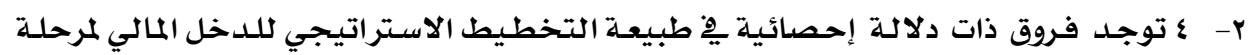

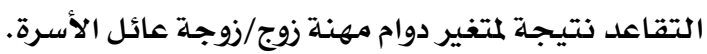

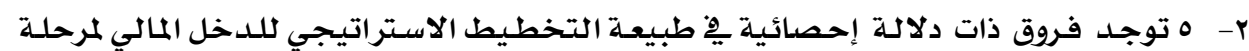

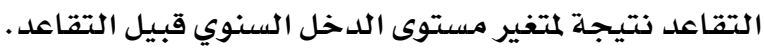

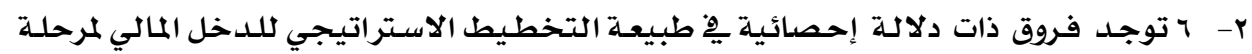
التقاعد نتيجة لمتغير حجم الأسرة.

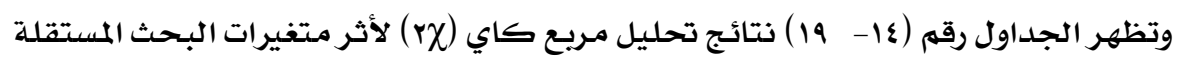

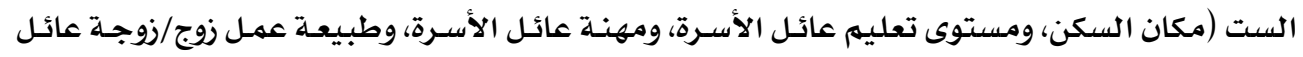

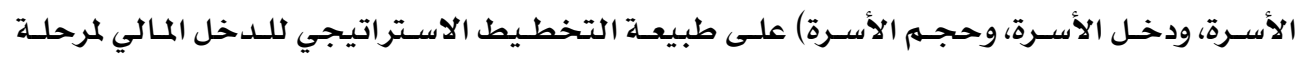
التقاعد.

الفرض الفرعي r- 1 : "توجد فروق ذات دلالة إحصائية يِّ طبيعـة التخطيط الاسـتراتيجي للدخل

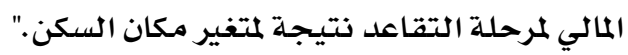

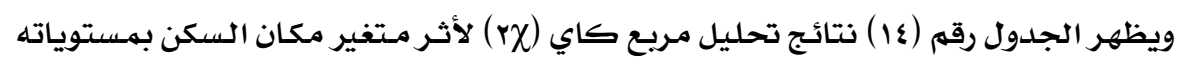

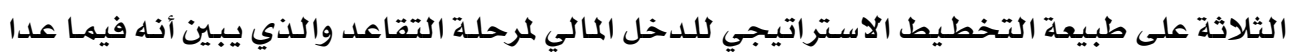

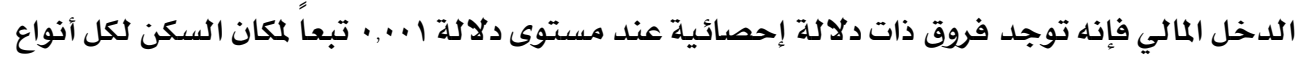

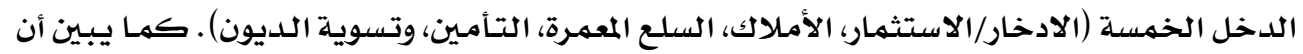

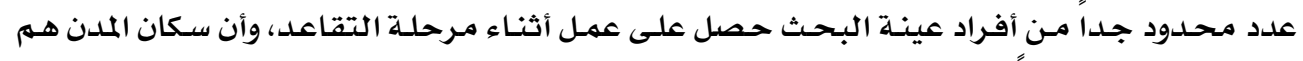

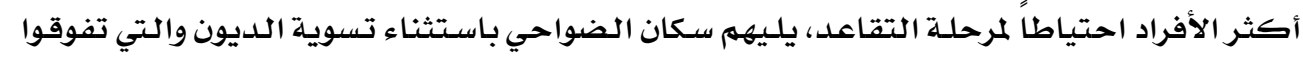

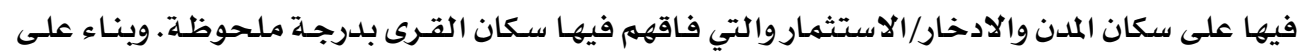

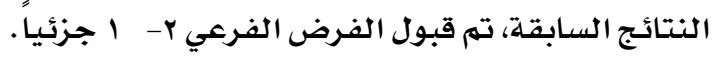

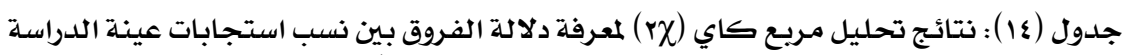

عن طبيعة تخطيط الدخل المالي لمرحلة التقاعد تبعا لمتغير مكان السكن.

\begin{tabular}{|c|c|c|c|c|c|c|c|c|c|c|c|c|}
\hline \multicolumn{2}{|c|}{ تسوية اللديوز } & \multicolumn{2}{|c|}{ التأمين بأنواعه } & \multicolumn{2}{|c|}{ السلع المعمرة } & \multicolumn{2}{|c|}{ الأملاك } & \multicolumn{2}{|c|}{ الادخار/الاستثمار } & \multicolumn{2}{|c|}{ الدخل المالي } & \multirow{2}{*}{ مكان السكن } \\
\hline$r \chi$ & $\%$ & $r \chi$ & $\%$ & $r \chi$ & $\%$ & $r \chi$ & $\%$ & $r \chi$ & $\%$ & $r \chi$ & $\%$ & \\
\hline & 80.0 & & 69.9 & & 71.2 & & 56.6 & & 36.5 & & 7.0 & ملدينة \\
\hline & 82.0 & & 60.8 & & 43.0 & & 44.0 & & 8.0 & & 8.0 & ضاحية \\
\hline & 25.0 & & 37.2 & & 29.2 & & 15.3 & & 18.9 & & 5.5 & قرية \\
\hline $43.9 \div$ & 70.3 & $59.2 \ddagger$ & 61.1 & $46.3 \div$ & 55.4 & $36.4 \div$ & 45.4 & $60.2 \ddagger$ & 29.3 & 0.6 & 7.0 & المججموع \\
\hline
\end{tabular}

* دالة عند مستوى 0 •.,

† دالة عند مستوى ا +., † دالة عند مستوى ا+.. 


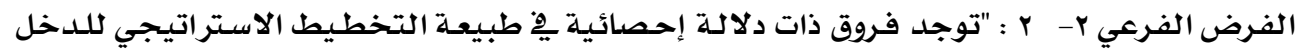

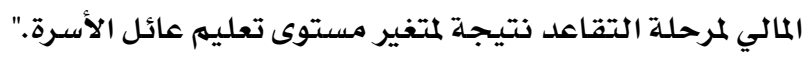

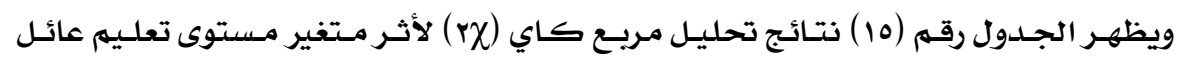

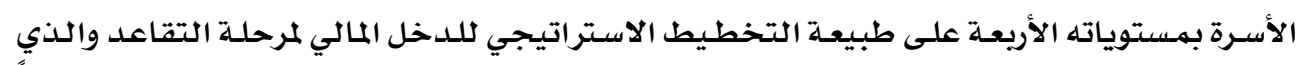

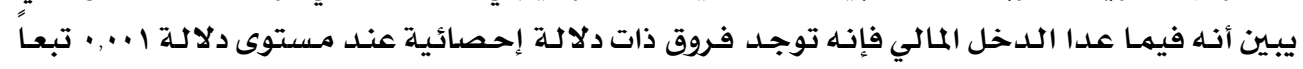

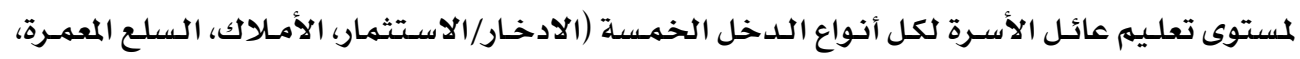

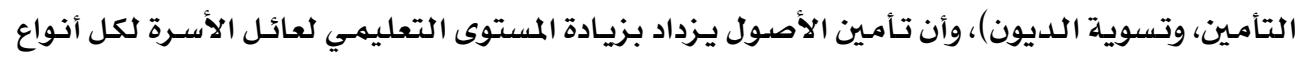

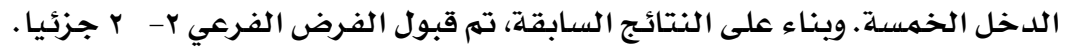

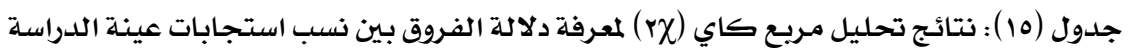

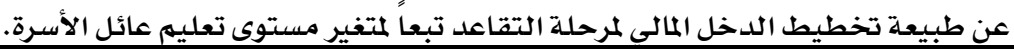

\begin{tabular}{|c|c|c|c|c|c|c|c|c|c|c|c|c|}
\hline \multicolumn{2}{|c|}{ تسوية الديون } & \multicolumn{2}{|c|}{ التأمين بأنواعه } & \multicolumn{2}{|c|}{ السلع المعمرة } & \multicolumn{2}{|c|}{ الأملاك } & \multicolumn{2}{|c|}{ الادخار/الاستثمار } & \multicolumn{2}{|c|}{ الدخل المالي } & \multirow{2}{*}{ مستوى التعليي } \\
\hline$r \chi$ & $\%$ & $r \chi$ & $\%$ & $r x$ & $\%$ & $r \chi$ & $\%$ & $r \chi$ & $\%$ & $r \chi$ & $\%$ & \\
\hline & 48.3 & & 44.8 & & 31.9 & & 27.6 & & 19.4 & & 7.8 & إعدادي \\
\hline & 72.9 & & 66.3 & & 60.4 & & 47.9 & & 28.4 & & 4.2 & ثانوي \\
\hline & 92.0 & & 75.2 & & 78.0 & & 60.0 & & 39.3 & & 6.0 & تعليم فني \\
\hline & 82.9 & & 72.2 & & 73.2 & & 57.3 & & 40.8 & & 9.8 & تعليه جامعي \\
\hline $22.9 \ddagger$ & 69.8 & $52.2 \ddagger$ & 61.9 & $47.7 \ddagger$ & 56.4 & $24.2 \ddagger$ & 45.1 & $70.9 \$$ & 30.0 & 2.6 & 7.0 & المجموع \\
\hline
\end{tabular}

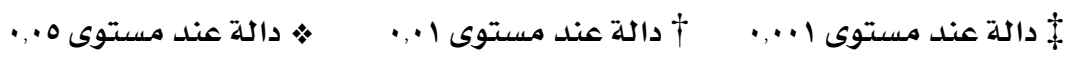

الفرض الفرعي r- r ب : "توجد فروق ذات دلالة إحصائية يِّ طبيعـة التخطيط الاسـتراتيجي للدخل

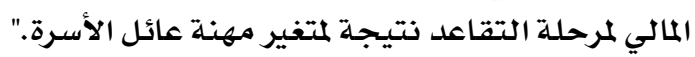

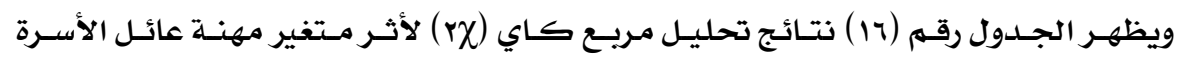

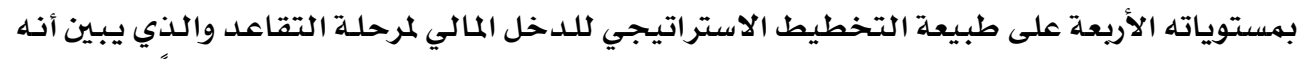

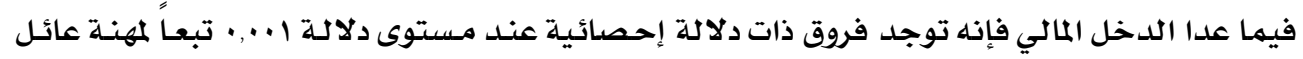

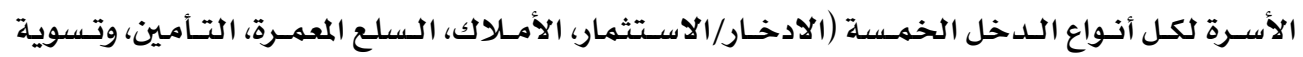

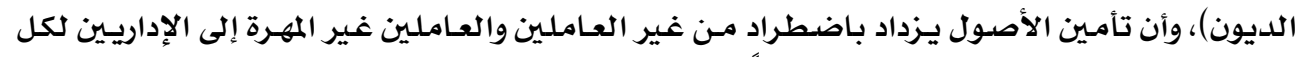

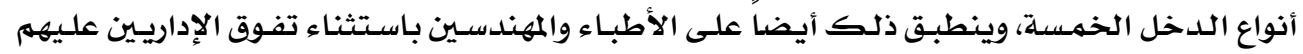

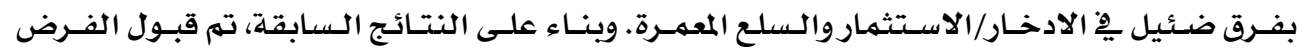
الفرعي r- r r بزئيا. 


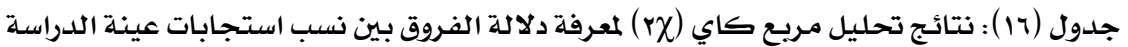

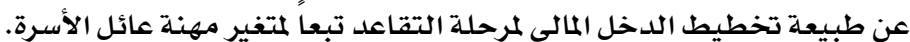

\begin{tabular}{|c|c|c|c|c|c|c|c|c|c|c|c|c|}
\hline \multicolumn{2}{|c|}{ تسوية الديون } & \multicolumn{2}{|c|}{ التأمين بأنواعه } & \multicolumn{2}{|c|}{ السلع المعمرة } & \multicolumn{2}{|c|}{ الأملاك } & \multicolumn{2}{|c|}{ الادخار/الاستثمار } & \multicolumn{2}{|c|}{ الدخل المالي } & \multirow{2}{*}{ الأصول } \\
\hline$r \chi$ & $\%$ & $r \chi$ & $\%$ & $r \chi$ & $\%$ & $r \chi$ & $\%$ & $r \chi$ & $\%$ & $r \chi$ & $\%$ & \\
\hline & 51.1 & & 48.5 & & 30.8 & & 28.7 & & 18.8 & & 8.2 & لا يعمل أو عامل غير ماهر \\
\hline & 68.3 & & 59.4 & & 51.6 & & 43.7 & & 26.3 & & 3.2 & فني \\
\hline & 78.8 & & 69.1 & & 75.8 & & 56.1 & & 39.3 & & 7.6 & إداري \\
\hline & 89.7 & & 71.8 & & 73.1 & & 60.3 & & 38.5 & & 11.5 & طبيب/مهندس \\
\hline $17.5 \ddagger$ & 70.3 & 29.0 \% & 61.0 & $44.6 \%$ & 55.2 & $20.7 \ddagger$ & 45.6 & $67.8+$ & 29.4 & 5.4 & 7.1 & المجموع \\
\hline
\end{tabular}

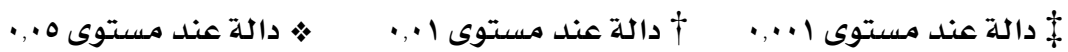
الفرض الفرعي r- ع ع : "توجد فروق ذات دلالة إحصائية يِّ طبيعـة التخطيط الاستراتيجي للدخل

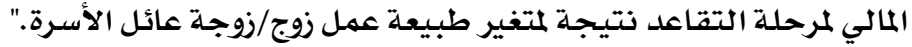

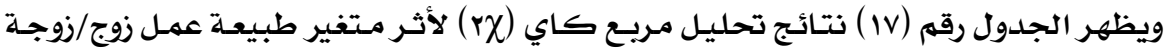

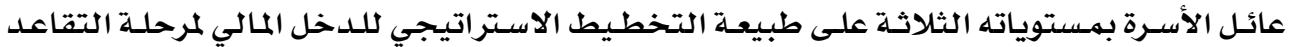

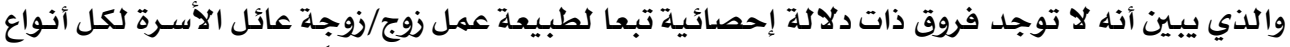

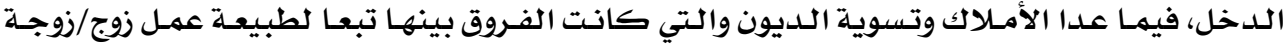

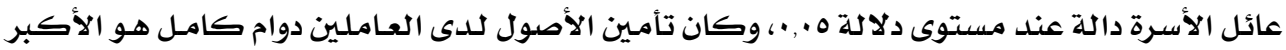

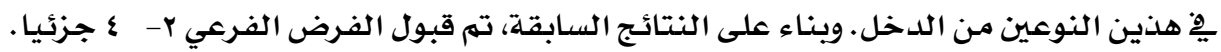

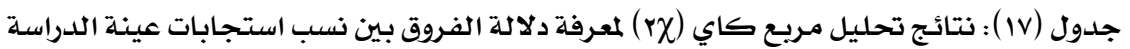

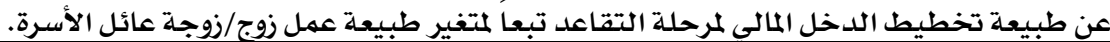

\begin{tabular}{|c|c|c|c|c|c|c|c|c|c|c|c|c|}
\hline \multicolumn{2}{|c|}{ تسوية الديون } & \multicolumn{2}{|c|}{ التأمين بأنواعه } & \multicolumn{2}{|c|}{ السلع المممرة } & \multicolumn{2}{|c|}{ الأملاك } & \multicolumn{2}{|c|}{ الادخار/الاستثمار } & \multicolumn{2}{|c|}{ الدخل المالي } & \multirow{2}{*}{ دوام المهنة لزوج/زوجة العائل } \\
\hline$r \chi$ & $\%$ & $r x$ & $\%$ & $r \chi$ & $\%$ & $r \chi$ & $\%$ & $r \chi$ & $\%$ & $r \chi$ & $\%$ & \\
\hline & 62.1 & & 60.6 & & 53.0 & & 45.5 & & 31.8 & & 6.1 & لا يعمل \\
\hline & 75.0 & & 63.3 & & 64.6 & & 41.7 & & 28.8 & & 6.3 & نصف دوام \\
\hline & 82.1 & & 69.3 & & 56.7 & & 53.0 & & 30.0 & & 3.2 & دوام كامل \\
\hline $6.8^{*}$ & 72.6 & 4.8 & 64.7 & 1.9 & 56.4 & $6.4^{*}$ & 48.1 & 1.0 & 30.6 & 0.7 & 7.0 & المجموع \\
\hline
\end{tabular}

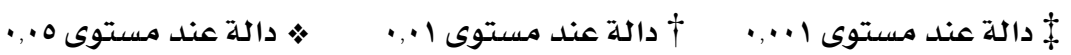

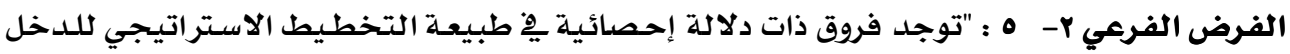
المالي لمرحلة التقاعد نتيجلة لمتغير الدخل السنوفي فروف دات دلأسلهرة.

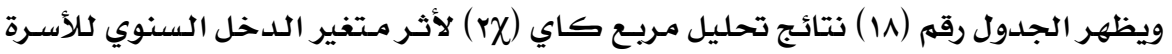

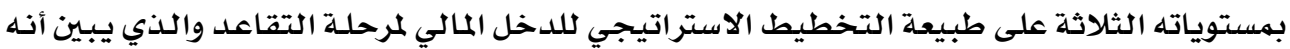




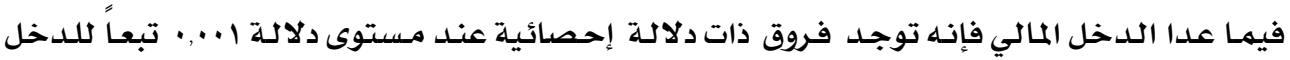

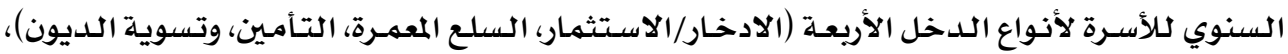

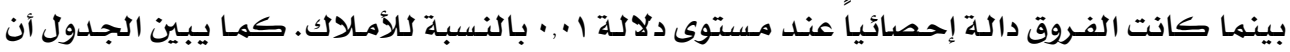

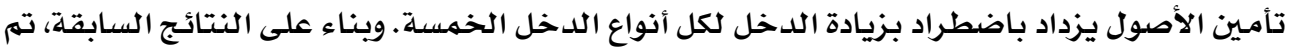

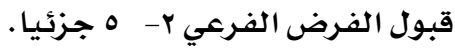

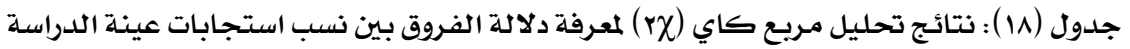
عن طبيعة تخطيط الدخل المالي لمرحلة التقاعد تبعا لمتغير الدخل السنوي للأسرة.

\begin{tabular}{|c|c|c|c|c|c|c|c|c|c|c|c|c|}
\hline \multicolumn{2}{|c|}{ تسوية الديوز } & \multicolumn{2}{|c|}{ التأمين بأنواعه } & \multicolumn{2}{|c|}{ السلع المعمرة } & \multicolumn{2}{|c|}{ الأملاكك } & \multicolumn{2}{|c|}{ |الادخار/الاستثمار } & \multicolumn{2}{|c|}{ الدخل المالي } & \multirow{2}{*}{ الدخل بالجنيه } \\
\hline$r \chi$ & $\%$ & $r \chi$ & $\%$ & $r \chi$ & $\%$ & $r \chi$ & $\%$ & $r \chi$ & $\%$ & $r \chi$ & $\%$ & \\
\hline & 50.6 & & 46.8 & & 39.0 & & 35.7 & & 21.0 & & 5.8 & أقل من ..., \\
\hline & 79.2 & & 63.3 & & 59.4 & & 46.9 & & 29.0 & & 9.4 & $1 \cdot, \cdots \_, \cdots, \cdots$ \\
\hline & 88.3 & & 77.7 & & 73.3 & & 55.8 & & 40.3 & & 6.7 & أكثر من .., •1 \\
\hline $25.3 \div$ & 70.3 & $68.5 \div$ & 61.1 & $33.0 \%$ & 55.4 & $11.1 \dagger$ & 45.1 & $66.7 \neq$ & 29.3 & 1.2 & 7.0 & المجموع \\
\hline
\end{tabular}

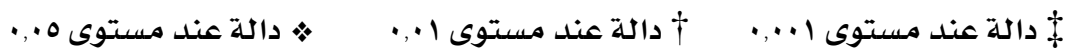

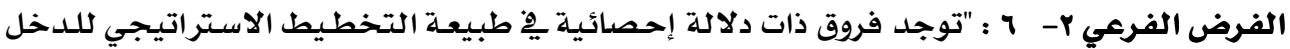

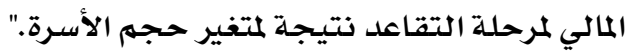

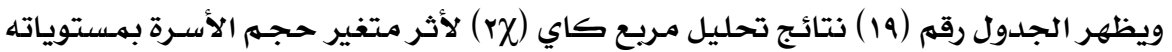

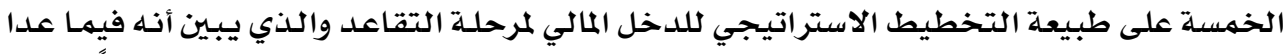

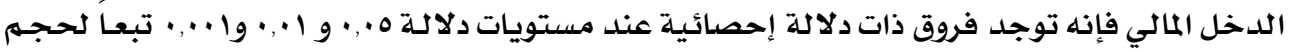

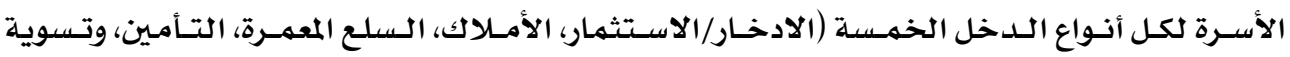

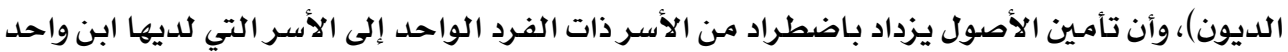

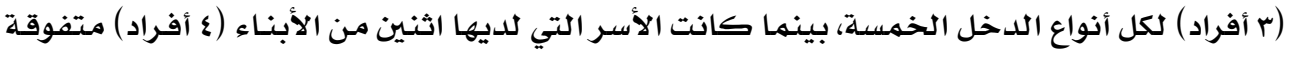

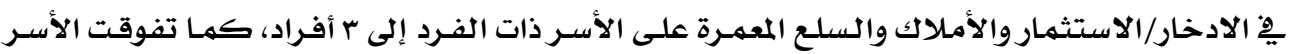

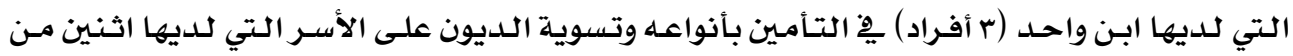

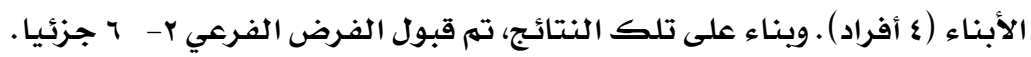




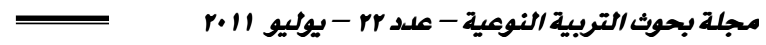

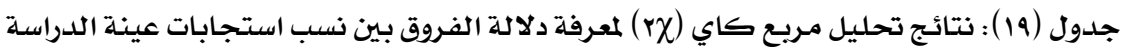

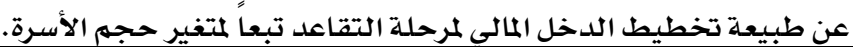

\begin{tabular}{|c|c|c|c|c|c|c|c|c|c|c|c|c|}
\hline \multicolumn{2}{|c|}{ تسوية الديون } & \multicolumn{2}{|c|}{ التأمين بأنواعه } & \multicolumn{2}{|c|}{ السلع المعمرة } & \multicolumn{2}{|c|}{ الأملاك } & \multicolumn{2}{|c|}{ الادخار/الاستثمار } & \multicolumn{2}{|c|}{ الدخل المالي } & \multirow{2}{*}{ حجم الأسرة } \\
\hline$r \chi$ & $\%$ & $r \chi$ & $\%$ & $r \chi$ & $\%$ & $r \chi$ & $\%$ & $r \chi$ & $\%$ & $r \chi$ & $\%$ & \\
\hline & 25.0 & & 22.5 & & 18.8 & & 6.3 & & 17.0 & & 0.0 & 1 \\
\hline & 71.9 & & 63.1 & & 54.7 & & 43.8 & & 29.5 & & 9.3 & $r$ \\
\hline & 83.1 & & 70.2 & & 61.9 & & 50.8 & & 32.5 & & 8.5 & $r$ \\
\hline & 71.4 & & 65.3 & & 71.4 & & 52.0 & & 34.0 & & 5.1 & $\varepsilon$ \\
\hline & 58.3 & & 48.3 & & 75.0 & & 37.5 & & 21.0 & & 6.9 & أكثر من ؛ \\
\hline $14.5 \dagger$ & 70.7 & $49.8 \neq$ & 61.3 & $22.9 \neq$ & 63.9 & $15.7 \dagger$ & 45.4 & $28.4^{*}$ & 29.4 & 3.8 & 7.1 & المجمهوع \\
\hline
\end{tabular}

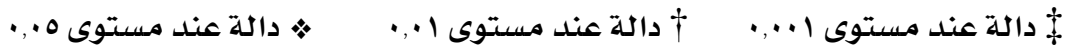
الفرض الثالث :

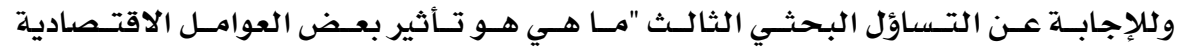

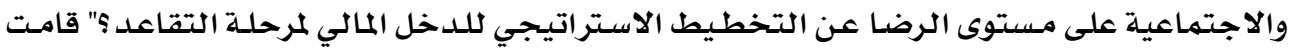

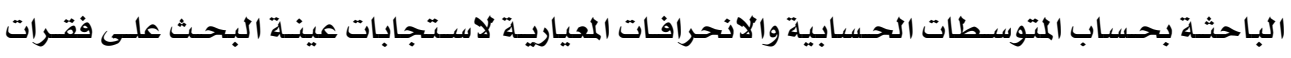

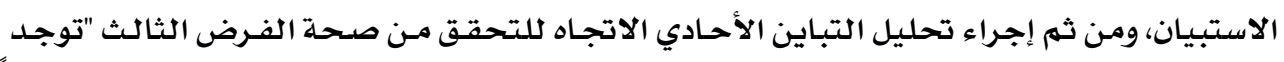

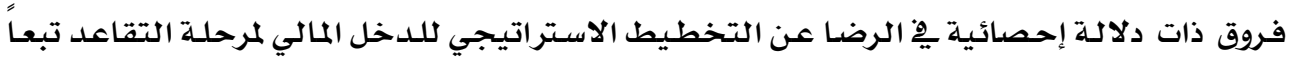
للعوامل الاقتصادية والاجتماعيـة" والفروض الفروعية المنبثقة منـه وهي :

ץ- ا توجد فروق ذات دلالدة إحصائية ِيخ الرضا عن التخطيط الاستراتيجي للدخل المالي لمرحلـة التقاعد نتيجة لمتغير مكان السكن.

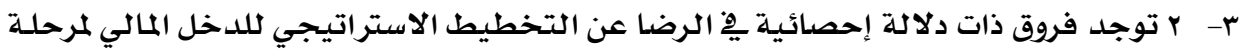
التقاعد نتيجـة لمتغير مستوى تعليهم عائل الأسـرة.

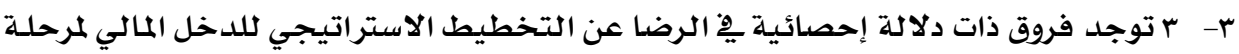
التقاعد نتيجحة لمتخير المهنـة.

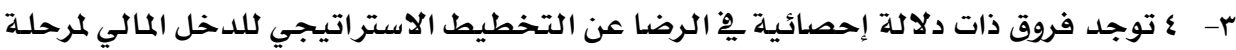

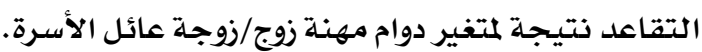

بـ - ه توجد فروق ذات دلالة إحصائية يِّ الرضنا عن التخطيط الاستراتيجي للدخل المالي لمرحلـة التقاعد نتيجـة لمتغير مستوى الدخل السنوي قبيل التقاعد.

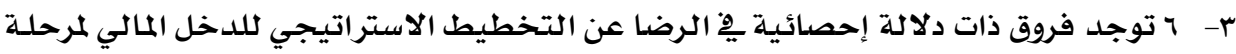
التقاعد نتيجة لمتغير حجمه الأسرة.

ويظهر الجدول رقم ( • ) نتائج تحليـل التبـاين لأثر مـتغيرات البـحث المستقلة الست (مكان السكن، ومستوى تعليهم عائل الأسـرة، ومهنـة عائل الأسـرة، وطبيعـة عمل زوج/زوجـة عائـل الأسـرة، ودخل 
الأسرة، وحجم الأسرة) على مستوى الرضا عن التخطيط الاستراتيجي للدخل المالي لمرحلة التقاعد.

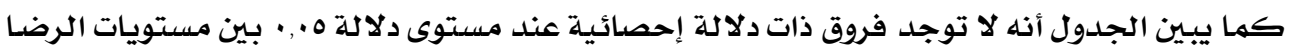

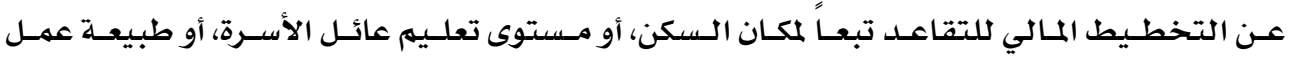

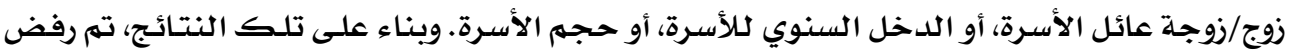

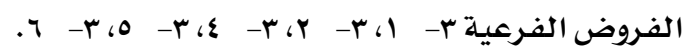

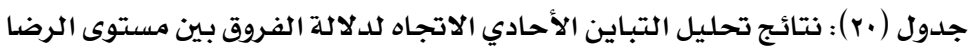

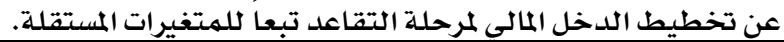

\begin{tabular}{|c|c|c|c|c|c|c|c|c|}
\hline الدلالة & ف & \begin{tabular}{|c|} 
متوسط \\
الانحراف \\
\\
\end{tabular} & متوسط الانحراف & العرجية & الحرية & مجموع مربعات & مجموع مربعات & المتفير \\
\hline غير دالة & 1.352 & 0.51 & 0.69 & ivr & r & 90.80 & 1.39 & مكان السكن \\
\hline 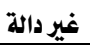 & 0.310 & 0.76 & 0.24 & 174 & $r$ & 124.35 & 0.71 & مستوى تعليم العائل \\
\hline 0.01 & 4.125 & 0.49 & 2.01 & ivo & $r$ & 85.14 & 6.02 & مهنة العائل \\
\hline غير دال & 0.872 & 0.62 & 0.54 & 101 & $r$ & 94.29 & 1.09 & عمل زوج/زوجة العائل \\
\hline غير دال & 2.637 & 0.66 & 1.73 & ivr & $r$ & 116.02 & 3.46 & دخل الأسرة \\
\hline غير دال & 0.454 & 0.63 & 0.28 & IV\& & $\varepsilon$ & 108.86 & 1.14 & حجم الأسرة \\
\hline
\end{tabular}

• استخدم مقياس رياعِ لتقدير الرضا عن الإعداد المالي للتقاعد وتراوح بـين "غير راض

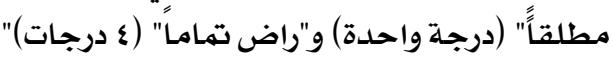

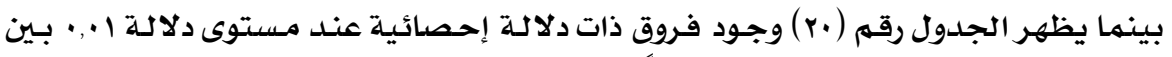

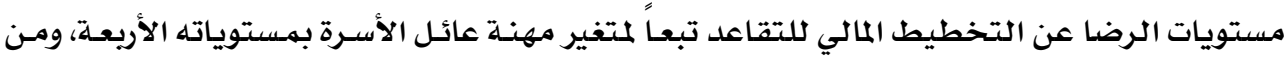

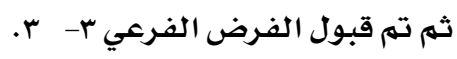

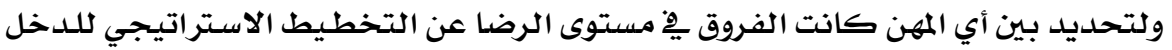

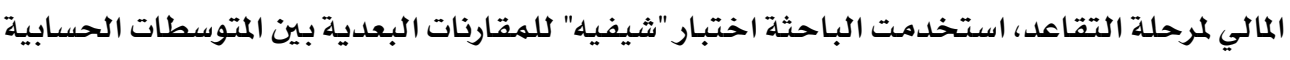

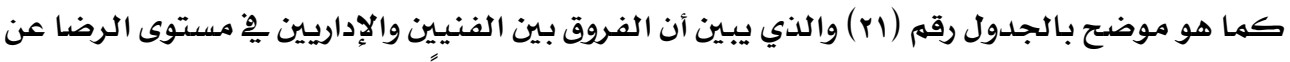

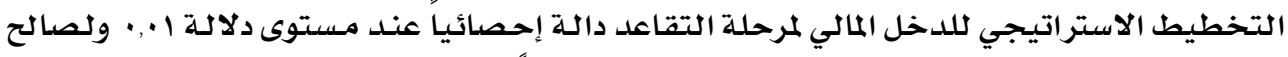

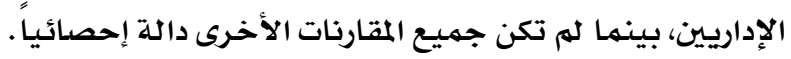

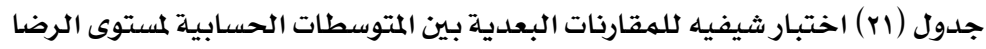
عن تخطيط الدخل المالي لمرحلة التقاعد تبعاً لمتغير مهندة البعائل المائل الأسرة.

\begin{tabular}{|c|c|c|c|c|}
\hline طبيب/مهندس & إداري & فني & لا يعمل أو عامل غير ماهر & \\
\hline •, 10_ & . & $\bullet,, \boldsymbol{\xi}$ & & لا يعمل أو عامل غير ماهر \\
\hline , 19 & $\pm \cdot, 0 \cdot$ & & & فني \\
\hline \multirow[t]{2}{*}{ • } & & & & إداري \\
\hline & & & & طبيب/مهندس \\
\hline
\end{tabular}

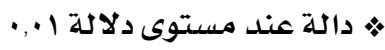




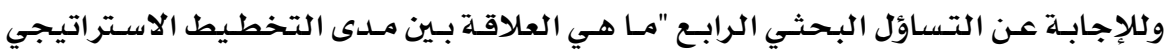

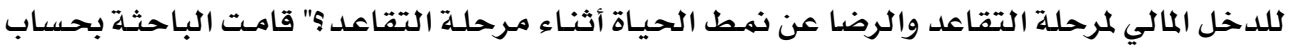

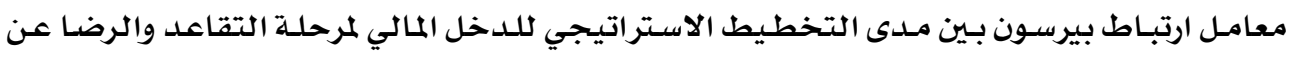
نمط الحيـاة أثناء مـرحلة التقاعد للتحقق من صححة الفرض الرابـع "توجد علاقة ذات دلالة بـين مـدى التخطيط الاستراتيجي للدخل المالي لمرحلة التقاعد والرضا عن نهط الحياة أثناء مـرحلة التقاعد".

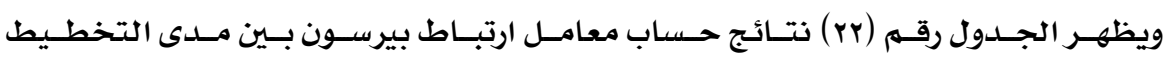

الاستراتيـي للدخل المالي لمرحلـة التقاعد والرضـا عن نهط الحيـاة أثنـاء مـرحلـة التقاعد والتي تبـين

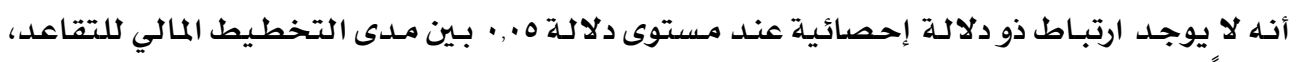

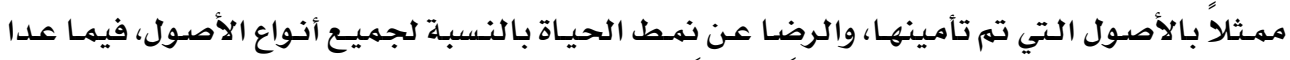

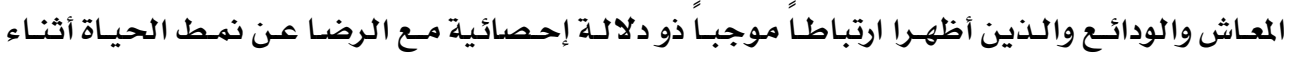

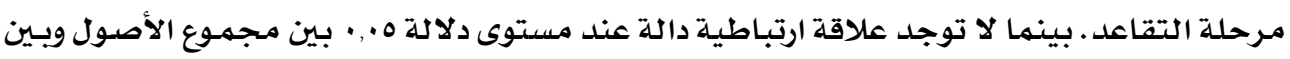

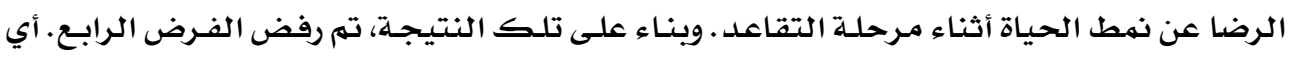

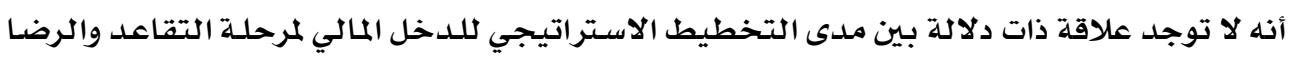
عن نمط الحياة أثناء مرحلة التقاعد. 


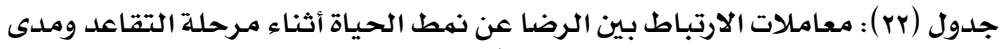

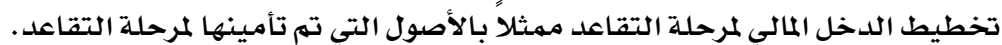

\begin{tabular}{|c|c|c|c|}
\hline 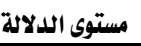 & معامل الارتباط & 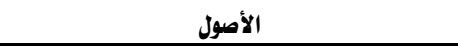 & \\
\hline 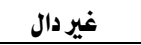 & 0.0949 & 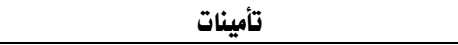 & 1 \\
\hline 0.044 & 0.1258 & 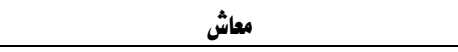 & $r$ \\
\hline 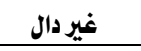 & -0.0166 & عمل عائل الأسرة الرئيسي أثناء التقاعد & $r$ \\
\hline 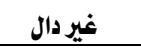 & -0.0685 & عمل زوج/زوجة عائل الأسرة الرئيسي & $\varepsilon$ \\
\hline 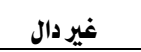 & -0.0124 & ريع أملاك مؤجرة & 0 \\
\hline 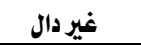 & 0.0197 & 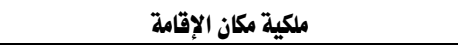 & 7 \\
\hline 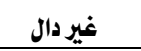 & -0.0657 & دفتر توفير ذو الجوائز & r \\
\hline 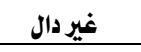 & 0.0676 & دفتر توفير & $\wedge$ \\
\hline 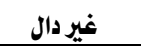 & 0.0770 & شهادات استثمار & 9 \\
\hline 0.018 & 0.1540 & 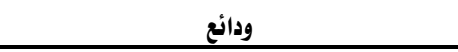 & 1. \\
\hline 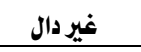 & 0.0396 & شراء سلع معمرة قبل التقاعد لتجنب ارتفاع سعرها & 11 \\
\hline 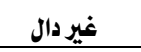 & -0.0009 & تأمين الحياة (عائل الأسرة الرئيسي) & ir \\
\hline 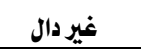 & 0.0540 & تأمين الحياة (زوج/زوجة عائل الأسرة الرئيسي) & ir \\
\hline 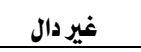 & -0.0072 & التأمين الصحي & $1 \varepsilon$ \\
\hline 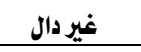 & 0.0760 & تأمين على المنزل & 10 \\
\hline غير دال & 0.0323 & تأمين على السيارة & 17 \\
\hline غير دال & 0.0582 & أسهم & iv \\
\hline غير دال & 0.0841 & أذون خزانة & in \\
\hline غير دال & 0.0691 & ودائع استثمار & 19 \\
\hline غير دال & 0.0038 & التأمين ذو العائد الجاري & r. \\
\hline غير دال & 0.0949 & أملاك أخرى خلاف المنزل & r \\
\hline غير دال & -0.0416 & تسوية ديون قبل التقاعد & rr \\
\hline غير دال & 0.8410 & مجموع الأصول & \\
\hline
\end{tabular}

الفرض الخامس :

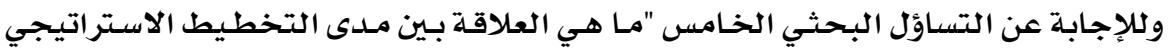

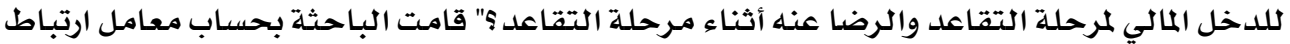

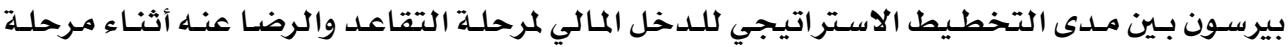

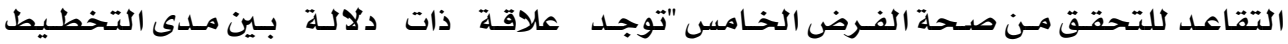

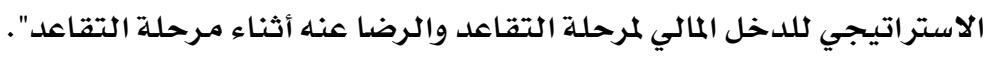




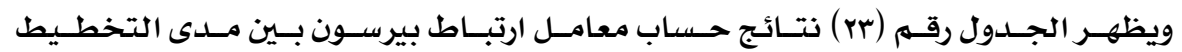

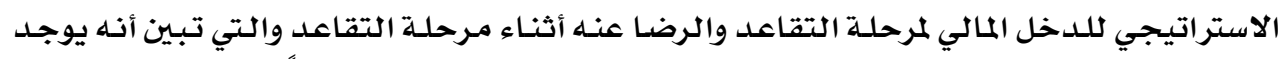

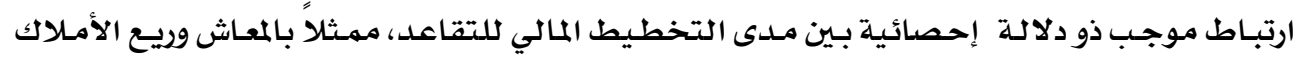

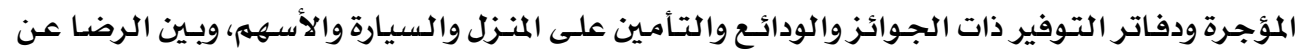

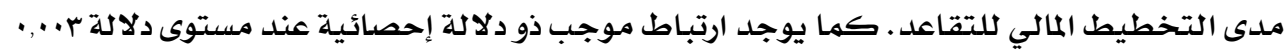

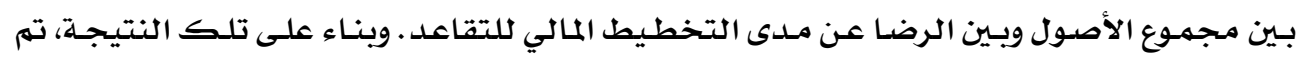
قبول الفرض الخامس.

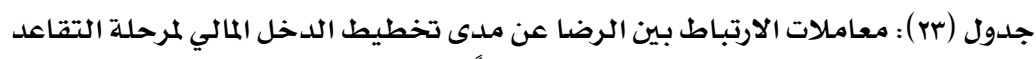

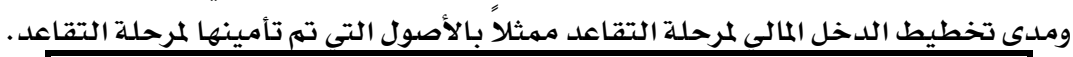

\begin{tabular}{|c|c|c|c|}
\hline مستوى الدلالة & معامل الارتباط & 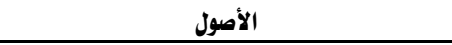 & \\
\hline 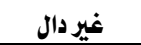 & -0.0547 & 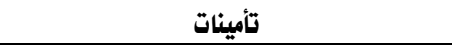 & 1 \\
\hline 0.038 & 0.1323 & 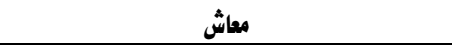 & $r$ \\
\hline 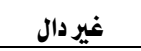 & -0.0510 & عمل عائل الأسرة الرئيسي أثناء التقاعد & $r$ \\
\hline 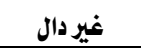 & -0.0147 & عمل زوج/زوجة عائل الأسرة الرئيسي & $\varepsilon$ \\
\hline 0.02 & 0.1530 & ريع أملاك مؤجرة & 0 \\
\hline 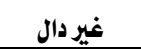 & 0.0775 & ملكية مكان الإقامة & 7 \\
\hline 0.006 & 0.1854 & دفتر توفير ذو الجوائز & $r$ \\
\hline 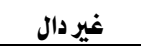 & 0.0324 & دفتر توفير & $\wedge$ \\
\hline 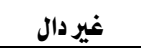 & 0.0975 & شهادات استثمار & 9 \\
\hline 0.001 & 0.2210 & 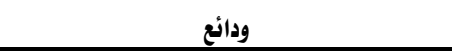 & 1. \\
\hline 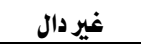 & 0.0425 & شراء سلع معمرة قبل التقاعد لتجنب ارتفاع سعرها & 11 \\
\hline 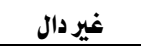 & -0.0817 & تأمين الحياة (عائل الأسرة الرئيسي) & ir \\
\hline 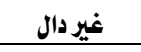 & 0.0591 & تأمين الجياة (زوج/زوجة عائل الأسرة الرئيسي) & ir \\
\hline 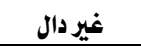 & 0.0410 & التأمين الصحي & $1 \varepsilon$ \\
\hline 0.003 & 0.2035 & تأمين على المنزل & 10 \\
\hline 0.001 & 0.2448 & تأمين على السيارة & 19 \\
\hline 0.01 & 0.1742 & أسهم & iv \\
\hline غير دال & 0.0843 & أذون خزانة & 11 \\
\hline غير دال & 0.1197 & ودائع استثمار & 19 \\
\hline غير دال & 0.0533 & التأمين ذو العائد الجاري & r. \\
\hline غير دال & 0.0839 & أملاك أخرى خلاف المنزل & $r$ \\
\hline غير دال & 0.1073 & تسوية ديون قبل التقاعل & $r$ \\
\hline 0.003 & 0.2032 & مجموع الأصول & \\
\hline
\end{tabular}




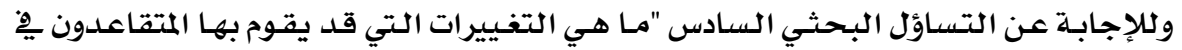

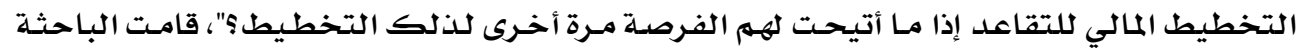

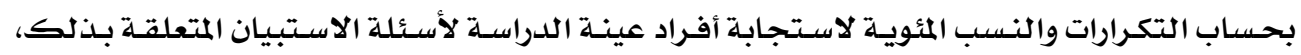

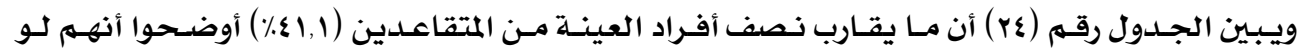

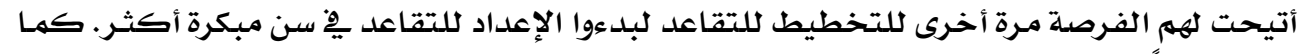

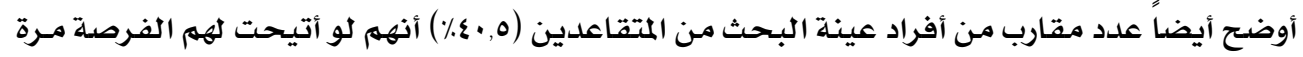

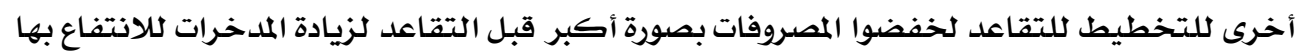
مِِ مرحلة التقاعد.

جدول (عץ) : الإجراءات التي يرغب المتقاعدون يِّ اتخاذها إذا ما سنحت لهم الفرصدة مرة أخرى لتخطيط

\begin{tabular}{|c|c|c|}
\hline النسبة المئوية ٪\% & العدد (1M0) & 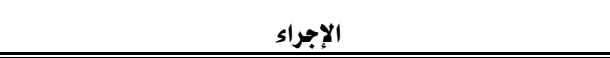 \\
\hline 41.1 & 76 & بلدى التخطيط للتقاعد في سن مبكرة أكثر \\
\hline 40.5 & 75 & خفض المصروفات بصورة أكبر قبل التقاعد لزيادة المدخرات \\
\hline 18.4 & 34 & التخطيط الأسري الجماعي للتقاعد \\
\hline 17.8 & 33 & شراء أنواع مختلفة من وثائق التأمين على الحياة \\
\hline 11.4 & 21 & استشارة الجهة المختصة بمكان العمل قبل التقاعد \\
\hline 9.2 & 17 & السماح لأفراد الأسرة باتخاذ القرارات فيما يختص بالتخطيط للتقاعد \\
\hline 8.6 & 16 & شراء وثائق للتأمين الصحي مكملة لبرامج التأمين الصحي الحكومي \\
\hline
\end{tabular}

\section{هلص النتائج وهناقشتها:}

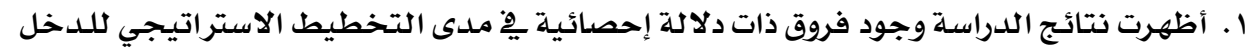

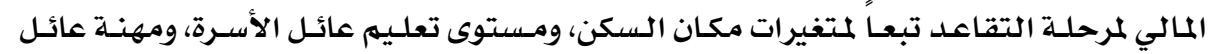

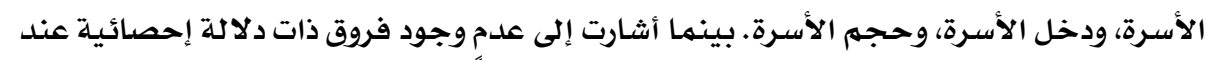

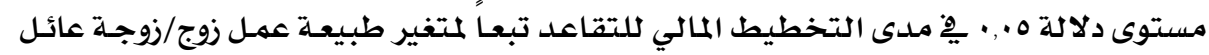

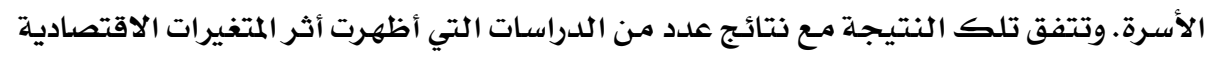

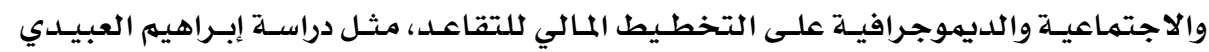

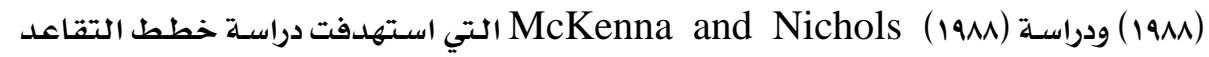

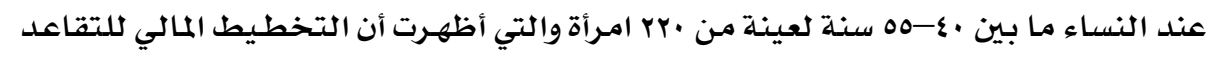

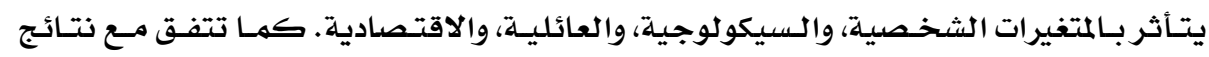

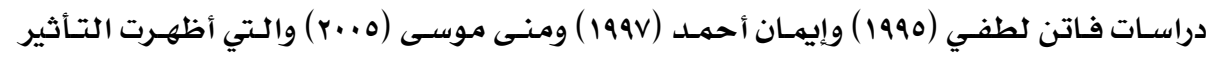

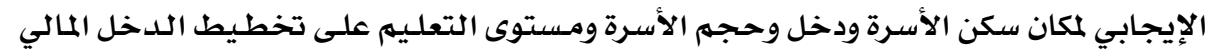

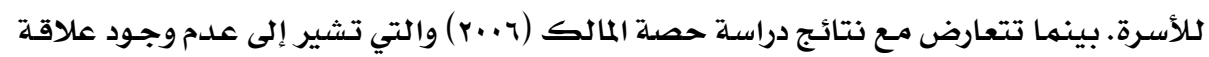

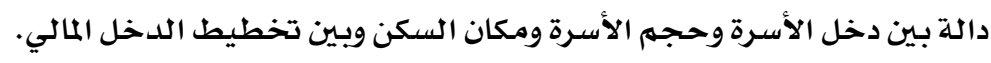




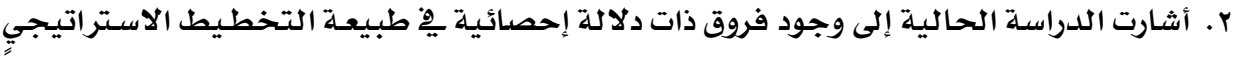

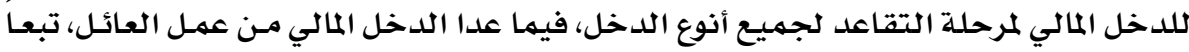

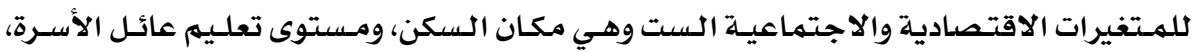

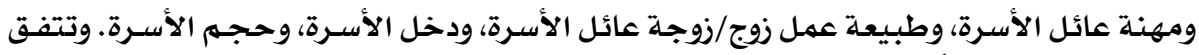

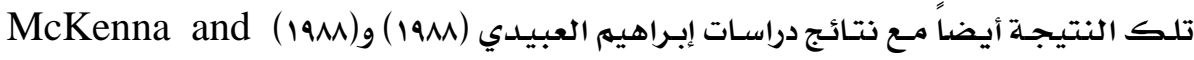
Nichols

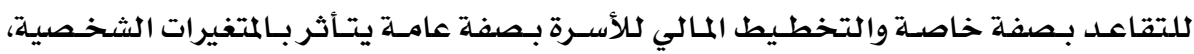
والسيكولوجية،، والعائلية، والاقتصادية.

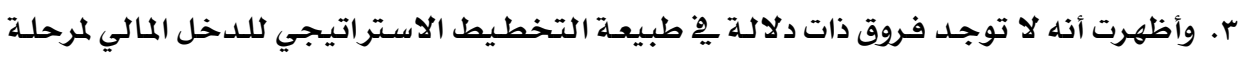

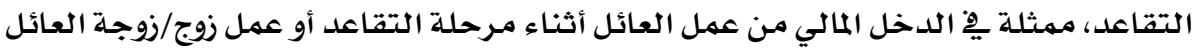

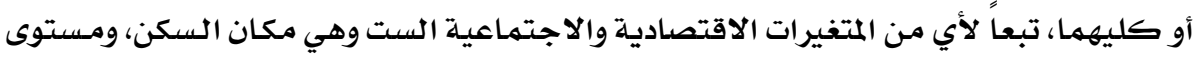

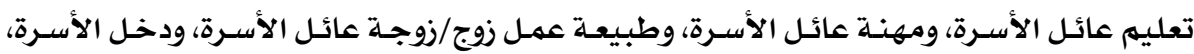

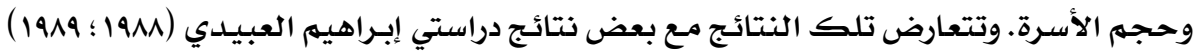

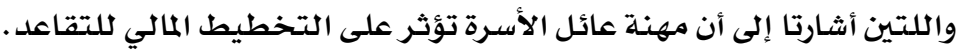

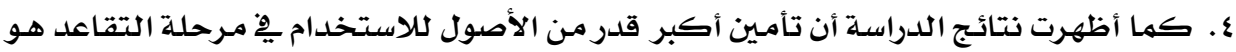

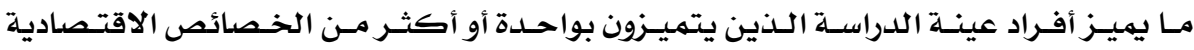

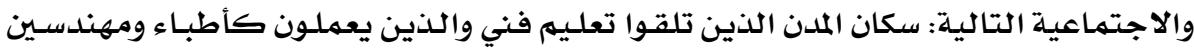

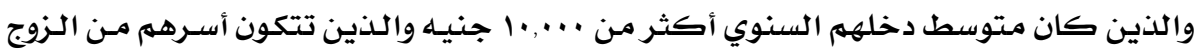
والزوجة وابن واحد (س أفراد).

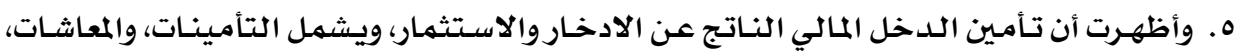

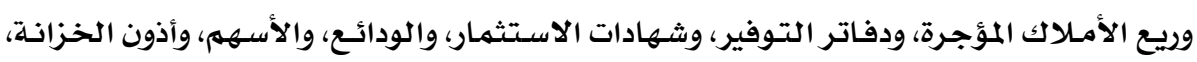

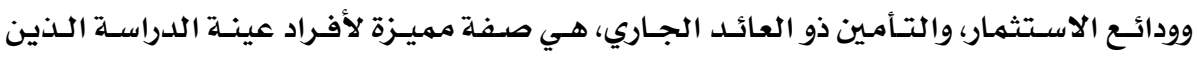

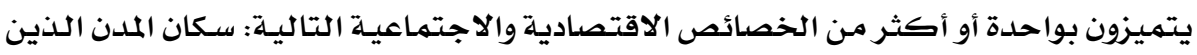

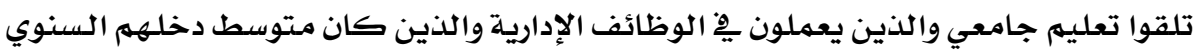

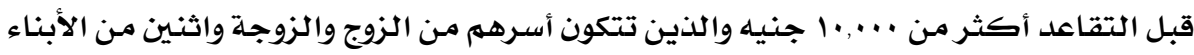

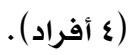

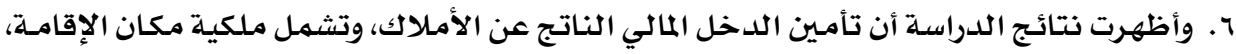

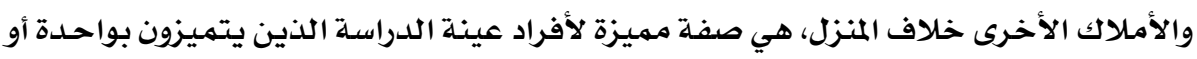

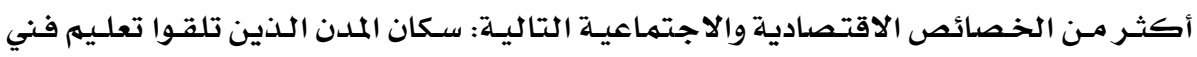

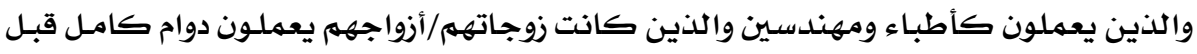

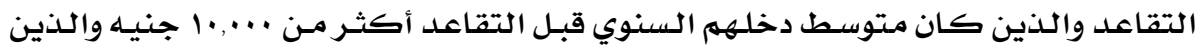
تتكون أسرهم من الزوج والزوجلة واثنـين من الأبناء (ع أفراد) . 
V. كما أظهرت أن تأمين السلع المعمرة قبل التقاعد لتجنب ارتفاع سعرها خلال مرحلة التقاعدة،

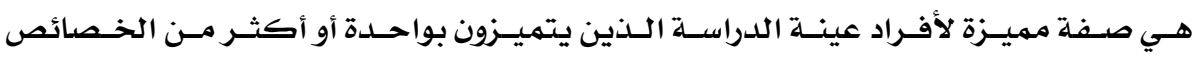

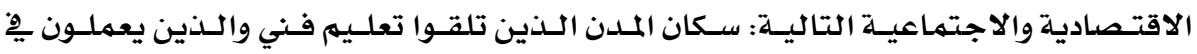

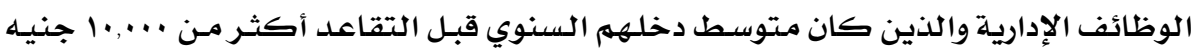

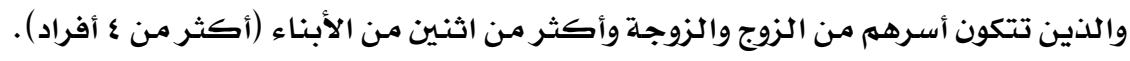

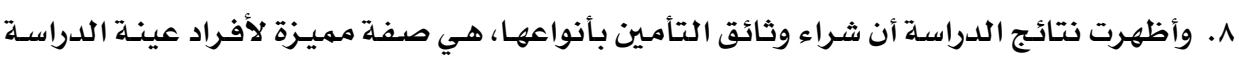

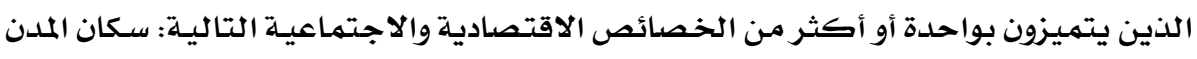

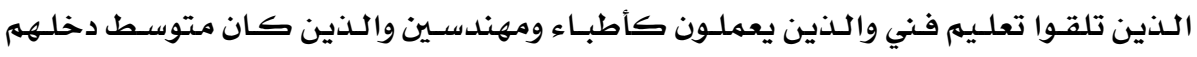

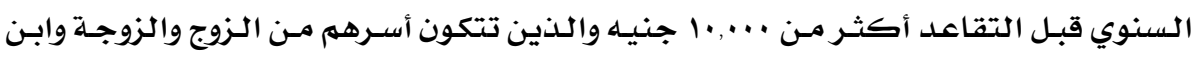

$$
\text { واحد (ب أفراد) . }
$$

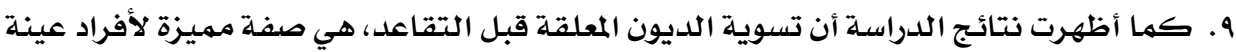

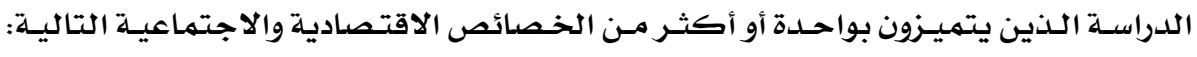

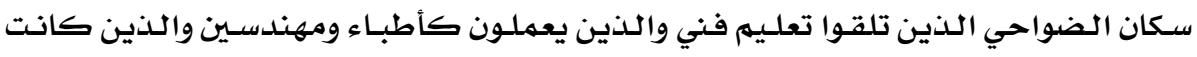

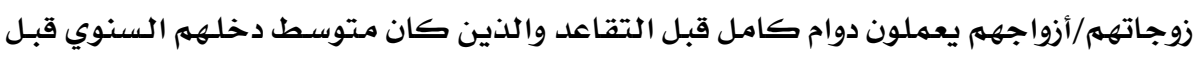

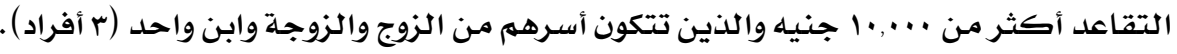

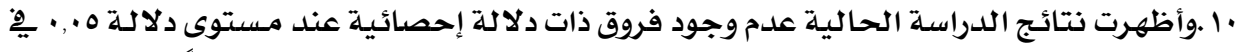

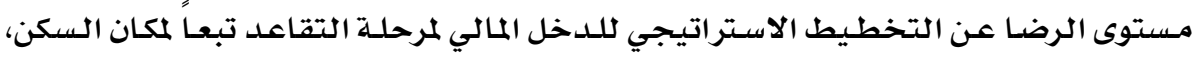

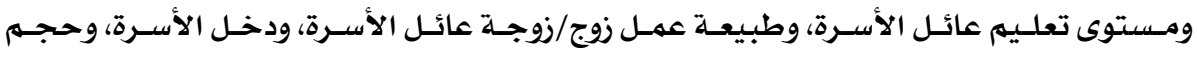

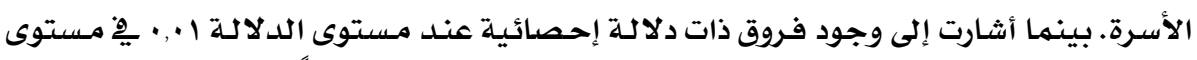

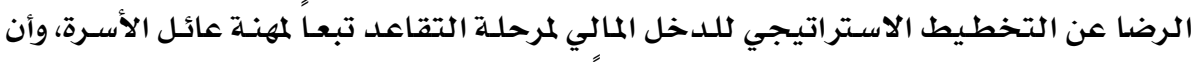

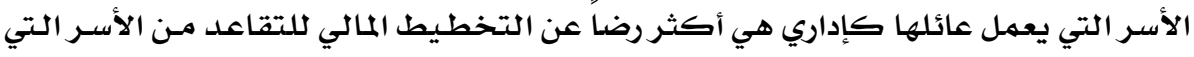

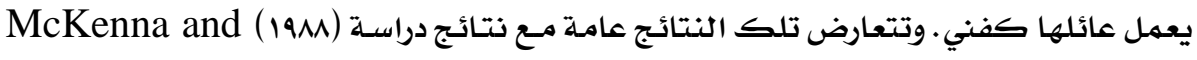

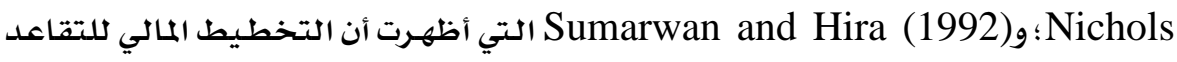

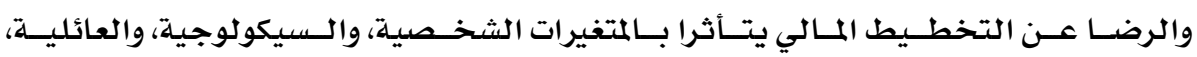
والاقتصسادية.

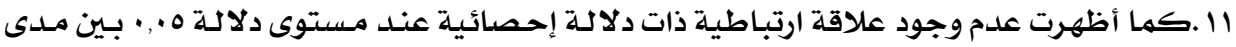

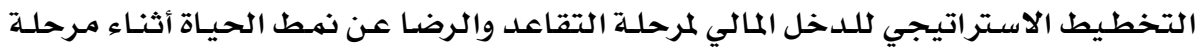

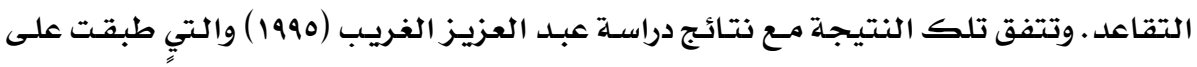

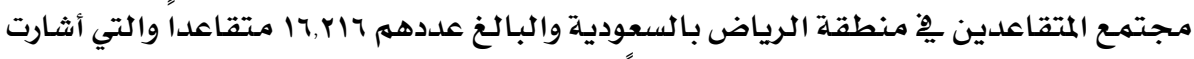

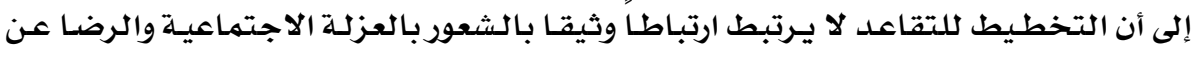

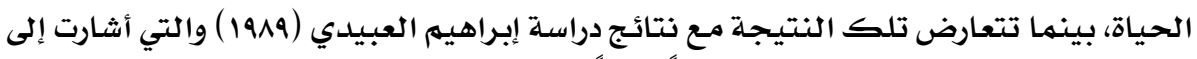

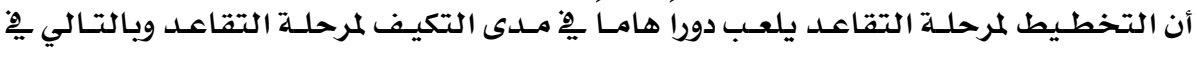

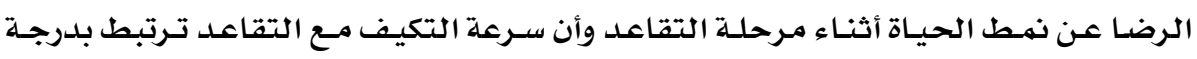




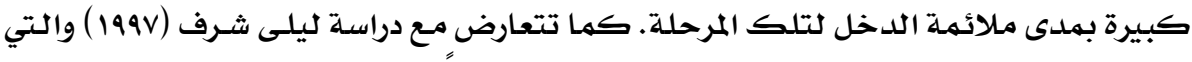

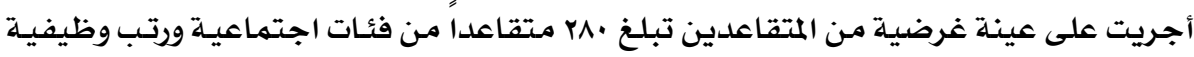

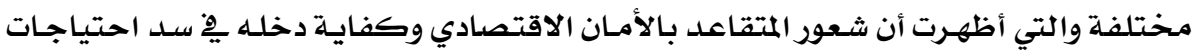

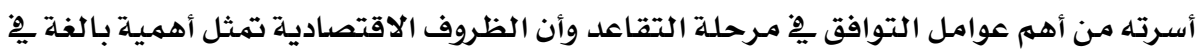

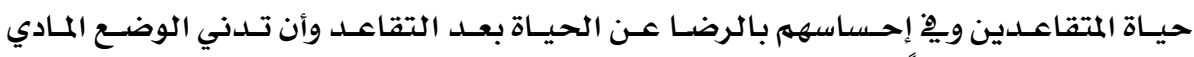

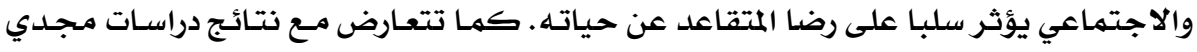

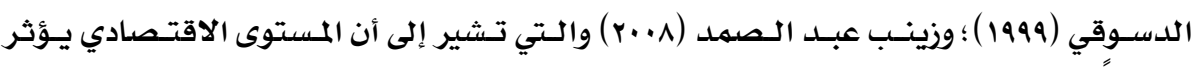
إيجابياً على الرضا عن الحياة.

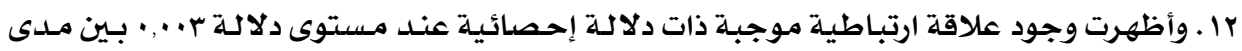

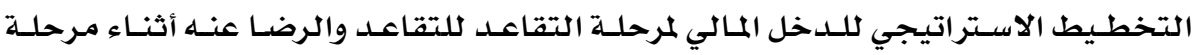

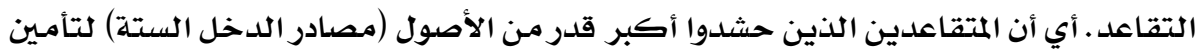

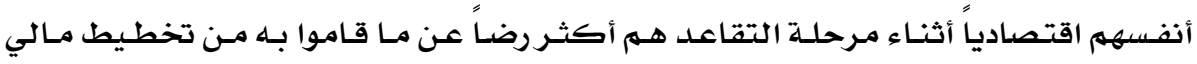

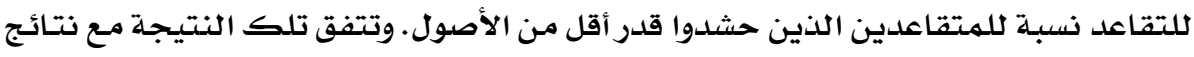

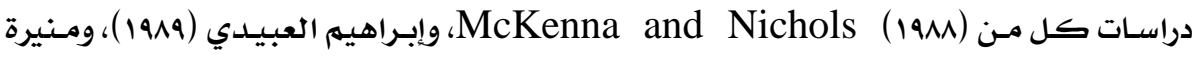

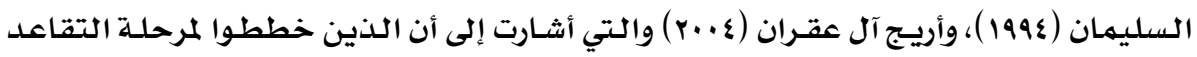

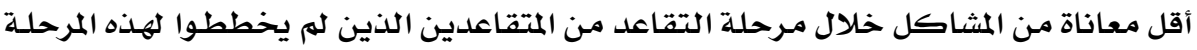

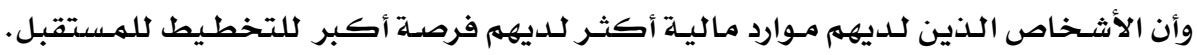

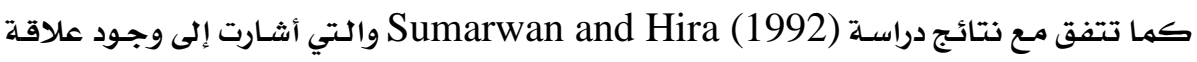

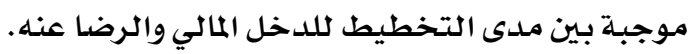

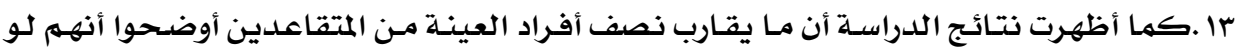

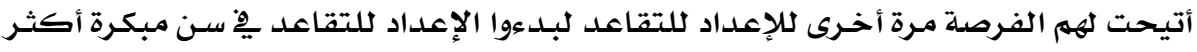

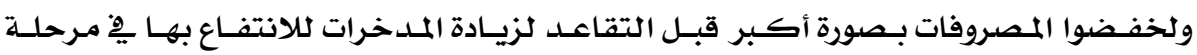

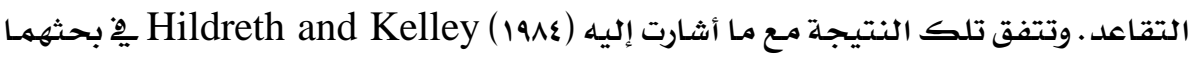

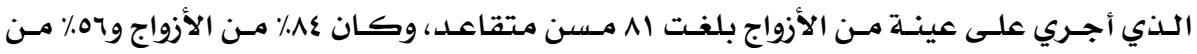

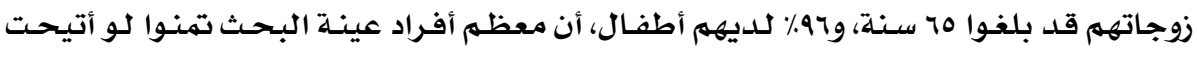

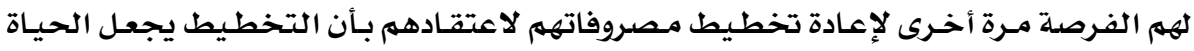
أفضل بعد التقاعد.

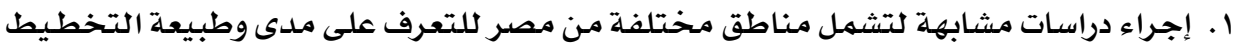

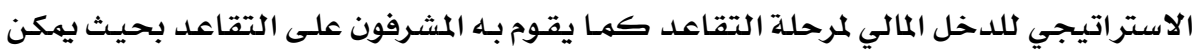

تعميم نتائجها.

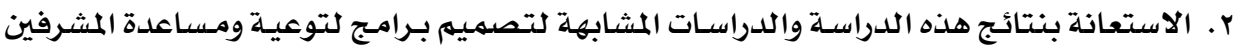

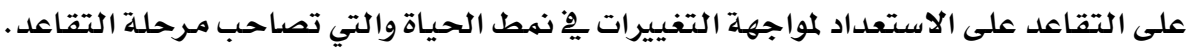


r. الاستعانة بنتائج هذه الدراسة والدراسات المثابهة وإيصا لها لأجهزة وهيئات الدولـة والجمعيـات

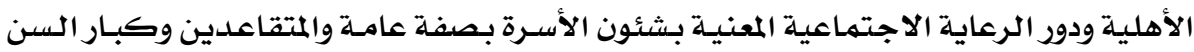

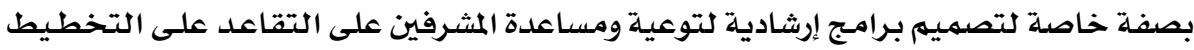

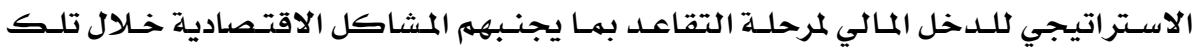

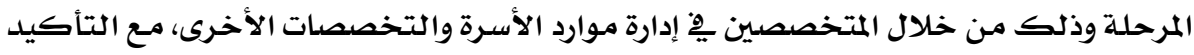

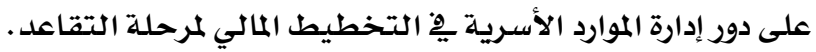

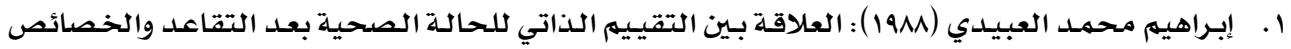

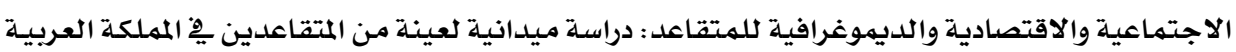

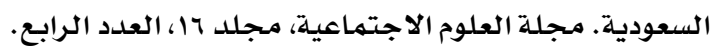

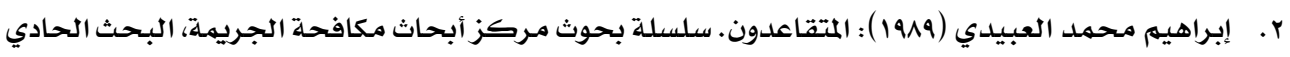
عشر، الرياض (. إعاهـ).

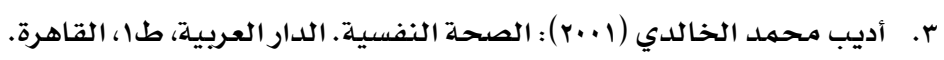

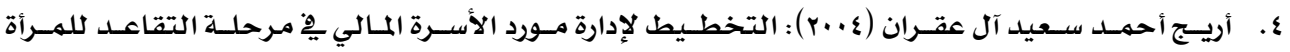

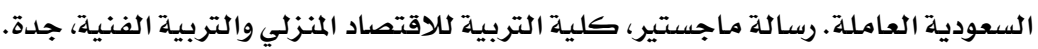

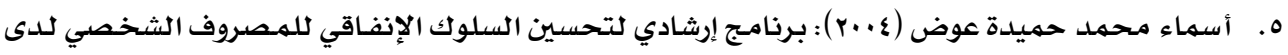

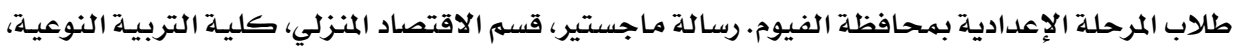

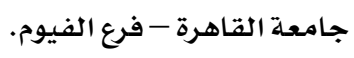

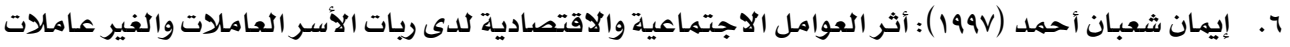

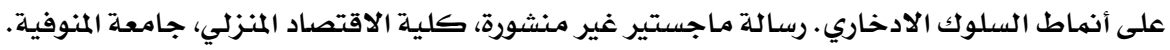

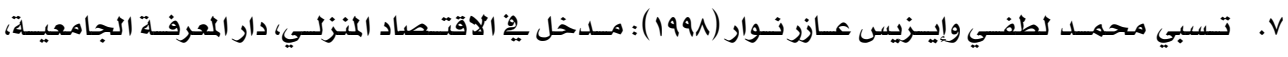
الإسكندرية.

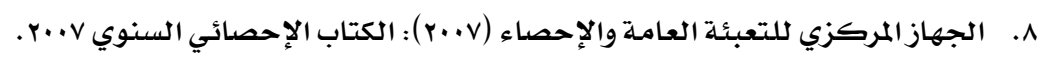

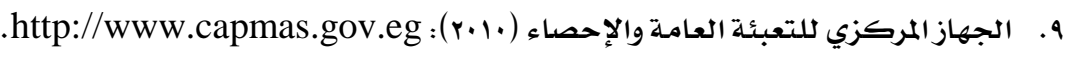

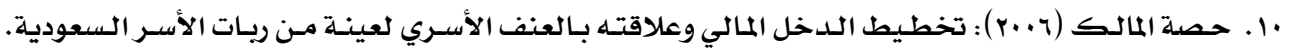

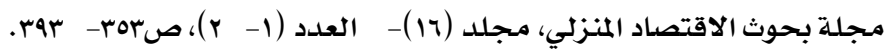

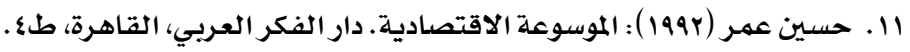

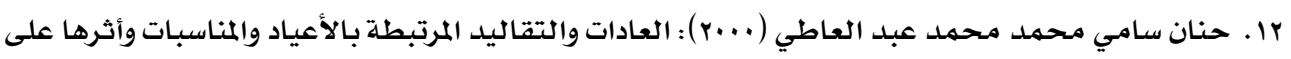

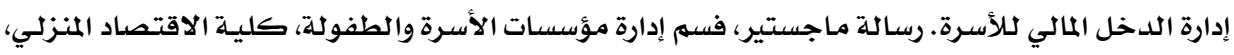




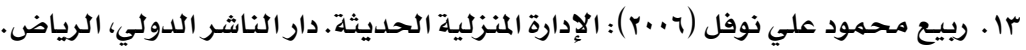

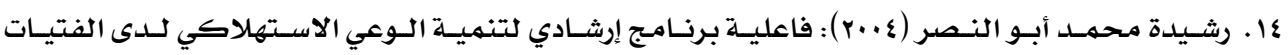

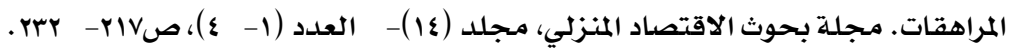

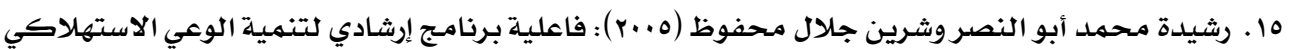

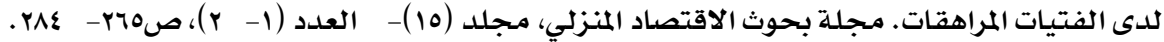

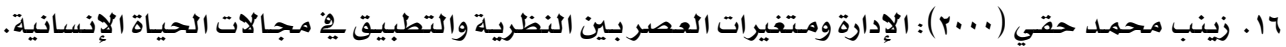

مكتبـة عين شمس، القاهرة.

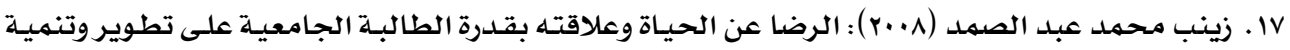

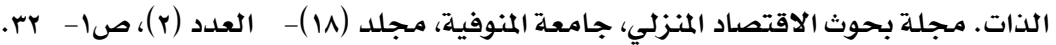

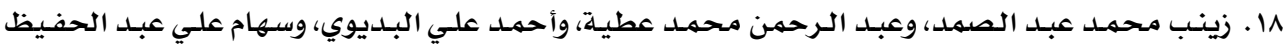

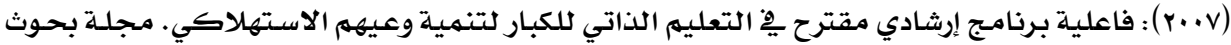

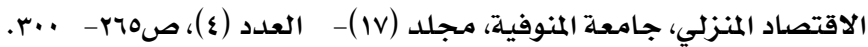

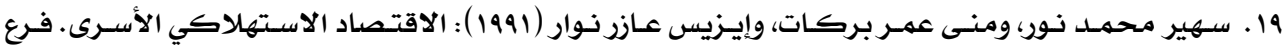
الاقتصداد المنزلي، كلية الزراعة، جامعة الإسكندريـة. •r. عباس محمود عوض (1999) : علهم النفس الإحصائي. دار المعرفة الجامعية، الاسكندريـة.

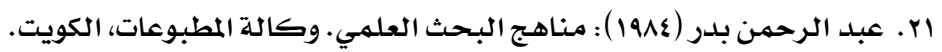

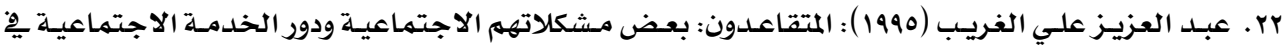

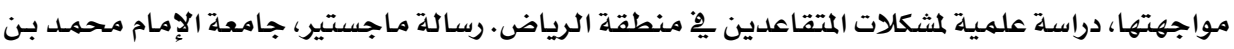

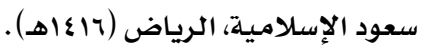

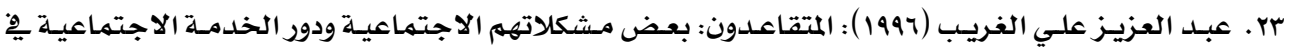
مواجهتها. مطابع نجد، الرياض.

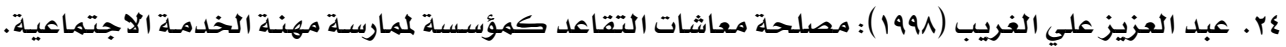

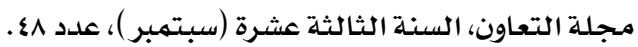

هr. عبد العزيز علي الغريب ( . . . ) : مـرثد المتقاعدين لقضاء وقت الفراغ. جامعة أم القرى، مكة المكرمـة.

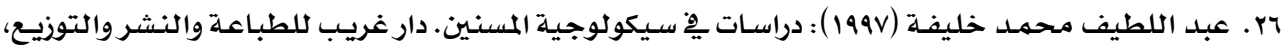
القاهرة.

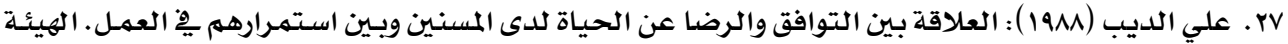
المصرية للكتاب، مجلة علم النفس، العدد ج، القاهرة. M . فاتن مصطفى كمال لطفي (1990) : العوامل الاقتصادية والاجتماعية وأثرها على الأنهاط الاستهلاكية لكلأسر المصرية. رسالة دكتوراه، قسم إدارة المنزل والمؤسسات، كلية الاقتصـاد المنزلي، جامعة المنوفية.

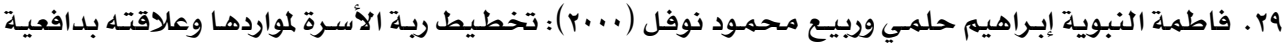
الإنجازووجهة الضبط لدى أبنائها المراهقين. المؤتمر العلمي السـادس للاقتصـاد المنزلي، كليـة الاقتصـاد المنزلي، جامعة حلوان. 


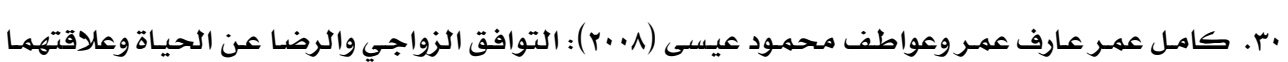

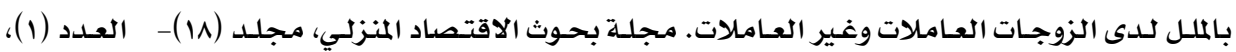

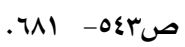

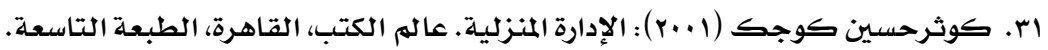

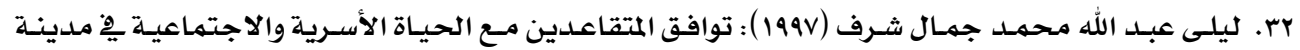

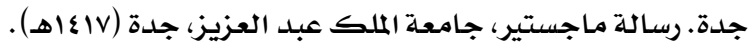

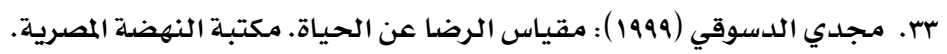

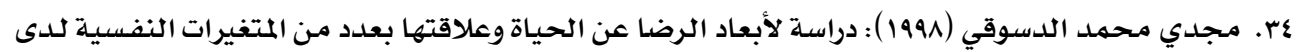

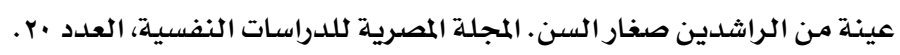

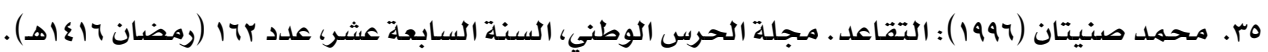

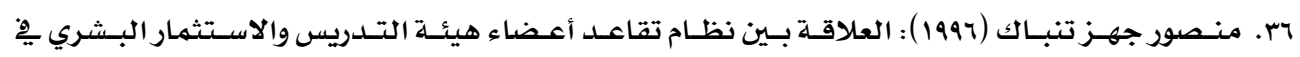
الجامعات السعودية. رسالة ماجستير، جامعة الملك عبد العزيز، جدة (17 (1) اهـ).

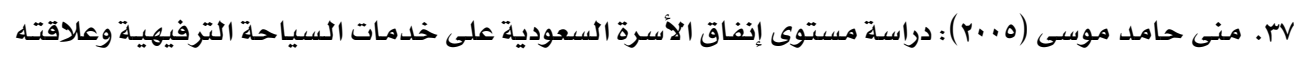
بتخطيط موردها المالي - دراسـة ميدانية بمنطقة مكـة المكرمـة. رسـالة دكتوراة، قسمى السكن وإدارة المنـزل، كلية التربية للاقتصداد المنزلي، جامعة أم القرى، المملكة العربية السعودية.

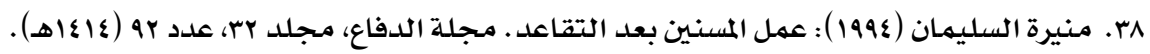

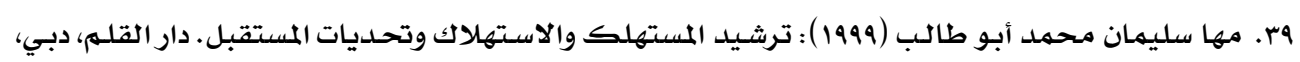
طا.

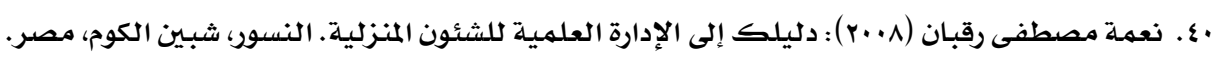

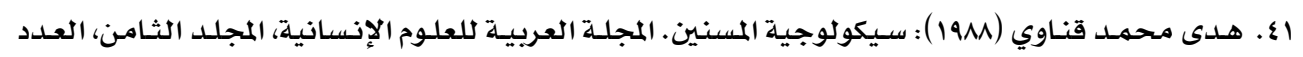

$$
\text { الثاني والثلاثون. }
$$

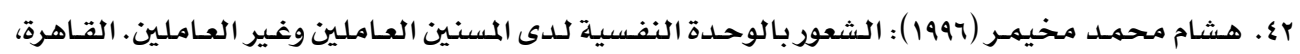
جامعة حلوان، كلية التربية، مجلة الدراسـات التربوية والاجتماعية، العدد الثاني.

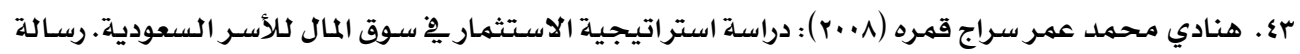

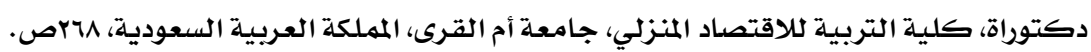

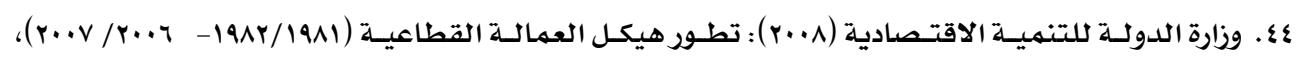

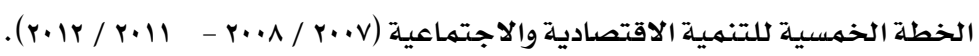

المراجع الأجنبية :

45. Baum, Martha; and Baum, Rainer C. (1980): Growing Old: A Societal Perspective. Prentice-Hall, Englewood Cliffs, NJ.

46. Diener, E. (1984): Subjective well-being. Psychological Bulletin, 95, 3, 543575 . 
47. Diener, E.; Emmons, R.A.; Larsen, R.J.; and Griffin, S. (1985): The Satisfaction With Life Scale. Journal of Personality Assessment, 49, 71-75.

48. EBRI (Employee Benefit Research Institute) (2003): Family savings: Results of the survey of consumer finances. April, EBRI Washington, DC.

49. EBRI (Employee Benefit Research Institute) (2010): EBRI Databook: Chapter 7: Sources of income for persons age 55 and over. EBRI Washington, DC.

50. Elovainio, Marko; Kivimaki, Mika; Vahtera, Jussi; Ojanlatva, Ansa; Korkeila, Katariina; Suominen, Sakari; Helenius, Hans; and Koskenvuo, Markku (2003): Social support, early retirement, and a retirement preference: A study of 10 \&^ฯ. Finnish adults. JOEM, 45, No. 4, 433-439.

51.Emmons, R.A.; and Diener, E. (1985): Personality correlates of subjective wellbeing. Personality and Social Psychology Bulletin, 11, 89-97.

52. Hildreth, Gladys J.; and Kelley, Eleanor (1984): Family expenditures before and after retirement: A research model for measuring priorities. Int. J. Aging and Human Development, 20, No. 2.

53. Hyer, L.; Carpenter, B.; Bishmann, D.; and Wu, H. (2005): Assessment and treatment of depression in long term care. Clinical Psychology: Science and Practice, 12, 3 .

54. Hyer, L.; Gouveia, I.; Harrison, W.R.; Warsaw, J.; and Coutsouridis, D. (1987): Depression, anxiety, paranoid reactions, hypochrondriasis, and cognitive decline in later-life inpatients. Journal of Gerontology, 42, 92-94.

55.Lewinsohn, P.M.; Rohde, P.; Seeley, J.R.; and Fischer, S.A. (1993): Age-cohort changes in the lifetime occurrence of depression and other mental disorders. Journal of Abnormal Psychology, 102, 110-120.

56. McKenna, Judy; and Nichols, Sharon Y. (1986): Retirement planning Strategies for midlife women. J. Home Economics.

57. McKenna, Judy; and Nichols, Sharon Y. (1988): Planning for retirement security: What helps or hinders women in the middle years? ". Home economics Research Journal, 17, No. 2. $\square$

58. Reitzes, Donald C.; Mutran, Elizabeth J.; and Fernandez, Maria E. (1998): The Decision to Retire: A Career perspective. Social Science Quarterly, 79, No. 3. 
59. Saunders, S.A.; and Roy, Ch. (2000): The relationship between depression, satisfaction with life, and social interest. South Pacific J. Psychology, 11, 1, 915.

60. Seligman, M. (1975): Helplessness: On depression, development, and death. Freeman, San Francisco, Ca.

61. Seligman, M. (1990): Why is there so much depression today? The waxing of the individual and the waning of the commons. In: R. Ingram (ed.), Contemporary Psychological Approaches to Depression (pp. 1-9). Plenum Press, NY.

62. Shin, D.; and Johnson, D. (1978): Avowed happiness as an overall assessment of the quality of life. Social Indicators Research, 5, 475-492.

63. Sumarwan, U.; and Hira, T.K. (1992): Credit, saving, and insurance practices influencing satisfaction with preparation for financial emergencies among rural households. Home Economics Research Journal, Vol. 21(2), 206-227.

64. Swanson, Betty B. (1981): Introduction To Home Management, MacMillan Publishing Co., New York. 